\title{
A new genus and eight new species of tail-wagger snails from eastern South Africa, with a key to genera within Sheldonia s.l. (Gastropoda: Urocyclidae)
}

\author{
David G. HERBERT \\ KwaZulu-Natal Museum, P. Bag 9070, Pietermaritzburg, 3200, South Africa and School of Life \\ Sciences, University of KwaZulu-Natal, P. Bag X01, Scottsville, 3209, South Africa. \\ E-mail: phasianella@gmail.com \\ urn:1sid:zoobank.org:author:0C09EE45-6198-482E-857A-EF690C2A016F
}

\begin{abstract}
A new genus and eight new species of urocyclid snails are described from eastern South Africa. The supra-specific taxa Kerkophorus Godwin-Austen, 1912 and Microkerkus Godwin-Austen, 1912 are considered distinct from Sheldonia Ancey, 1887 and are treated as separate genera. The diagnostic morphological features of all three genera are detailed and a fourth genus, for which there is no existing name, is described as new: Selatodryas gen. nov. A provisional key to genus-level taxa within Sheldonia s.l. is provided. Eight species are described as new: Kerkophorus piperatus sp. nov., K. vittarubra sp. nov., K. scrobicolus sp. nov., K. terrestris sp. nov., Microkerkus sibaya sp. nov., Selatodryas roseosoma gen. et sp. nov., S. luteosoma gen. et sp. nov. and Sheldonia fingolandensis sp. nov.
\end{abstract}

Keywords. Sheldonia s.l., key to genera, genital morphology, new species, narrow-range endemism.

Herbert D.G. 2017. A new genus and eight new species of tail-wagger snails from eastern South Africa, with a key to genera within Sheldonia s.l. (Gastropoda: Urocyclidae). European Journal of Taxonomy 309: 1-50. https://doi. org/10.5852/ejt.2017.309

\section{Introduction}

On-going field work in southern Africa continues to bring to light new species of terrestrial molluscs, particularly in speciose genera that are presumed to be relatively young and prone to neoendemism (Herbert 2016). In this paper I describe eight new species of urocyclid snails from the eastern region of South Africa. These would previously have been referred to the genus Sheldonia s.l., but unpublished anatomical and molecular studies clearly show that this is a composite entity comprising several distinct, monophyletic lineages that warrant recognition as separate genus-level entities. In some instances names currently employed as subgenera or treated as synonyms of Sheldonia Ancey, 1887 are available for these lineages (e.g., Kerkophorus Godwin-Austen, 1912 and Microkerkus Godwin-Austen, 1912), but in other cases the lineages are novel discoveries for which existing names are not available. One such, Ptilototheca, was recently described (Herbert 2016) and another is described below.

Shell morphology generally offers few taxonomically diagnostic characters in this group of snails, except in occasional species-specific instances (e.g., the spirally banded shell of Sheldonia cotyledonis 
(Benson, 1850) and the sinuous columella of S. phytostylus (Benson, 1864)). Protoconch sculpture may sometimes be distinctive, but it alone is not diagnostic of lineages. The same is true for radula morphology, for though I have illustrated the radula of all the species described herein, there appears to be no consistent variation that is independent of size and that can be clearly correlated with supraspecific groupings. Variation in radula morphology is limited. The most variable and taxonomically informative characters are found in the morphology of the male component of the distal reproductive tract and the spermatophores. Preliminary studies show that these characters correlate well with molecular data (Herbert \& Moussalli 2009; Herbert \& Davis 2016) and are those most likely to lead to a robust phylogenetic framework.

\section{Material and methods}

The material studied was derived primarily from the collection at the KwaZulu-Natal Museum. This was accumulated over many years, but has been significantly augmented in the last two decades through a programme of field work targeting poorly-surveyed regions of South Africa. All live-collected samples were drowned overnight in sealed containers and subsequently preserved in $75 \%$ ethanol. For selected specimens, tissue samples from the hind end of the foot were excised prior to drowning and preserved in $99 \%$ ethanol for on-going molecular studies.

All dissections were performed under a Wild M4 dissecting microscope with drawing tube. Shells were photographed using a Nikon D70 digital camera and living specimens with a Nikon CoolPix 8800 digital camera. For SEM study, radulae were extracted by maceration of the buccal mass in dilute $\mathrm{NaOH}$, rinsed in distilled water and subsequently dehydrated in ethanol, mounted and air-dried on stubs, coated with gold-palladium, and examined at low accelerating voltage $(5 \mathrm{kV})$ in a Zeiss EVO 10LS scanning electron microscope. Immature shells were excluded from the data used to calculate height:diameter (H:D) ratios. All data for spermatophores relate to allospermatophores removed from the gametolytic sac.

Abbreviations for morphological terms used in line drawings:

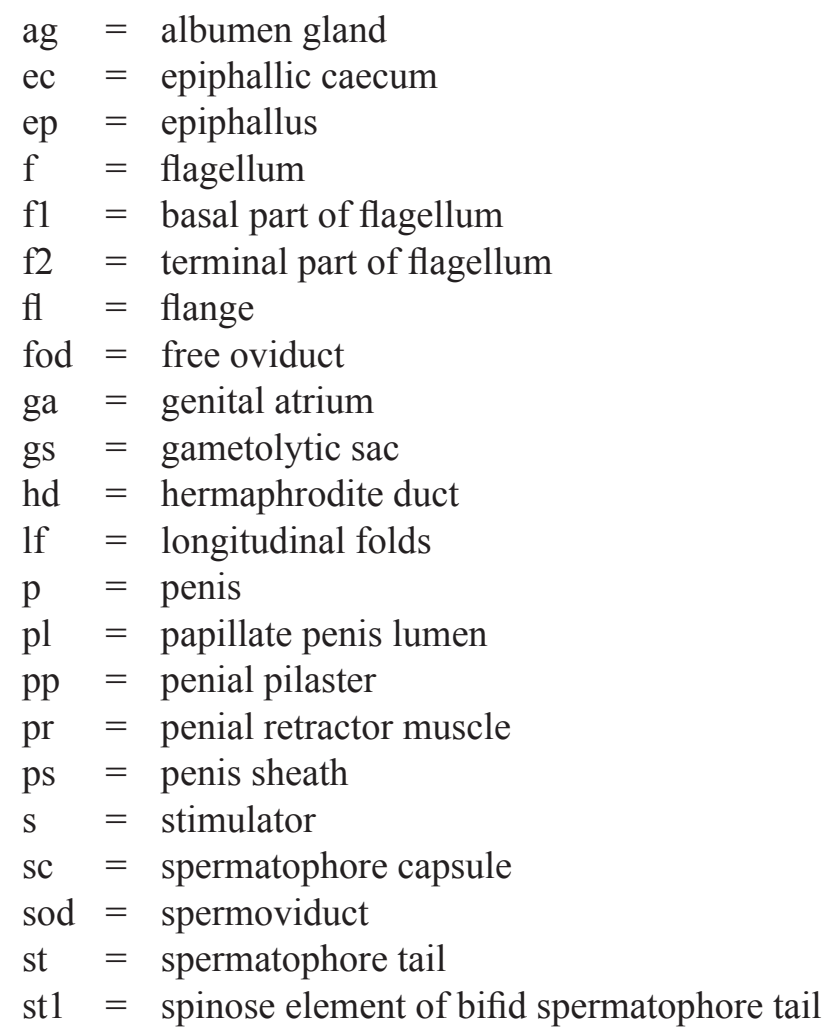




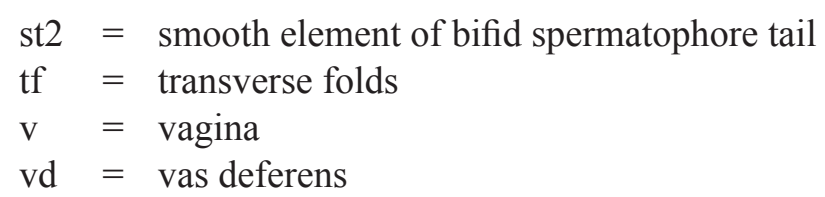

Institutional abbreviations:

EKZNW = Ezemvelo KwaZulu-Natal Wildlife

ELM = East London Museum, East London, South Africa

NHMUK $=$ Natural History Museum, London, UK

NMSA = KwaZulu-Natal Museum, Pietermaritzburg, South Africa

RMNH $=$ Naturalis Biodiversity Center, Leiden, the Netherlands

\section{Results}

Class Gastropoda Cuvier, 1795

Subclass Heterobranchia Burmeister, 1837

Order Stylommatophora A. Schmidt, 1855

Family Urocyclidae Simroth, 1889

Subfamily Sheldoniinae Connolly, 1925 (1912) (cf. Bouchet \& Rocroi 2005)

\section{Key to genera within Sheldonia s.l.}

1. Epiphallic caecum arising close to penis apex and adjacent to insertion of penial retractor muscle

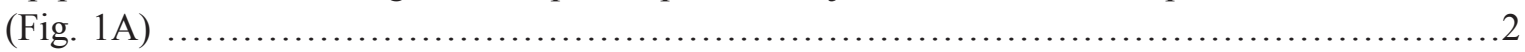

- Epiphallic caecum arising nearer to mid-point of epiphallus (Fig. 1B-C) .......................

2. Flagellum short and stout (Fig. 1D); epiphallus short; vas deferens thick, long and convoluted; spermatophore tail plumose (Fig. 1E); protoconch spirally punctate ........Ptilototheca Herbert, 2016

- Flagellum longer, divided into distinct $\mathrm{fl}$ and $\mathrm{f} 2$ components (Fig. 1A); vas deferens slender and relatively short, not convoluted; spermatophore tail with branched spines (Fig. 1F), but not plumose; protoconch smooth (rarely spirally lirate), not punctate.

Kerkophorus Godwin-Austen, 1912

3. Epiphallic caecum small and globular (Fig. 1B); spermatophore tail bifid (Fig. 1G)

Microkerkus Godwin-Austen, 1912

- Epiphallic caecum large, cylindrical and usually curved (Fig. 1C); spermatophore tail not bifid ...4

4. Protoconch spirally punctate or with numerous, close-set, incised spiral microstriae; nonspinose distal portion of spermatophore tail long, the subterminal region with short, stout projections on both sides (Fig. 1H, inset)

Sheldonia s.s. Ancey, 1887

- Protoconch essentially smooth; non-spinose distal portion of spermatophore tail short, lacking lateral projections (Fig. 1I, arrow)

Selatodryas gen. nov.

This key must be considered provisional and is provided as a guide to the identification of the existing supra-specific taxa within Sheldonia s.l. However, there remain taxa within Sheldonia s.l. that do not fit well into any of these taxa (e.g., Sheldonia monsmaripi Herbert, 2016 and S. wolkbergensis Herbert, 2016). Establishing the true relationships of these enigmatic species will require additional insights from molecular data. Furthermore, even within these genera, there is significant variation and future research may reveal that this encompasses additional lineages worthy of recognition as distinct genera, particularly within Kerkophorus and Microkerkus. Construction of a key should thus be viewed as an iterative process, for which this is a first step. 
Genus Kerkophorus Godwin-Austen, 1912

Kerkophorus Godwin-Austen, 1912a: 127. Type species (original designation) Zingis inuncta Melvill \& Ponsonby, 1899.

?Andrarion Godwin-Austen, 1912b: 582. Type species (monotypy) Andrarion pumilio Melvill \& Ponsonby, 1909.
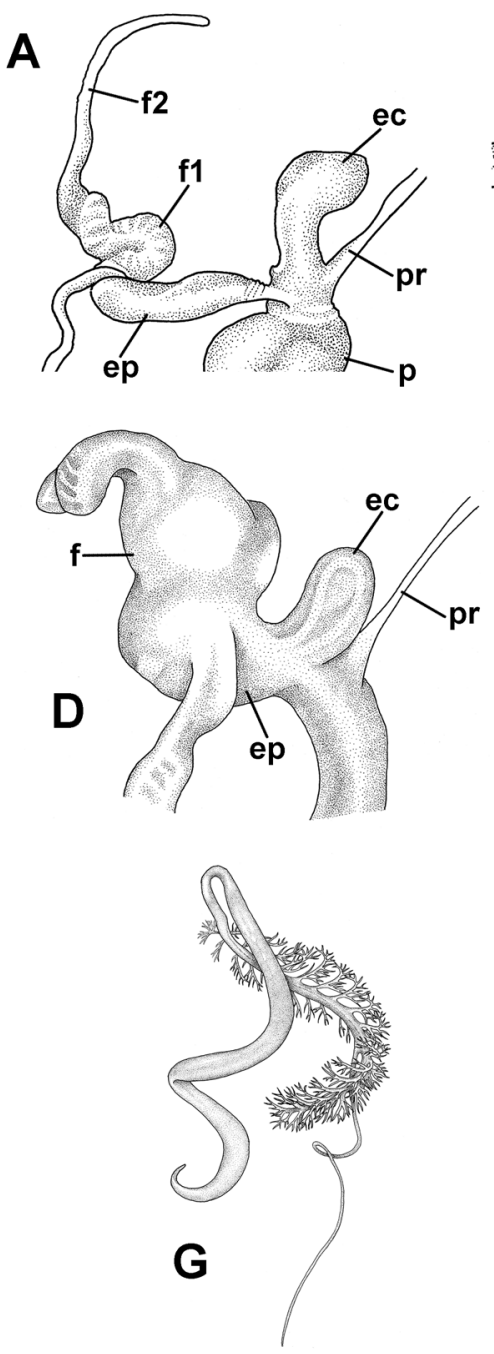
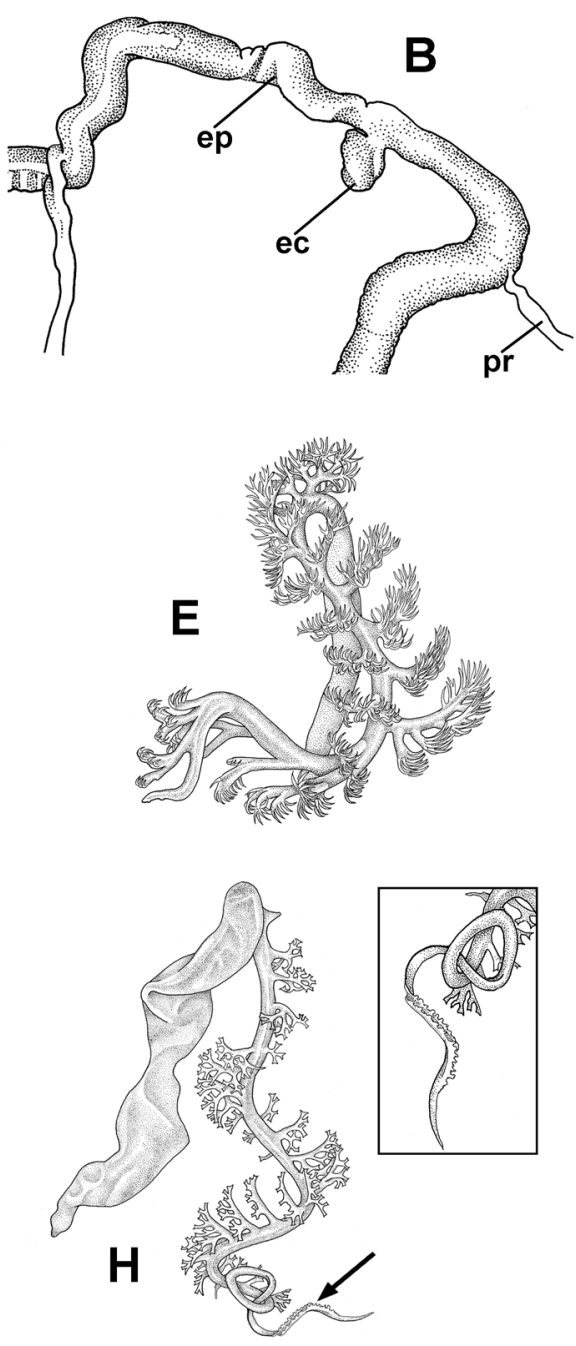
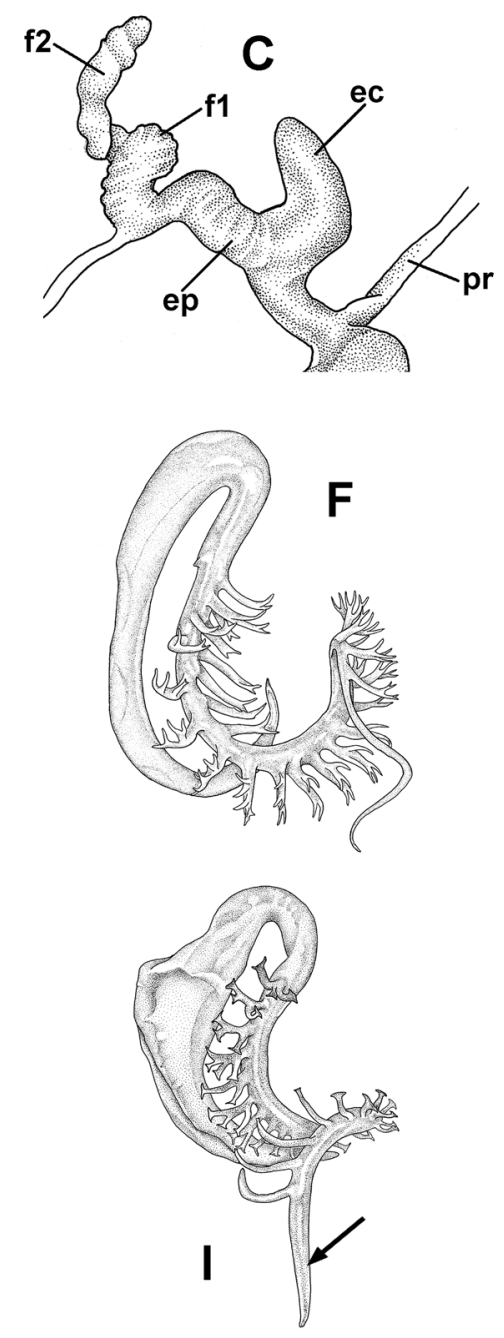

Fig. 1. Illustrations of characters mentioned in key to genera within Sheldonia s.l. A. Kerkophorus vittarubra sp. nov., epiphallus, caecum and flagellum (paratype, NMSA V4725/T4062). B. Microkerkus burnupi (Godwin-Austen, 1914), epiphallus and caecum (NMSA W3660). C. Sheldonia fingolandensis sp. nov., epiphallus, caecum and flagellum (paratype, NMSA W4169/T3385). D. Ptilototheca soutpansbergensis Herbert, 2016, epiphallus, caecum and flagellum (paratype, NMSA P0304/T4060). E. Ptilototheca soutpansbergensis, spermatophore (paratype, NMSA W2259/T4067). F. Kerkophorus poeppigii (Pfeiffer, 1846), spermatophore (NMSA W4911). G. Microkerkus arnotti (Benson, 1864), spermatophore (NMSA W6082). H. Sheldonia capsula (Benson, 1864), spermatophore, arrow indicates short, stout projections on both sides of the subterminal region of the tail, enlarged in inset (NMSA W4686). I. Selatodryas luteosoma gen. et sp. nov., spermatophore, arrow indicates non-spinose distal portion of tail (paratype, NMSA W9691/T3874). 


\section{Remarks}

Kerkophorus includes both arboreal and ground-dwelling species exhibiting relatively diverse shell morphology and considerable variation in the form of the male distal genitalia. The shells may be glossy or lustreless, lenticular to sub-globose, uniformly coloured, bicoloured or peripherally banded, and the genital atrium may or may not be enlarged and possess a fleshy stimulator. In general, however, all have a non-punctate protoconch, a rimate umbilicus, a relatively short epiphallus and the caecum is large and elongate, arising very close to the insertion of the penial retractor muscle. In addition, the spermatophore usually has a single tail, its spines are antler-like, terminating in deeply V-shaped bifurcations, with slender, pointed tips, and the spineless distal portion of the tail is relatively short and lacks lateral projections. However, some of these characters are not without exception and in reality Kerkophorus itself almost certainly encompasses a number of distinct sub-lineages, as exemplified by Kerkophorus s.s. (arboreal, lenticular), K. puzeyi (Connolly, 1939) and K. scrobicolus sp. nov. (arboreal with bifid spermatophore tail), K. poeppigii (Pfeiffer, 1846) (ground-dwelling, sub-globose) and K. perlevis (ground-dwelling, lenticular), and probably others (cf. K. terrestris sp. nov., below).

In Microkerkus Godwin-Austen, 1912, which Watson (1934) and Connolly (1939) considered a synonym of Kerkophorus, the epiphallus is much longer and the caecum is small, globose rather than elongate, and it is situated closer to the middle of the epiphallus, rather than adjacent to the insertion of the penial retractor muscle. In addition, the tail of the spermatophore is bifid in Microkerkus.

Godwin-Austen (1912b) provided very limited data to support his taxon Andrarion and it remains poorly known. Like Watson (1934), I believe that it may have been based on juvenile specimens of a species of Kerkophorus (Herbert 2016) and I consider that it is best treated as a synonym thereof.

\section{Kerkophorus piperatus sp. nov. urn:1sid:zoobank.org:act:34727BE3-D632-4478-ADEE-0C816F23244F}

Figs $2-6$

Sheldonia inuncta (non Melvill \& Ponsonby, 1899) - Connolly 1939: 145 (in part). - Herbert \& Kilburn 2004: 264 (in part), un-numbered figure.

\section{Diagnosis}

Characterised by the combination of moderate size, silky surface and red-brown spiral line situated well above mid-whorl, together with the generally brownish colour of the animal, dark speckling of the pulmonary lining and the absence of a stimulator in the genital atrium.

\section{Etymology}

From the Latin 'piper, piperatus', pepper, peppered; referring to the speckled black and cream pigmentation of the pulmonary lining visible through the shell.

\section{Material examined}

\section{Holotype}

SOUTH AFRICA: KwaZulu-Natal, Makowe, $27.9617^{\circ}$ S, $32.1179^{\circ}$ E, \pm 500 m, J. Crosly leg. (NMSA A8172/T4057, shell only).

Paratypes (listed north to south)

SOUTH AFRICA: Mpumalanga: Mariepskop Forest, $24.55952^{\circ} \mathrm{S}, 30.88760^{\circ} \mathrm{E}, 1420 \mathrm{~m}$, indigenous Afromontane forest, in leaf-litter, J. Horn leg., 28 Feb. 2005 (NMSA W4433/T4050, three dry shells with bodies in ethanol, plus one whole specimen in ethanol); Mariepskop Forest, $24.563^{\circ} \mathrm{S}, 30.863^{\circ} \mathrm{E}$, $1400 \mathrm{~m}$, indigenous Afromontane forest, A.C. and W.H. van Bruggen leg., 29 Jan. 1966 (NMSA 
W3652/T4048, one dry shell with body in ethanol); Mariepskop Forest, $24.56374^{\circ} \mathrm{S}, 30.86293^{\circ} \mathrm{E}$, $1640 \mathrm{~m}$, northern mistbelt forest, in leaf-litter, D. Herbert, L. Davis and M. Cole leg., st. 14-22, 3 Dec. 2014 (ELM D18023/T152, two dry shells); Mariepskop Forest, $24.56683^{\circ} \mathrm{S}, 30.86232^{\circ} \mathrm{E}, 1520 \mathrm{~m}$, indigenous Afromontane forest, in leaf-litter, J. Horn leg., 28 Feb. 2005 (NMSA W3717/T4053, 15 dry shells with bodies in ethanol, plus 10 whole juveniles in ethanol); Mariepskop Forest, Bushpig Trail, $24.56694^{\circ} \mathrm{S}, 30.86270^{\circ} \mathrm{E}, 1491 \mathrm{~m}$, mistbelt forest, A. Moussalli and D. Stuart-Fox leg., 15 Dec. 2006 (NMSA W6002/T4052, one dry shell); Mariepskop Forest, Picnic Trail, 24.56847 ${ }^{\circ}$ S, $30.85920^{\circ} \mathrm{E}, 1545 \mathrm{~m}$, northern mistbelt forest, in leaf-litter, D. Herbert, L. Davis and M. Cole leg., st. 14-27, 4 Dec. 2014 (NMSA P0229/T4051, 1 dry shell with body in ethanol); Mariepskop Forest, M. Cole leg., 18 Oct. 2010 (NMSA W9365/T4049, one dry shell with body in ethanol); Mariepskop Forest, on slope of escarpment, $24.570932^{\circ} \mathrm{S}, 30.860407^{\circ} \mathrm{E}, 1514 \mathrm{~m}$, M. Cole leg., 18 Oct. 2010 (ELM D16958/T038, one dry shell). - KwaZulu-Natal: Ngome Forest, $27.824405^{\circ} \mathrm{S}, 31.419130^{\circ} \mathrm{E}$, $1136 \mathrm{~m}$ on Clivia, W. Haselau leg., 15 Jun. 2010 (ELM W3683/T153, whole specimen in ethanol); Ngome Forest, $27.850^{\circ} \mathrm{S}, 31.383^{\circ} \mathrm{E}, 800-1300 \mathrm{~m}$, mistbelt and coastal scarp sections of forest, mostly under logs, occasionally also on understorey vegetation and bark, D. Herbert leg., Dec. 1995 (NMSA V2250/T4056, 13 dry shells with nine bodies in ethanol, plus seven whole specimens in ethanol); same data as holotype (NMSA A8173/T4058, two dry shells); Hluhluwe Game Reserve, 28.04 ${ }^{\circ} \mathrm{S}, 32.10^{\circ} \mathrm{E}$, $170 \mathrm{~m}$, forest patches in bushveld, in leaf-litter, D. Herbert leg., 2 Jan. 1996 (NHMUK 20160240, one dry shell; NMSA V2360/T4055, six dry shells with four bodies in ethanol); Hluhluwe Game Reserve, Mbombe Forest, 28.05654 $4^{\circ} \mathrm{S}, 32.05045^{\circ} \mathrm{E}, 532 \mathrm{~m}$, scarp forest, A. Armstrong and A. Gomez leg. (EKZNW 341146), 6 Oct. 2011 (NMSA W9644/T4054, one dry shell with body in ethanol, plus one whole specimen in ethanol); Hluhluwe Game Reserve, $28.067^{\circ} \mathrm{S}, 32.040^{\circ} \mathrm{E}, 450 \mathrm{~m}$, scarp forest, on tree trunks, D. Herbert leg., 31 Dec. 1995 (NMSA V2279/T4059, three dry shells with two bodies in ethanol; RMNH.5004183, one dry shell).

\section{Other material (listed north to south, NMSA)}

SOUTH AFRICA: Mpumalanga: Mariepskop Forest, $24.56353^{\circ} \mathrm{S}, 30.86252^{\circ} \mathrm{E}, 1620 \mathrm{~m}$, indigenous Afromontane forest, $3 \mathrm{~m}$ above ground in epiphytes of standing tree, J. Horn leg., 22 May 2005 (W3680); Mariepskop Forest, $24.56374^{\circ} \mathrm{S}, 30.86293^{\circ} \mathrm{E}, 1640 \mathrm{~m}$, northern mistbelt forest, in leaf-litter, D. Herbert, L. Davis and M. Cole leg., st. 14-22, 3 Dec. 2014 (P0277); Mariepskop Forest, 24.56708 S, 30.8599 ${ }^{\circ}$ E, 1540 m, Afromontane forest, in leaf-litter, J. Horn leg., 24 Nov. 2005 (W3906). - KwaZulu-Natal: Ngome Forest, $27.8017^{\circ} \mathrm{S}, 31.4376^{\circ} \mathrm{E}$, mistbelt forest, active on understorey foliage, A. Moussalli and D. Stuart-Fox leg., 8 Jan. 2004 (W3309); Ngome Forest, Ntendeka Wilderness Area, 27.80177 $\mathrm{S}$, $31.43765^{\circ} \mathrm{E}$, mistbelt forest, on understorey foliage, A. Moussalli and D. Stuart-Fox leg., 8 Jan. 2004 (W5035); Ngome Forest, 27.8370 $\mathrm{S}, 31.3917^{\circ} \mathrm{E}, 1200 \mathrm{~m}$, mistbelt Podocarpus forest, in leaf-litter, D. Herbert, M. Seddon and P. Tattersfield leg., 2 Dec. 1998 (V8553); Hluhluwe Game Reserve, 28.05278 S, $32.05327^{\circ}$ E, 568 m, forest, A. Armstrong leg. (EKZNW 323534), 30 Sep. 2002 (W7301); Hluhluwe Game Reserve, Mbombe Forest, 28.056539 $\mathrm{S}, 32.050450^{\circ} \mathrm{E}, 532 \mathrm{~m}$, scarp forest, A. Armstrong and A. Gomez leg. (EKZNW 341146), 6 Oct. 2011 (W9644); Hluhluwe Game Reserve, 28.06377 S, $32.04388^{\circ}$ E, $450 \mathrm{~m}$, forest, under log, A. Armstrong and P. Sokhela leg. (EKZNW No. 478152), 28 Oct. 2013 (W9760); Hluhluwe Game Reserve, in forest between research st. and perimeter fence, $28.07360^{\circ} \mathrm{S}$, $32.03909^{\circ}$ E, 460 m, scarp forest, D. Herbert leg., 12-14 Jan. 1995 (V580); Hluhluwe Game Reserve, $28.075^{\circ} \mathrm{S}, 32.055^{\circ} \mathrm{E}, 400 \mathrm{~m}$, scarp forest, in leaf-litter, D. Herbert, M. Seddon and P. Tattersfield leg., 30 Nov. 1998 (V7664); Hluhluwe Game Reserve, $28.077^{\circ} \mathrm{S}, 32.045^{\circ} \mathrm{E}, 460 \mathrm{~m}$, scarp forest, in leaf-litter, D. Herbert, M. Seddon and P. Tattersfield leg., 29 Nov. 1998 (V7679); Hluhluwe Game Reserve, Hilltop Camp walk, $28.0830^{\circ} \mathrm{S}, 32.0417^{\circ} \mathrm{E}, 400 \mathrm{~m}$, scarp forest, in leaf-litter, D. Herbert leg., 31 Dec. 1995 (V2162); Hlabisa, $28.145^{\circ} \mathrm{S}, 31.882^{\circ} \mathrm{E}, \pm 540$ m, H.C. Burnup leg., pre 1928 (A8174). 


\section{Description}

SHELl (Fig. 2). Lenticular to globose-lenticular; periphery at mid-whorl, evenly rounded; shell proportions variable, $\mathrm{H}: \mathrm{D}$ 0.61-0.74 $(\mathrm{N}=15)$; suture shallowly indented, inserting well above periphery; thin, translucent, straw-buff when fresh, fading to pale buff, with a thin red-brown line level with suture and obscured by it on spire whorls; surface silky and lacking lustre. Protoconch diameter 1.65-1.90 mm $(\mathrm{N}=17)$; junction with teleoconch usually weakly marked; essentially smooth, but bearing faint, closeset, microspiral sculpture. Teleoconch of up to 3.3 whorls; coiling relatively tight, whorls not expanding rapidly; sculptured by weak growth-lines and exceptionally fine and close-set, microscopic spiral lines, slightly finer than those on protoconch; later whorls also with microscopic axial sculpture of a similar nature, giving surface its lustreless sheen. Umbilicus patent but narrow, mostly obscured by reflected upper portion of columella lip. Aperture roundly and obliquely lunate. Diameter up to $18.8 \mathrm{~mm}$; holotype, diameter $18.6 \mathrm{~mm}$, height $11.4 \mathrm{~mm}$; specimens from Mpumalanga somewhat smaller (Fig. 2G), maximum diameter $14.0 \mathrm{~mm}$.

Living ANimal (Fig. 3). Head-foot pale greyish-brown, neck and posterior of foot usually slightly darker; optic tentacles and their retractor muscles darker grey; body lobes of mantle of similar coloration to head-foot; shell lobes well developed, slender and elongate; caudal appendage dark grey; much of body, particularly the neck, body lobes of mantle and posterior of foot with microscopic cream or pale orange pigment granules. Lining of pulmonary cavity speckled, sometimes heavily so, with irregular black and cream blotches and spots; portion overlying reno-pericardial area cream with a distinct horizontal black

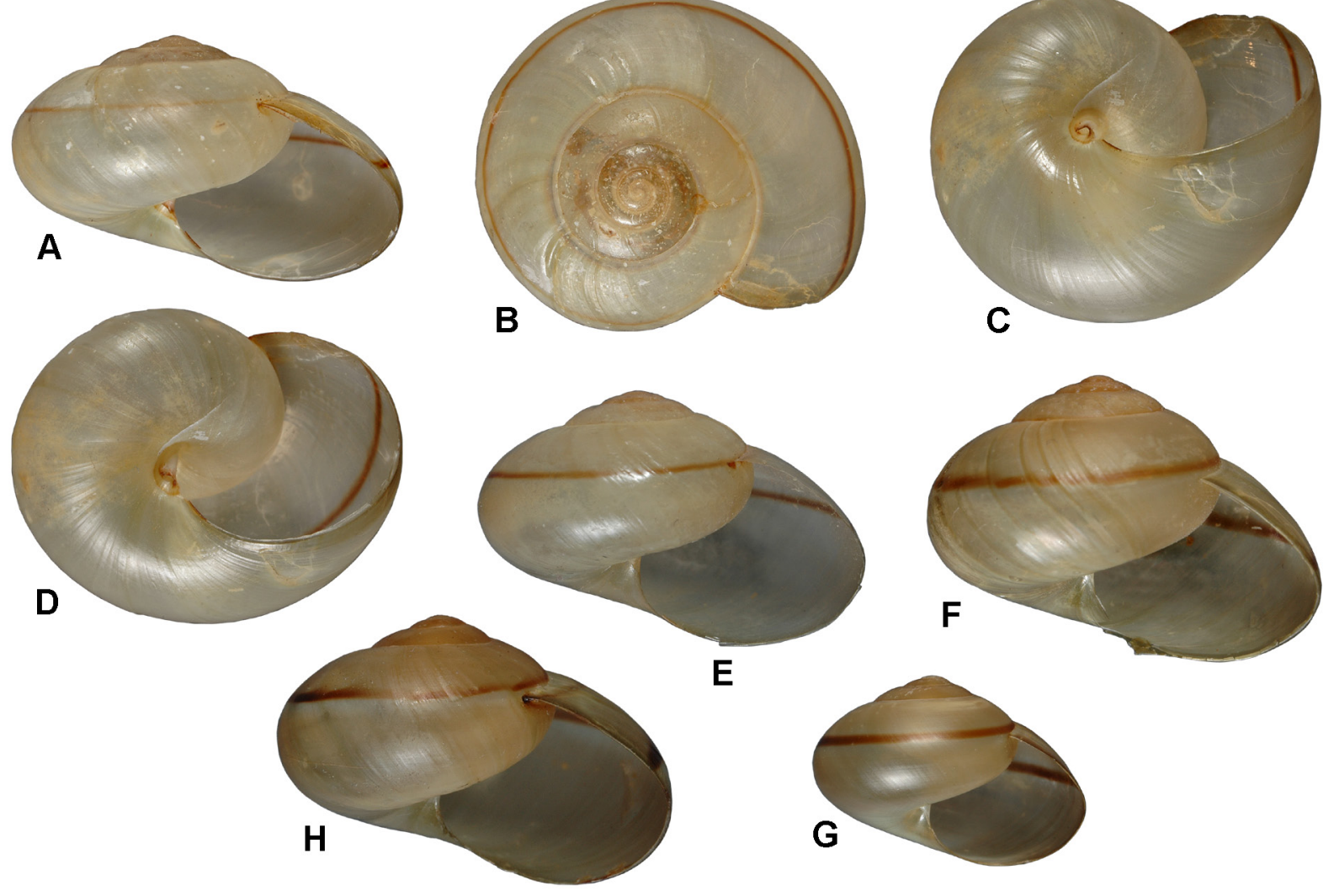

Fig. 2. Kerkophorus piperatus sp. nov. A-D. Holotype, diameter $18.6 \mathrm{~mm}$ (NMSA A8172/T4057). E. Hluhluwe Game Reserve, KwaZulu-Natal, diameter 18.4 mm (paratype, NMSA V2360/T4055). F. Ngome Forest, KwaZulu-Natal, diameter 18.8 mm (paratype, NMSA V2250/T4056). G. Mariepskop, Mpumalanga, diameter $13.0 \mathrm{~mm}$ (paratype, NMSA W9365/T4049). H. Possible K. piperatus $\times$ vittarubra hybrid, Nkandla Forest, KwaZulu-Natal, diameter 18.8 mm (NMSA W1116). 

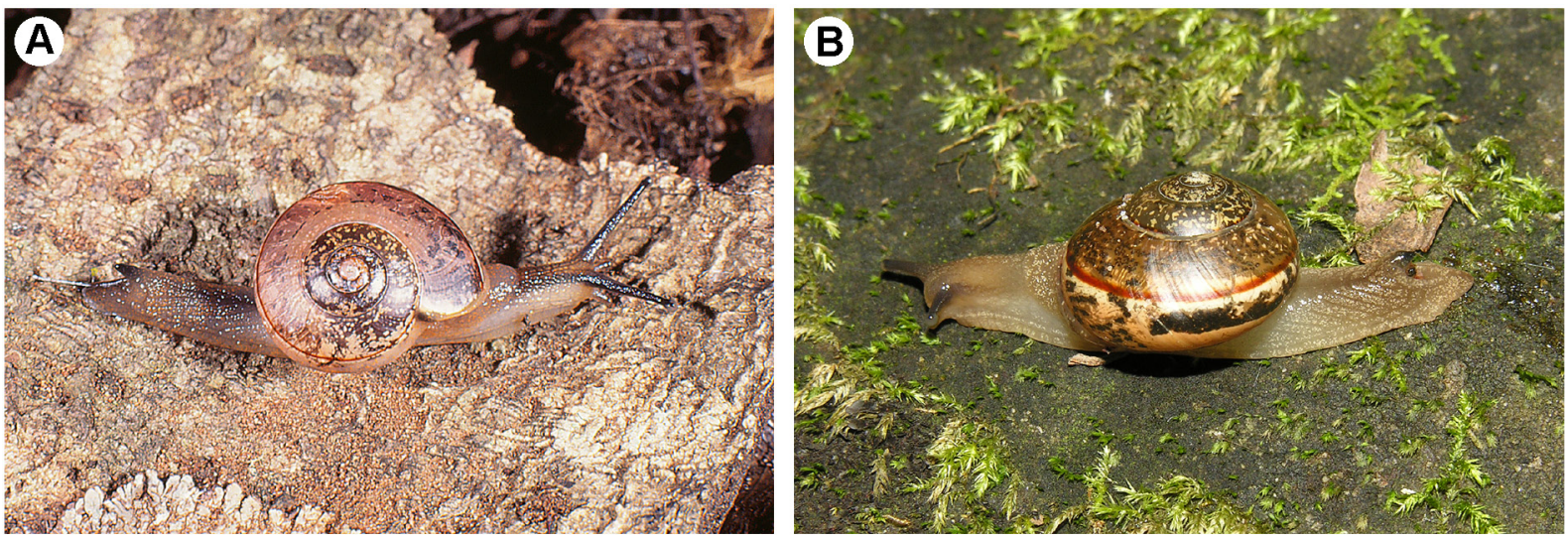

Fig. 3. Kerkophorus piperatus sp. nov., living animals. A. Hluhluwe Game Reserve, KwaZulu-Natal, shell diameter $16.0 \mathrm{~mm}$ (paratype, NMSA V2279/T4059). B. Mariepskop, Mpumalanga, shell diameter $13.3 \mathrm{~mm}$ (paratype, NMSA P0229/T4051).

band; mantle margin beneath outer lip of shell bordered by a narrow cream line. Spire viscera darker brown with scattered irregular cream markings.

Radula (Fig. 4). Formula $\mathrm{R}+14+(1-2)+(60-70)$; rachidian tricuspid, anterior margin of shaft base shallowly indented; laterals essentially bicuspid with a mesocone and strong basal ectocone, but also with a minute endocone on side of mesocone; laterals followed by 1-2 teeth of intermediate shape and then a long series of marginals; marginals curved and bicuspid, with a large terminal cusp with a slightly
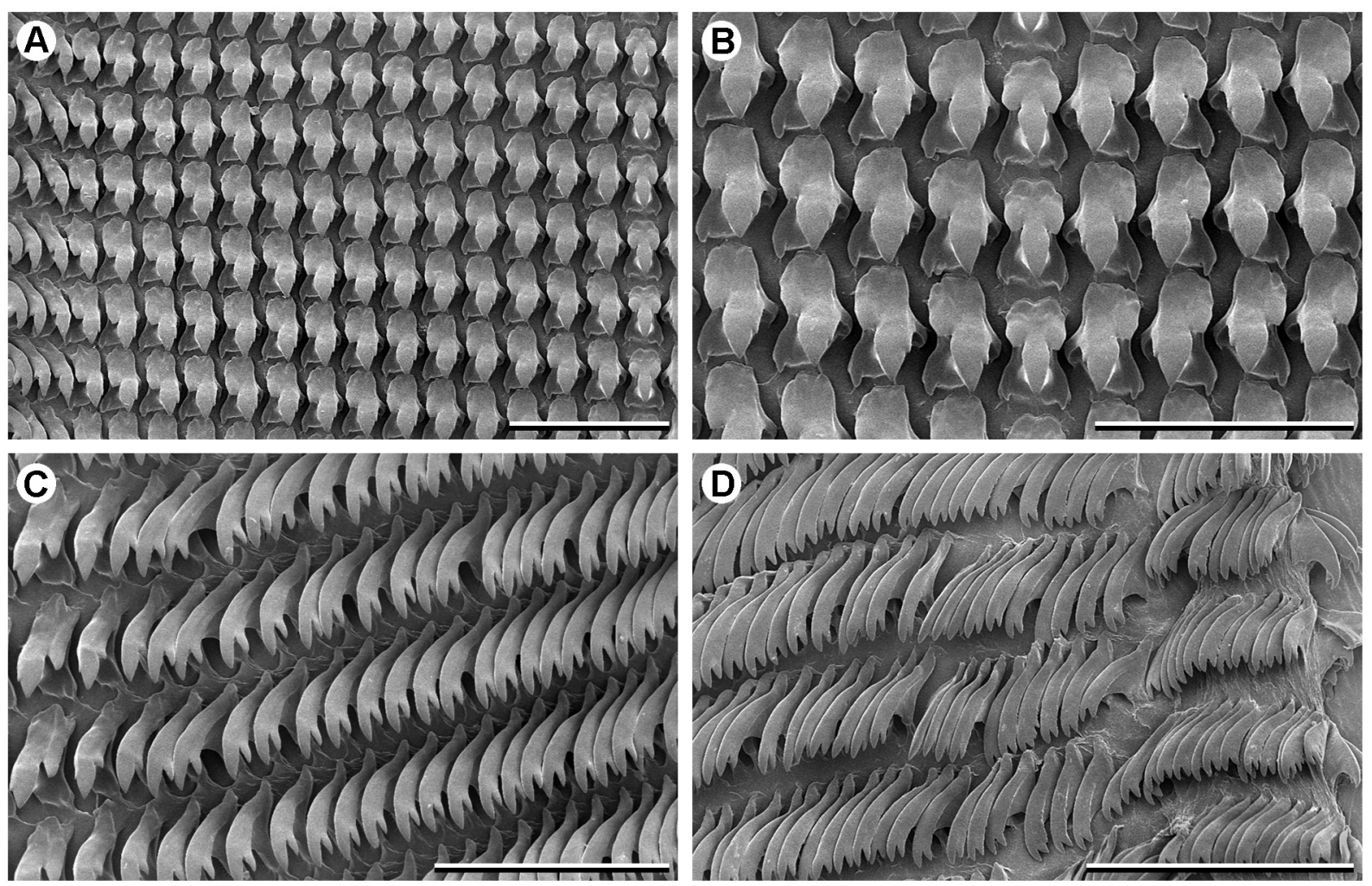

Fig. 4. Kerkophorus piperatus sp. nov., radula (paratype, NMSA V2250/T4056). A. Rachidian and left lateral teeth. B. Rachidian and innermost lateral teeth. C. Inner right marginal teeth. D. Outer right marginal teeth. Scale bars $=100 \mu \mathrm{m}$. 
smaller subterminal one on outer (concave) margin; shaft lacking serrations; marginals progressively decreasing in size toward edge of radula, but otherwise morphologically similar.

Distal genitalia (Fig. 5A-B). Penis encased in thin sheath and usually with a distinct S-shaped bend in basal half, sometimes another in apical half; retractor muscle attached to penis apex; base of penis defined by fusion with sheath and constriction of lumen; penis base may bulge into preputial region joining penis base to atrium; internally penis divided into two sections, basal third rather thin-walled, with two longitudinal ridges and lined throughout by microscopic papillae, apical two-thirds thickerwalled with more numerous, smooth longitudinal folds; junction between sections delimited by a slight constriction, but no verge evident in this region. Epiphallus very short; caecum well developed, considerably longer than epiphallus, cylindrical, but somewhat sinuous, distal portion slightly broader, with bluntly rounded apex; caecum lined internally with a complex lattice of interconnected folds and lumen largely obstructed; distal portion of caecum compartmentalised and sometimes with chalky contents; caecum arising very close to penis apex and insertion of retractor muscle; epiphallus, caecum and penis apex forming a triple junction. Basal part of flagellum (f1) stout, comprising \pm 1 whorl, with distinct transverse internal structure; $\mathrm{f} 2$ slender, longer than $\mathrm{f} 1$, straight in some specimens, variously curved in others; little evidence of chalky material inside proximal epiphallus; vas deferens simple and slender. Genital atrium simple, lacking stimulator, its lining comprising an oblique latticework of narrow interconnected ridges; vagina short; gametolytic sac thin walled and irregularly pyriform, its duct of moderate length; base of free oviduct swollen, dark (brown/black) in fresh material; spermoviduct divided into distinct prostatic and oviductal portions.

Spermatophore (Fig. 5C). Elbowed, with a crescent-shaped capsule (length approx. $4.7 \mathrm{~mm}$ ) and a long coiled tail; proximal part of tail bearing two rows of stout branching spines spiralling around tail; primary row extending for approx. one coil; spines in mid-region larger and more complexly branched; a shorter, secondary row of approx. 10 spines on opposite side of proximal part of spinose region, these

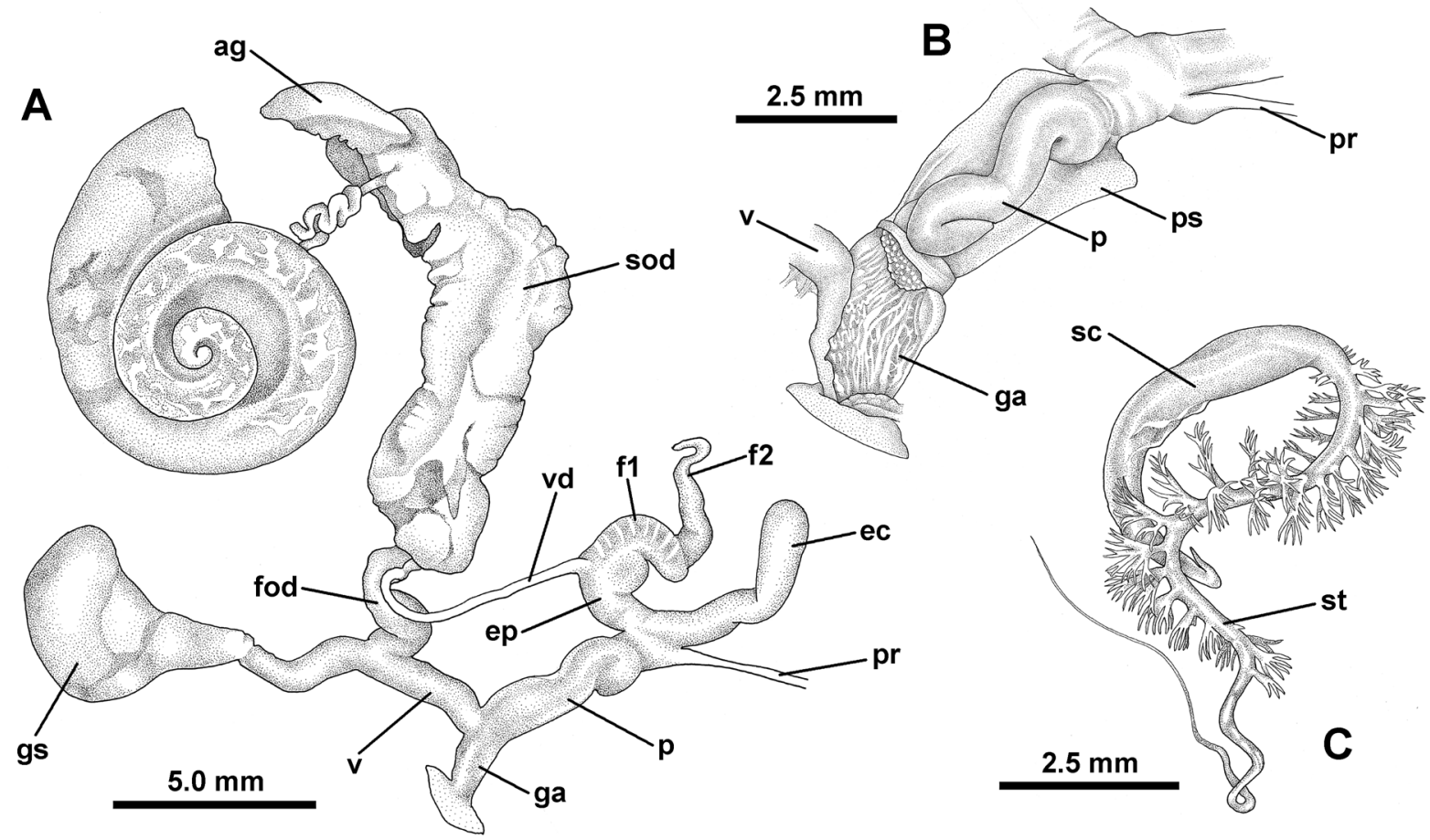

Fig. 5. Kerkophorus piperatus sp. nov., genitalia and spermatophore. A-B. Genitalia, Mariepskop, Mpumalanga (paratype, NMSA W4433/T4050). A. Entire genital tract. B. Dissection of genital atrium and penis sheath. C. Spermatophore, Mariepskop, Mpumalanga (NMSA W3906). 
initially similar to those of primary row, but distal ones with progressively fewer branches; spines of primary row flabellate, terminating in deeply V-shaped bifurcations, their tips slender and pointed, not or at most weakly curved; distal half of tail lacking spines, very slender and variously curved or coiled.

\section{Distribution (Fig. 6)}

Endemic to north-eastern South Africa (and probably also Swaziland), ranging from the coastal escarpment of north-eastern KwaZulu-Natal to the Drakensberg of northern Mpumalanga; at altitudes between $170 \mathrm{~m}$ and $1640 \mathrm{~m}$ above sea level.

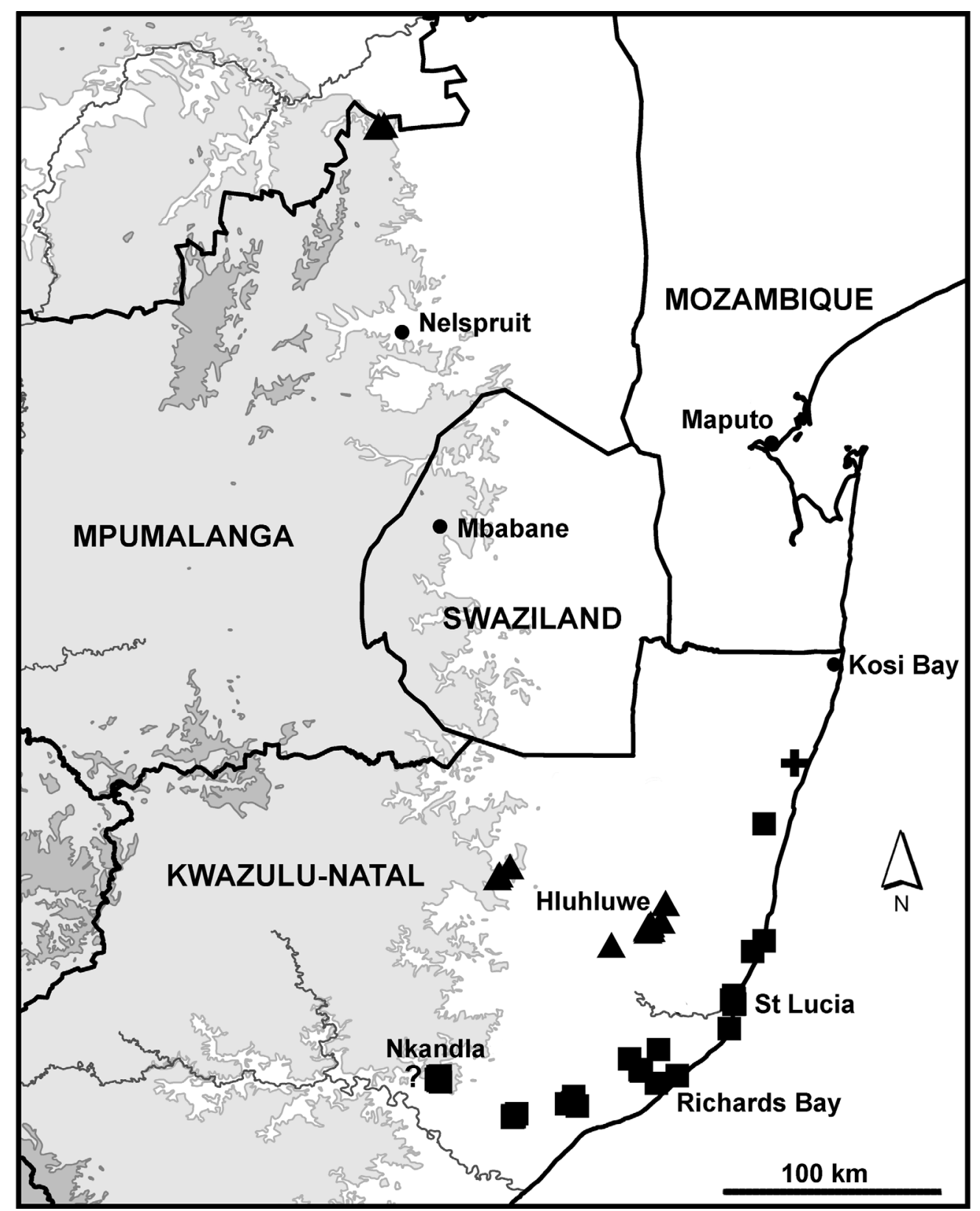

Fig. 6. Distribution of Kerkophorus piperatus sp. nov. (triangles), Kerkophorus vittarubra sp. nov. (squares), and Microkerkus sibaya sp. nov. (cross). The population at Nkandla marked '?' is a potentially hybrid population with shell characters resembling $K$. piperatus sp. nov., but with genitalia resembling K. vittarubra sp. nov. Contours at 1000 and $1500 \mathrm{~m}$. 


\section{Habitat}

Scarp Forest and both Southern and Northern Mistbelt Forest (Mucina \& Rutherford 2006); mostly in leaf-litter, under logs and low down on tree trunks, but occasionally on understorey vegetation.

\section{Remarks}

This and the following species have until now been confused with Kerkophorus inunctus (Melvill \& Ponsonby, 1899) and were usually identified under that name (Connolly 1939; Herbert \& Kilburn 2004). Kerkophorus piperatus sp. nov., however, has a more elevated shell than K. inunctus, less rapidly expanding whorls and does not attain such a large size (max. diameter $19 \mathrm{~mm}$ vs $25 \mathrm{~mm}$ ). In addition, the present species lacks the large stimulator in the genital atrium that is found in both $K$. inunctus and $K$. vittarubra sp. nov. (below). In the field, the generally brownish colour of $K$. piperatus sp. nov., its silky shell and the dense dark speckling of the pulmonary lining are distinctive features. In $K$. inunctus the pulmonary lining lacks black speckling and the spire viscera exhibit much yellowishwhite pigmentation. Additional comments are given below in the remarks for K. vittarubra sp. nov.

The apparent hiatus in the known range of the species, between the KwaZulu-Natal population and that in northern Mpumalanga, is almost certainly an artefact stemming from insufficient field surveys.

\section{Conservation}

Kerkophorus piperatus sp. nov. is a relatively widespread species and it is known to occur in a number of formal conservation areas (Hluhluwe Game Reserve, Ngome State Forest and Mariepskop State Forest). Provided that the integrity of these habitats is preserved, they will provide a degree of security. However, the preservation of indigenous forest in western Swaziland is also likely to be important for the conservation of this species, if future field research demonstrates its occurrence in this region.

\section{Kerkophorus vittarubra sp. nov. urn:1sid:zoobank.org:act:B8D472B5-F565-47B1-B8D2-FDACFD810B3F}

Figs 6-10

Sheldonia inuncta (non Melvill \& Ponsonby, 1899) - Connolly 1939: 145 (in part). - Herbert \& Kilburn 2004: 264 (in part), un-numbered figure.

\section{Diagnosis}

Shell characterised by its large size, weakly angled periphery, elevated spire, silky surface, narrow redbrown peripheral line slightly above mid-whorl and large protoconch. Genital atrium large, containing a well-developed stimulator.

\section{Etymology}

From the Latin 'vitta', f., ribbon and the Latin 'ruber, rubra', red; referring to the infernal bureaucratic red tape now bedevilling scientific endeavour (and the red-brown peripheral spiral line on the shell). Noun in apposition.

\section{Material examined}

\section{Holotype}

SOUTH AFRICA: KwaZulu-Natal, Maphelane, 28.4050 $\mathrm{S}, 32.4217^{\circ} \mathrm{E}, 0-60 \mathrm{~m}$, dune forest, on understorey vegetation, D. Plisko leg., May 1997 (NMSA P0353/T4061, dry shell with body in ethanol). 
Paratypes (listed north to south, all KwaZulu-Natal)

SOUTH AFRICA: Greater St Lucia Wetland Park, Manzimbomvu-Ozabeni area, $27.6167^{\circ} \mathrm{S}, 32.5500^{\circ} \mathrm{E}$, woodland, under leaves, G. Davies leg., 28 May 2006 (NMSA W4283/T4042, one dry shell with body in ethanol); Cape Vidal, 28.128 ${ }^{\circ} \mathrm{S}, 32.550^{\circ} \mathrm{E}$, dune forest, P. Reavell leg., 1 Dec. 1978 (NMSA W2277/ T4047, four dry shells); same data as holotype (NHMUK 20160241, one dry shell; NMSA V4725/T4062, six dry shells with bodies in ethanol; RMNH.5004184, one dry shell); Maphelane, forest between dunes and Umfolozi swamp, $28.407^{\circ} \mathrm{S}, 32.418^{\circ} \mathrm{E}, 0-15 \mathrm{~m}$, on vegetation, abundant, D. Herbert leg., 30 Nov. 1995 (NMSA V2194/T4044, 51 dry shells with 46 bodies in ethanol); Ongoye Forest, 28.830767 S, 31.736298 E, 307 m, M. and K. Cole and G. Williams-Wynn leg., 11 Apr. 2015 (ELM W3904/T155, one dry shell with body in ethanol); Ongoye Forest, $28.83617^{\circ} \mathrm{S}, 31.71252^{\circ} \mathrm{E}, 327 \mathrm{~m}$, on understorey trees and bushes, C. Stoffels leg., 9 Jan. 2014 (NMSA W9692/T4046, seven dry shells with bodies in ethanol, plus one whole specimen in ethanol); Eshowe, $28.885^{\circ} \mathrm{S}, 31.468^{\circ} \mathrm{E}, 500 \mathrm{~m}$, Falcon collection (NMSA A8166/T4043, 37 dry shells with 11 bodies in ethanol); Eshowe, Dlinza Forest, 28.893419 $\mathrm{S}$, $31.451602^{\circ}$ E, on Dracaena leaf, M. Cole leg., 13 Jan. 2010 (ELM W3447/T154, one dry shell with body in ethanol); Eshowe, Dlinza Forest, $28.90^{\circ} \mathrm{S}, 31.45^{\circ} \mathrm{E}, 500 \mathrm{~m}$, scarp forest, on Tabernaemontana leaf, D. Eckard leg., 4 Sep. 1997 (NMSA V5270/T4045, three dry shells).

\section{Other material (listed north to south, all KwaZulu-Natal, NMSA)}

SOUTH AFRICA: St Lucia, Eastern Shores, $28.175^{\circ} \mathrm{S}, 32.500^{\circ} \mathrm{E}$, swamp forest, on Barringtonia racemosa leaves, P. Reavell leg., 5 Jan. 1990 (S869); Greater St Lucia, near St Lucia River mouth, $28.38213^{\circ} \mathrm{S}, 32.41981^{\circ} \mathrm{E}$, dune forest, attached to understorey vegetation, A. Moussalli and D. StuartFox leg., 17 Dec. 2003 (W4301); St Lucia Village, forest walk, coastal lowland forest, on low vegetation, D. Herbert leg., 19 Oct. 1997 (V5380); Maphelane, $28.4033^{\circ}$ S, 32.2034 ${ }^{\circ}$ E, dune forest, H. van der Bank et al. leg., 17 Oct. 2011 (W8617) (CO1 barcode vouchers, BIN ABW7223); Maphelane, 28.4050 S, 32.4217 E, dune forest, R. Kilburn leg., 11 Jan. 1983 (B6045), O. Bourquin leg., 15 Jul. 1981 (B6046, V7216), S. Mclean leg., 16 Jul. 1987 (E1100), R. Kilburn, D. Herbert and R. Fregona leg., 10 May 1987 (E382), D. Morgan leg., 16 Feb. 1991 (S3401), D. Herbert leg., 30 Dec. 1995 (V2274), D. Plisko leg., 1 May 1997 (V5017); Maphelane area, 28.51162 ${ }^{\circ}$ S, 32.39775 $\mathrm{E}$, on road to lighthouse, R. Kilburn, D. Herbert and R. Fregona leg., 13 May 1987 (E360); Enseleni Nature Reserve, 28.64410 ${ }^{\circ} \mathrm{S}, 31.96180^{\circ} \mathrm{E}$, coastal forest, on understorey vegetation, A. Moussalli and D. Stuart-Fox leg., 11 Nov. 2006 (W4705); Enseleni Nature Reserve, $28.6917^{\circ} \mathrm{S}, 32.0070^{\circ} \mathrm{E}$, coastal forest, crawling over leaf-litter, D. Herbert leg., 13 Apr. 1997 (V4803); Enseleni Nature Reserve, 28.6917 $\mathrm{S}, 32.0070^{\circ} \mathrm{E}$, in Barringtonia forest beside lake, D. Herbert leg., 15 Jan. 1995 (V656); Richards Bay area, S of Nhlabane River, $28.717^{\circ}$ S, $32.170^{\circ} \mathrm{E}$, at base of dunes, G. Anderson leg., 20 May 1996 (V3929); Empangeni, $12 \mathrm{~km} \mathrm{~N}$ of Mdibi swamp forest, $28.7519^{\circ} \mathrm{S}, 32.0794^{\circ} \mathrm{E}$, on leaves, P. Reavell leg., 1 Mar. 1998 (V6526); Ongoye Forest, $28.808^{\circ} \mathrm{S}, 31.717^{\circ} \mathrm{E}, 350 \mathrm{~m}$, under $\log$ on forest floor, D. Herbert leg., 18 Sep. 1999 (V7387); Ongoye Forest, $28.833^{\circ} \mathrm{S}, 31.717^{\circ} \mathrm{E}, 350 \mathrm{~m}$, scarp forest, crawling over leaf-litter, D. Herbert leg., 6 Sep. 1997 (V5118); Ongoye Forest, $28.8417^{\circ} \mathrm{S}, 31.6870^{\circ} \mathrm{E}, 410 \mathrm{~m}$, scarp forest dominated by Millettia and Drypetes, on leaves of understorey saplings, M.J. Lawes leg., 30 May 1999 (V7403); Ongoye Forest, west-central portion, $28.8417^{\circ} \mathrm{S}, 31.6888^{\circ} \mathrm{E}$, scarp forest, in leaf-litter, G. Davies leg., 27 Jul. 2002 (W221); Ongoye Forest, $28.8417^{\circ} \mathrm{S}, 31.6870^{\circ} \mathrm{E}$, scarp forest, on understorey foliage, A. Moussalli and D. Stuart-Fox leg., 22 Dec. 2003 (W3314, W4966); Ongoye Forest, $28.850^{\circ} \mathrm{S}, 31.733^{\circ} \mathrm{E}, 250 \mathrm{~m}$, scarp forest, J. Londt leg., 29 Jan. 1988 (V6677); Eshowe, Dlinza Forest, $28.892^{\circ} \mathrm{S}, 31.450^{\circ} \mathrm{E}, 500 \mathrm{~m}$, scarp forest, abundant on low vegetation, R. Miller leg., 1 Jan. 1996 (V2895); Eshowe, Dlinza Forest, $28.89743^{\circ} \mathrm{S}, 31.45711^{\circ} \mathrm{E}$, indigenous forest, on understorey foliage, D. Stuart-Fox leg., 25 Mar. 2004 (W3320; W3222); Eshowe, Dlinza Forest, near 'Oval', 28.90 $\mathrm{S}, 31.45^{\circ} \mathrm{E}, 500 \mathrm{~m}$, scarp forest, D. Eckard leg., 25 Jul. 1996 (V4020), on Tabernaemontana, D. Eckard leg., 5 Mar. 1996 (V4018), on fronds of fan palm in forest swamps, D. Eckard leg., 13 Jan. 1997 (V4528), on Dracaena leaf, D. Eckard leg., 4 Sep. 1997 (V5267), on Allophylus leaf, D. Eckard leg., 4 Sep. 1997 (V5268); Eshowe, Dlinza Forest, near twinspot hide, $28.90^{\circ} \mathrm{S}, 31.45^{\circ} \mathrm{E}$, scarp forest, D. Eckard leg., 25 Jul. 1996 (V4019). 


\section{Literature record}

SOUTH AFRICA: Kwazulu-Natal, Umbonambi (Kwambonambi) (Connolly 1939: 145).

\section{Potentially hybrid material of Kerkophorus piperatus sp. nov. $\times$ vittarubra sp. nov.}

SOUTH AFRICA: KwaZulu-Natal: Nkandla Forest, 28.72239 $\mathrm{S}, 31.12373^{\circ}$ E, mistbelt forest, on understorey foliage, A. Moussalli and D. Stuart-Fox leg., 3 Jan. 2004 (NMSA W3311); Nkandla Forest, Chibini area, $28.7227^{\circ} \mathrm{S}, 31.1282^{\circ} \mathrm{E}, 1200 \mathrm{~m}$, mistbelt forest, under logs and in leaf-litter, D. Herbert, M. Bursey and T. Nangammbi leg., 20 Oct. 2003 (NMSA W1116; ELM D13805); Nkandla Forest, $28.740^{\circ} \mathrm{S}, 31.125^{\circ} \mathrm{E}, 1000-1100 \mathrm{~m}$, mistbelt Podocarpus forest, A.C. and W.H. van Bruggen leg., 17 Jan. 1964 (NMSA V6960); Nkandla Forest, Mdonini area, 28.74531 ${ }^{\circ} \mathrm{S}, 31.13567^{\circ} \mathrm{E}, 1050 \mathrm{~m}$, mistbelt forest, under logs and in leaf-litter, D. Herbert, M. Bursey and T. Nangammbi leg., 21 Oct. 2003 (NMSA W1184); Nkandla Forest, $28.733^{\circ}$ S, 31.117 E (NMSA A8167).

\section{Description}

SHELL (Fig. 7). Lenticular to globose-lenticular, spire remaining relatively prominent; periphery at midwhorl, weakly angled in adults, more strongly so in juveniles; H:D 0.61-0.70 (N=25); suture shallowly indented, inserting at or slightly above periphery; thin, translucent, milky-white to pale buff, with a thin red-brown line just above periphery; surface silky, with little lustre. Protoconch large, diameter 2.2$2.7 \mathrm{~mm}(\mathrm{~N}=20)$; junction with teleoconch weakly marked; essentially smooth, but bearing faint, closeset, microspiral sculpture. Teleoconch of up to 3.5 whorls; coiling relatively tight, whorls not expanding rapidly; sculptured by weak growth-lines and exceptionally fine and close-set, microscopic spiral lines resembling those on protoconch; later whorls also with microscopic axial sculpture of a similar nature,
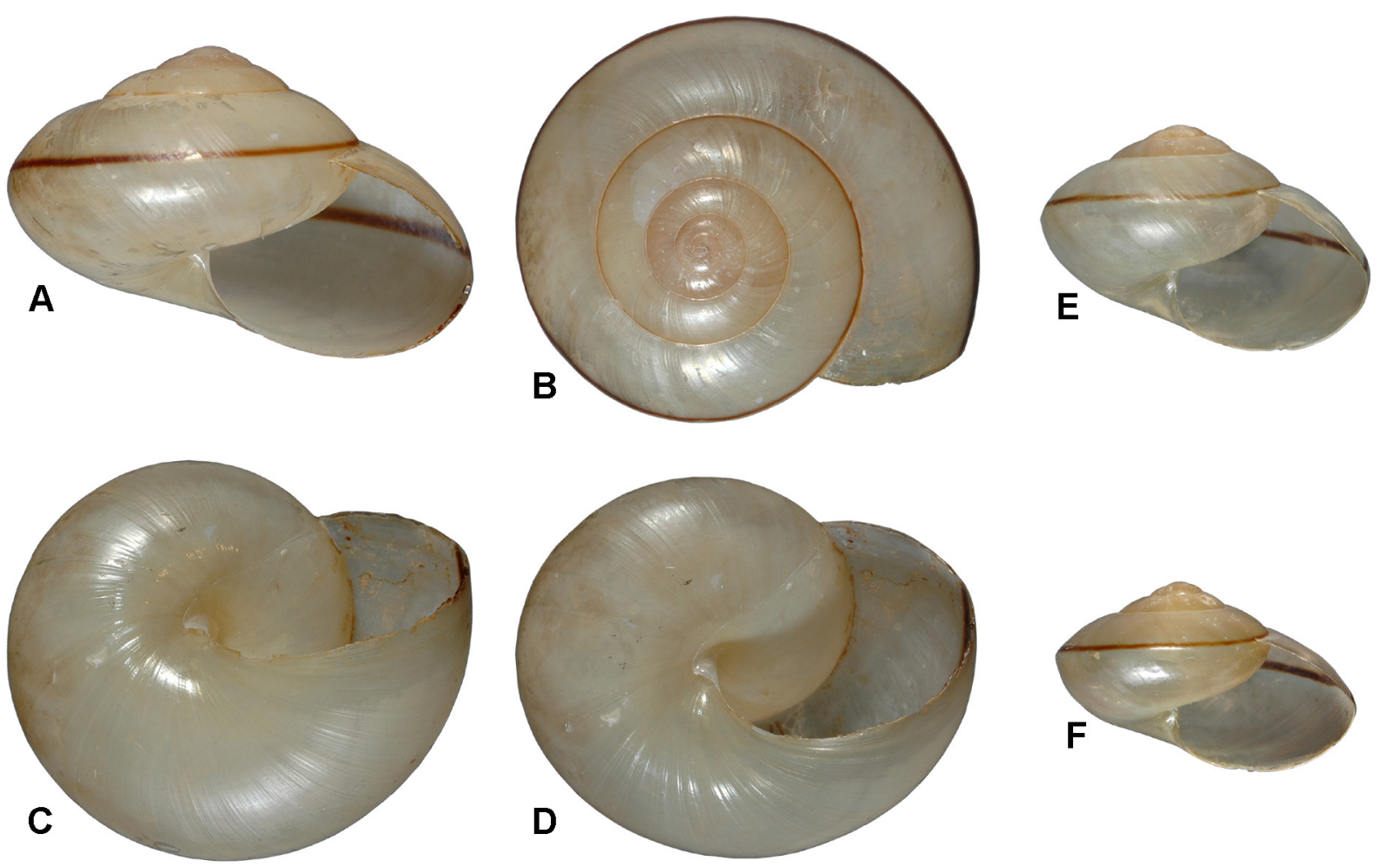

Fig. 7. Kerkophorus vittarubra sp. nov. A-D. Holotype, diameter $24.8 \mathrm{~mm}$ (NMSA P0353/T4061). E-F. Ongoye Forest, juvenile specimens with angular periphery (paratypes, NMSA W9692/T4046), diameter $17.5 \mathrm{~mm}$ and $16.0 \mathrm{~mm}$, respectively. 
giving surface its lustreless sheen. Umbilicus narrow, mostly obscured by reflected upper portion of columella lip. Aperture roundly and obliquely lunate. Diameter up to $26.3 \mathrm{~mm}$; holotype, diameter 24.8 $\mathrm{mm}$, height $16.4 \mathrm{~mm}$; specimens from inland localities smaller than those from coastal lowland and dune forest (diameter usually less than $20 \mathrm{~mm}$ ).

Living ANimal (Fig. 8). Head-foot greyish-white to greyish-brown, with minute cream-white pigment granules; dorsal neck and tail regions sometimes slightly darker; tentacles and optic retractor muscles usually darker grey; coloration of body lobes of mantle similar to head-foot; shell lobes slender and elongate; caudal appendage dark grey to black. Lining of pulmonary cavity weakly speckled with irregular black markings (less obvious in specimens from dune forest) and scattered cream spots, usually more dense beneath peripheral red-brown line of shell; pulmonary venation often conspicuous. Spire viscera brown with irregular cream markings and reticulate threads, more dense in inland specimens.

Radula (Fig. 9). Formula $\mathrm{R}+(18-20)+(1-2)+(100-110)$; rachidian tricuspid, anterior margin of shaft base poorly defined; laterals essentially bicuspid with a mesocone and strong basal ectocone, but also with a minute endocone on side of mesocone; laterals followed by 1-2 teeth of intermediate shape and then a very long series of marginals; marginals curved with a large terminal cusp and a weak subterminal one on outer (concave) margin; shaft lacking serrations; marginals progressively decreasing in size toward edge of radula, but otherwise morphologically similar.

Distal genitalia (Fig. 10A-B). Penis tightly looped inside a short sheath situated on top of enlarged genital atrium; penis divided into two portions separated by a constriction in mid-region; lumen wall
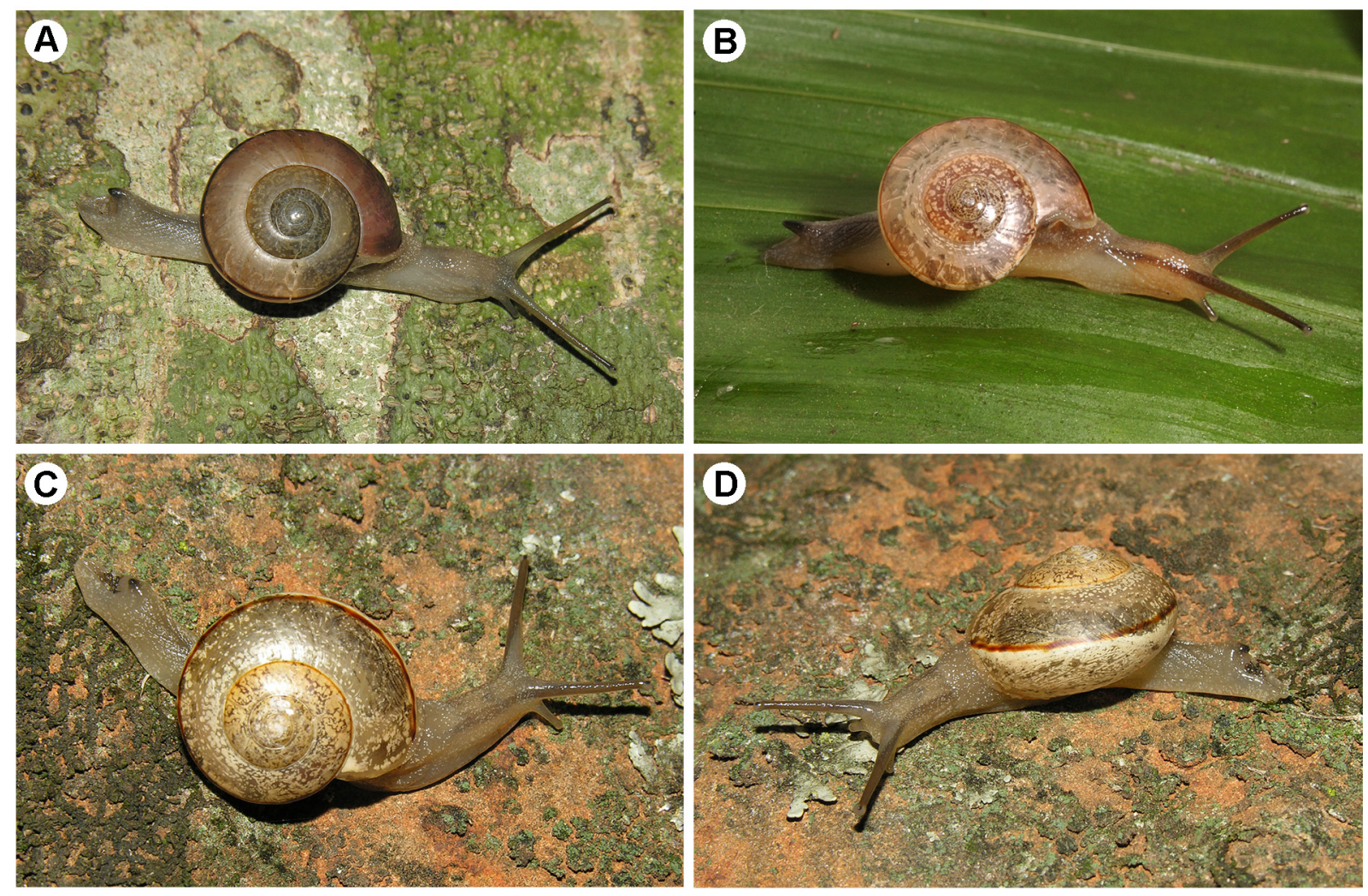

Fig. 8. Kerkophorus vittarubra sp. nov., living animals. A. Maphelane, KwaZulu-Natal, shell diameter $18.3 \mathrm{~mm}$ (NMSA P0391). B. Enseleni, KwaZulu-Natal, shell diameter $12.6 \mathrm{~mm}$ (NMSA W4705). C-D. Ongoye Forest, KwaZulu-Natal, shell diameter 17.0 mm (NMSA P0386). 
of apical half with longitudinal folds, that of lower portion with close-set micropapillae; no penis papilla or verge evident at constriction. Epiphallus short; caecum well developed, more or less equal to epiphallus in length, somewhat curved, distal portion broader with bluntly rounded apex, not internally compartmentalised in this region; lumen wall with two raised longitudinal ridges and additional fine folds; caecum arising very close to penis apex and retractor muscle; epiphallus, caecum and penis apex forming a triple junction. Basal part of flagellum (f1) comprising \pm 1 whorl, with distinct transverse internal structure; f2 slender, considerably longer than f1, variously curved but not convoluted; some evidence of chalky material inside proximal epiphallus; vas deferens slender and relatively short. Genital atrium greatly enlarged above lateral insertion of vagina; apical region containing a long, welldeveloped stimulator; lining of basal portion of atrium with low folds and a raised longitudinal pilaster running to base of stimulator; vagina short; gametolytic sac thin-walled and ovate to pyriform, often narrowing apically, gametolytic duct of moderate length; base of free oviduct swollen, dark charcoalgrey to black in fresh specimens; spermoviduct divided into distinct prostatic and oviductal portions.

SPERmatophore (Fig. 10C). Elbowed, with a cylindrical capsule (length approx. $5.3 \mathrm{~mm}$ ) and a long coiled tail; proximal part of tail smooth, followed by two rows of stout branching spines spiralling around tail; primary row extending for \pm 1.25 coils; spines in mid-region larger and more complexly branched; a shorter, secondary row of approx. 10 spines on opposite side of proximal part of spinose region, these initially similar to those of primary row, but distal 4-5 smaller and with fewer branches; spines of primary row flabellate, terminating in stout, V-shaped bifurcations, the tips pointed and somewhat curved; distal third of tail lacking spines, very slender and variously curved or coiled.
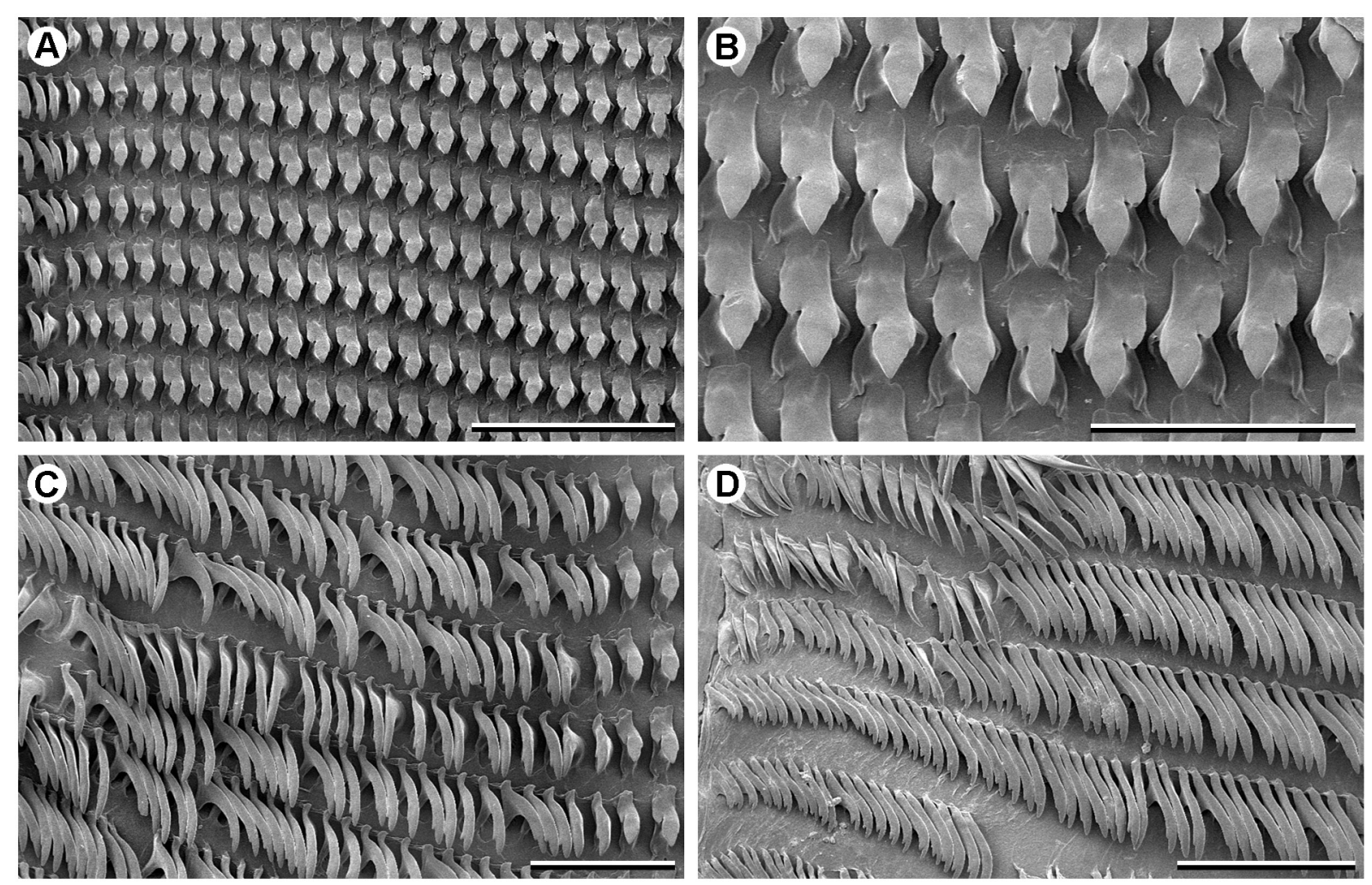

Fig. 9. Kerkophorus vittarubra sp. nov., radula (paratype, NMSA V4725/T4062). A. Rachidian and left lateral teeth. B. Rachidian and innermost lateral teeth. C. Inner left marginal teeth. D. Outer left marginal teeth. Scale bars: A $=200 \mu \mathrm{m} ; \mathrm{B}-\mathrm{D}=100 \mu \mathrm{m}$. 


\section{Distribution (Fig. 6)}

Endemic to the coastal region of northern KwaZulu-Natal, from Eshowe to just south of Sodwana Bay; at altitudes between sea-level and $500 \mathrm{~m}$.

\section{Habitat}

Scarp Forest and Northern Coastal Forest (Mucina \& Rutherford 2006); living on leaves of understorey vegetation, sometimes abundant.

\section{Remarks}

Typical specimens of Kerkophorus vittarubra sp. nov. from coastal forests in the St Lucia area are relatively distinctive on account of their large, pale, silky textured shells with a narrow brown peripheral spiral line, and the rather limited dark speckling of the pulmonary lining. However, specimens from inland localities (e.g., Dlinza, Enseleni and Ongoye forests) are somewhat smaller (diameter $<20 \mathrm{~mm}$ ), of a more brownish colour and may exhibit some dark speckling of the pulmonary lining. These can be confused with $K$. piperatus sp. nov. (above), but in that species the shell has a more rounded periphery, the brown spiral line and suture are situated well above mid-whorl and the protoconch is not so large (1.65-1.90 mm vs $2.2-2.7 \mathrm{~mm}$ ). The pigmentation of the pulmonary lining of $K$. piperatus sp. nov. is also darker and more dense. Further differences are evident in the distal genitalia and behaviour, specifically the genital atrium of $K$. piperatus sp. nov. is not enlarged and lacks a stimulator, whereas

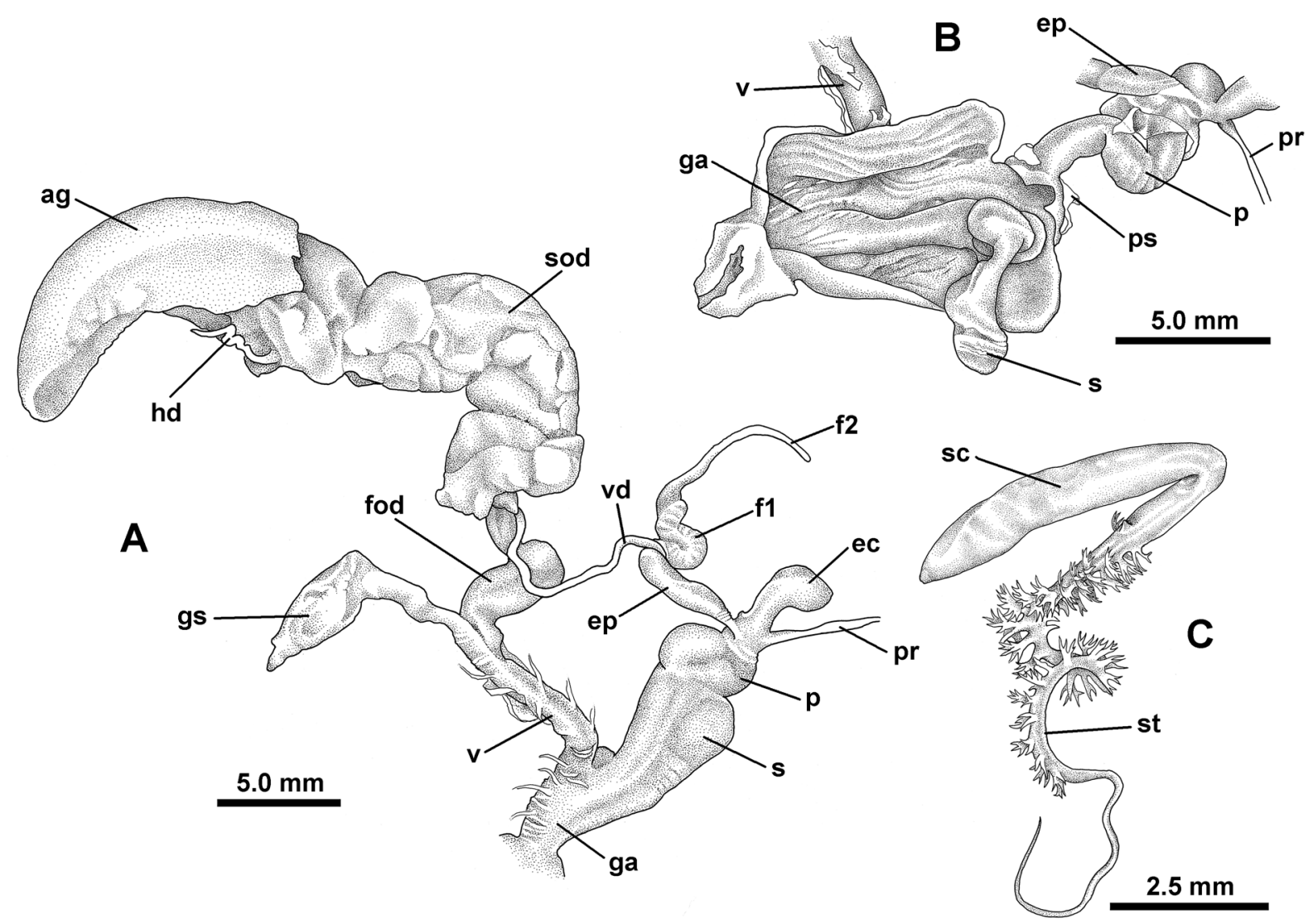

Fig. 10. Kerkophorus vittarubra sp. nov., genitalia and spermatophore (paratype, NMSA V4725/T4062). A. Genital tract (minus ovotestis). B. Dissection of genital atrium and penis sheath revealing stimulator and sinuous penis. C. Spermatophore. 
its epiphallic caecum is proportionately longer in relation to the epiphallus than is that of $K$. vittarubra sp. nov. In terms of behaviour, K. piperatus sp. nov. is primarily an inhabitant of the forest floor, whereas $K$. vittarubra sp. nov. lives mostly on the leaves of understorey vegetation during the wet season, retreating to the leaf-litter only to aestivate during the dry winter months. Over-wintering animals are of intermediate size (shell diameter 17-18 mm), suggesting that the life cycle extends over two wet seasons. The distribution data available thus far indicate that the two species do not co-occur.

The above notwithstanding, material collected in Nkandla Forest appears to be intermediate. The shell shape and coloration (Fig. $2 \mathrm{H}$ ), and body colour are close to those of $K$. piperatus sp. nov., yet the genital atrium is enlarged and contains a stimulator. The possibility exists that this is a hybrid population.

To date this species has been identified with Kerkophorus inunctus (Connolly 1939; Herbert \& Kilburn 2004). Although of a large size and similarly silky, that species occurs primarily to the south of Durban, has a less elevated spire, and a more rapidly expanding and more evenly rounded body whorl in which the brown spiral line lies well above the periphery. . inunctus, like $K$. vittarubra sp. nov. and several other Kerkophorus species from central and southern KwaZulu-Natal (e.g., K. phaedimus (Melvill \& Ponsonby, 1892) and K. vitalis (Melvill \& Ponsonby, 1908)), possesses an enlarged genital atrium with a well-developed stimulator.

\section{Conservation}

The distribution of Kerkophorus vittarubra sp. nov. extends for approximately $200 \mathrm{~km}$ along the coast and coastal hinterland of central and southern Zululand. In this region it occurs in a number of formal conservation areas, including Ongoye, Dlinza and Enseleni nature reserves managed by Ezemvelo KZN Wildlife, as well as the southern part of the iSimangaliso Wetland Park World Heritage Site. Though not wide-ranging, its habitat is thus afforded a relatively high level of protection and the conservation of the species need not currently be viewed as a matter of concern.

Kerkophorus scrobicolus sp. nov.

urn:1sid:zoobank.org:act:EB0294D6-0D65-432A-9B63-A72299417580

Figs 11-15

\section{Diagnosis}

Characterised by its relatively wide umbilicus, tight coiling, lenticular to globose-lenticular profile, weakly angled periphery, smooth protoconch, somewhat glossy surface and uniform colour (no peripheral brown spiral line).

\section{Etymology}

From the Anglo-Saxon 'scrob' a shrub and the Latin 'colus', dweller, inhabitant; referring to the climbing habit of the species.

\section{Material examined}

\section{Holotype}

SOUTH AFRICA: E Cape, Mkambati Nature Reserve, $31.31374^{\circ} \mathrm{S}, 29.96914^{\circ} \mathrm{E}, 71 \mathrm{~m}$, coastal dune forest, on understorey foliage, A. Moussalli and D. Stuart-Fox leg., 1 Nov. 2005 (NMSA W4109/T4164, dry shell with body in ethanol).

Paratypes (listed north to south)

SOUTH AFRICA: KwaZulu-Natal: Umtamvuna Nature Reserve, Beacon Hill, 31.001459 $\mathrm{S}$, $30.168292^{\circ}$ E, M. Bursey leg., 10 Dec. 2006 (ELM W3150/T157, two dry shells with bodies in ethanol, three whole juvenile specimens in ethanol); Umtamvuna Nature Reserve, below Clearwater Camp, 
$31.04361^{\circ} \mathrm{S}, 30.16806^{\circ} \mathrm{E}, 205 \mathrm{~m}$, riverine forest in gorge on $\mathrm{E}$ bank of river, under leaves, M. Bursey leg., 9 Dec. 2006 (NMSA W5258/T4166, two dry shells with bodies in ethanol). — E Cape: Mkambati Nature Reserve, 'Super Bowl' forest, $31.297840^{\circ}$ S, $29.929333^{\circ}$ E, M. Bursey and V. Ndibo leg., 18 Oct. 2005 (ELM W2870/T156, two dry shells and one juvenile specimen in ethanol); Mkambati Nature Reserve, 'Super Bowl' forest at junction of Msikaba and KwaDlambu Rivers, 31.2979 ${ }^{\circ}$ S, $29.9294^{\circ} \mathrm{E}$, $200 \mathrm{~m}$, indigenous forest, under leaves of understorey vegetation, D. Herbert leg., 5 Mar. 2001 (NMSA V8911/T4163, two dry shells with one body in ethanol); Mkambati Nature Reserve, 'Super Bowl' forest, $31.29892^{\circ} \mathrm{S}, 29.92872^{\circ} \mathrm{E}, 208 \mathrm{~m}$, coastal indigenous forest, on understorey foliage, A. Moussalli and D. Stuart-Fox leg., 1 Nov. 2005 (NMSA W4111/T4165, one dry shell with body in ethanol).

\section{Other material}

SOUTH AFRICA: E Cape: Mkambati Nature Reserve, Horseshoe Falls on Mkambati River, $31.2673^{\circ} \mathrm{S}$, $30.0121^{\circ} \mathrm{E}, 70 \mathrm{~m}$, forest on $\mathrm{N}$ bank below falls, in leaf-litter, D. Herbert leg., 6 Mar. 2001 (NMSA V9006); Mkambati Nature Reserve, 31.29599 $\mathrm{S}, 29.92570^{\circ} \mathrm{E}, 156 \mathrm{~m}$, forest, Earthwatch 'Hidden Species', 31 Jan. 2008 (NMSA W6342).
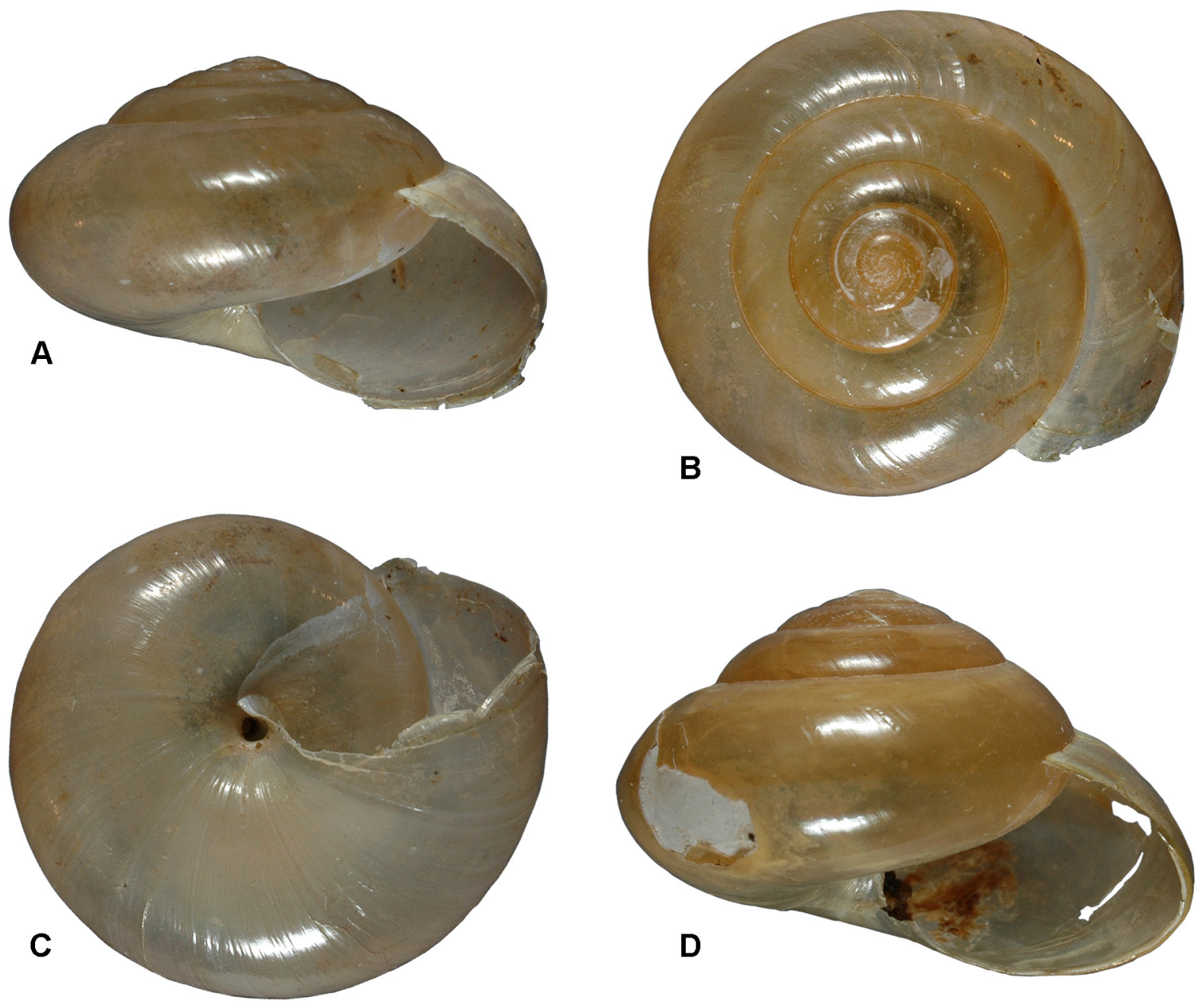

Fig. 11. Kerkophorus scrobicolus sp. nov. A-C. Holotype, diameter 15.3 mm (NMSA W4109/T4164). D. Umtamvuna, KwaZulu-Natal, diameter 16.4 mm (paratype, NMSA W5258/T4166). 


\section{Description}

SHELL (Fig. 11). Lenticular to globose-lenticular, spire remaining relatively prominent; periphery at midwhorl, weakly angled; H:D 0.66-0.69 $(\mathrm{N}=4)$; suture shallowly indented, inserting just above periphery; thin, translucent, uniformly pale buff to pale honey-coloured; surface glossy but with a slight silky sheen. Protoconch diameter 1.80-1.93 mm ( $\mathrm{N}=4)$; junction with teleoconch weakly marked; essentially smooth with only traces of microspiral sculpture. Teleoconch of up to 4.25 whorls; coiling relatively tight, whorls not expanding rapidly; sculptured by weak growth-lines and exceptionally fine and closeset, microscopic spiral lines. Umbilicus open and relatively wide. Aperture obliquely lunate, upper portion of columella lip reflected and partially obscuring umbilicus. Diameter up to $16.4 \mathrm{~mm}$; holotype, diameter $15.3 \mathrm{~mm}$, height $10.1 \mathrm{~mm}$.

Living animal (Fig. 12). Head-foot fawn-brown, optic tentacles and their retractor muscles slightly darker; body lobes of mantle of similar coloration to body; shell lobes well developed, slender and elongate; caudal appendage dark grey. Lining of pulmonary cavity variously speckled with irregular black and cream pigment spots and blotches; a large, more diffuse dark blotch lies just above and behind pneumostome; mantle margin beneath outer lip of shell bordered by a narrow cream line, broader above pneumostome. Spire viscera darker brown, with scattered irregular cream markings.

Radula (Fig. 13). Formula R+13+(1-2)+(130-140); rachidian tricuspid, mesocone broad and ectocones relatively small; anterior margin of shaft base not indented in mid-line; laterals essentially bicuspid with a mesocone and strong basal ectocone, but also with a minute endocone on side of mesocone; laterals followed by 1-2 teeth of intermediate shape and then a very long series of marginals; marginals stout and strongly curved, terminally bicuspid, with additional irregular serrations on outer edge of shaft; marginals progressively decreasing in size toward edge of radula, but otherwise morphologically similar.

Distal genitalia (Fig. 14A-C). Penis encased in thin sheath and with a distinct S-shaped bend or kink in basal half; retractor muscle attached to penis apex. Interior of penis lacking a distinct verge, but with a constriction at approximately one-third of its length from base; lumen below constriction with low longitudinal folds bearing minute, close-set, transverse wrinkles; lumen above constriction with smooth longitudinal folds (Fig. 14B). Epiphallus very short; caecum cylindrical, approximately equal to epiphallus in length, hollow, lined with widely spaced, interrupted longitudinal ridges; caecum arising very close to penis apex and retractor muscle. Flagellum stout and relatively short, comprising 1-2

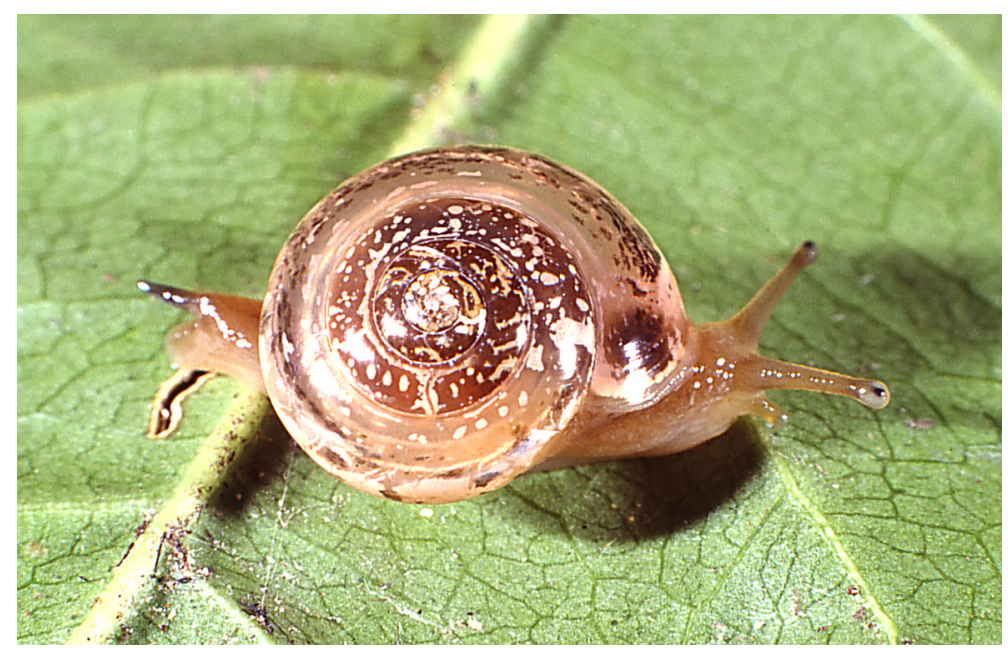

Fig. 12. Kerkophorus scrobicolus sp. nov., living animal, Mkambati Nature Reserve, E Cape, shell diameter $14.1 \mathrm{~mm}$ (paratype, NMSA V8911/T4163). 
whorls, f1 with distinct transverse internal structure, broadest in mid-region and tapering distally; $\mathrm{f} 2$ slender, straight in some specimens, slightly twisted in others, and with a central tube-like core that extends into (beneath) f1; junction of epiphallus and flagellum, at insertion of vas deferens, with opaque white contents; vas deferens simple and slender. Genital atrium swollen, internal wall with a welldeveloped stimulator projecting into atrial lumen, below opening of vagina (Fig. 14C); stimulator rolled to form an open tube; remainder of atrial wall with numerous, close-set, longitudinal folds; vagina relatively short; gametolytic sac almost spherical and thin-walled, its duct of moderate length; base of free oviduct swollen, dark brown to black in fresh material; spermoviduct divided into distinct prostatic and oviductal portions.

SPERMATOPHORE (Fig. 14D). Elbowed, with a crescent-shaped capsule and a bifid tail comprising a short, relatively stout and elaborately spinose element of approx. 1.25 whorls and a long, slender, spineless element that splits off the spinose element shortly after is origin from capsule; proximal portion of spinose element with a row of spines on each side, rows converging distally and ending as a single row of progressively smaller, less elaborate spines that continue to tip; larger spines flabellate and very finely divided (plumose), terminal branches deeply V-shaped, with curved, pointed tips. Slender element has a loose coil of approx. one whorl close to its base, but otherwise straight for much of its length. Coiled length of entire spermatophore approx. $9.0 \mathrm{~mm}$.

\section{Distribution (Fig. 15)}

A narrow-range endemic, known only from the coastal hinterland in the extreme south of KwaZuluNatal and the north-eastern E Cape (Pondoland); at altitudes between $70 \mathrm{~m}$ and $210 \mathrm{~m}$ above sea level.
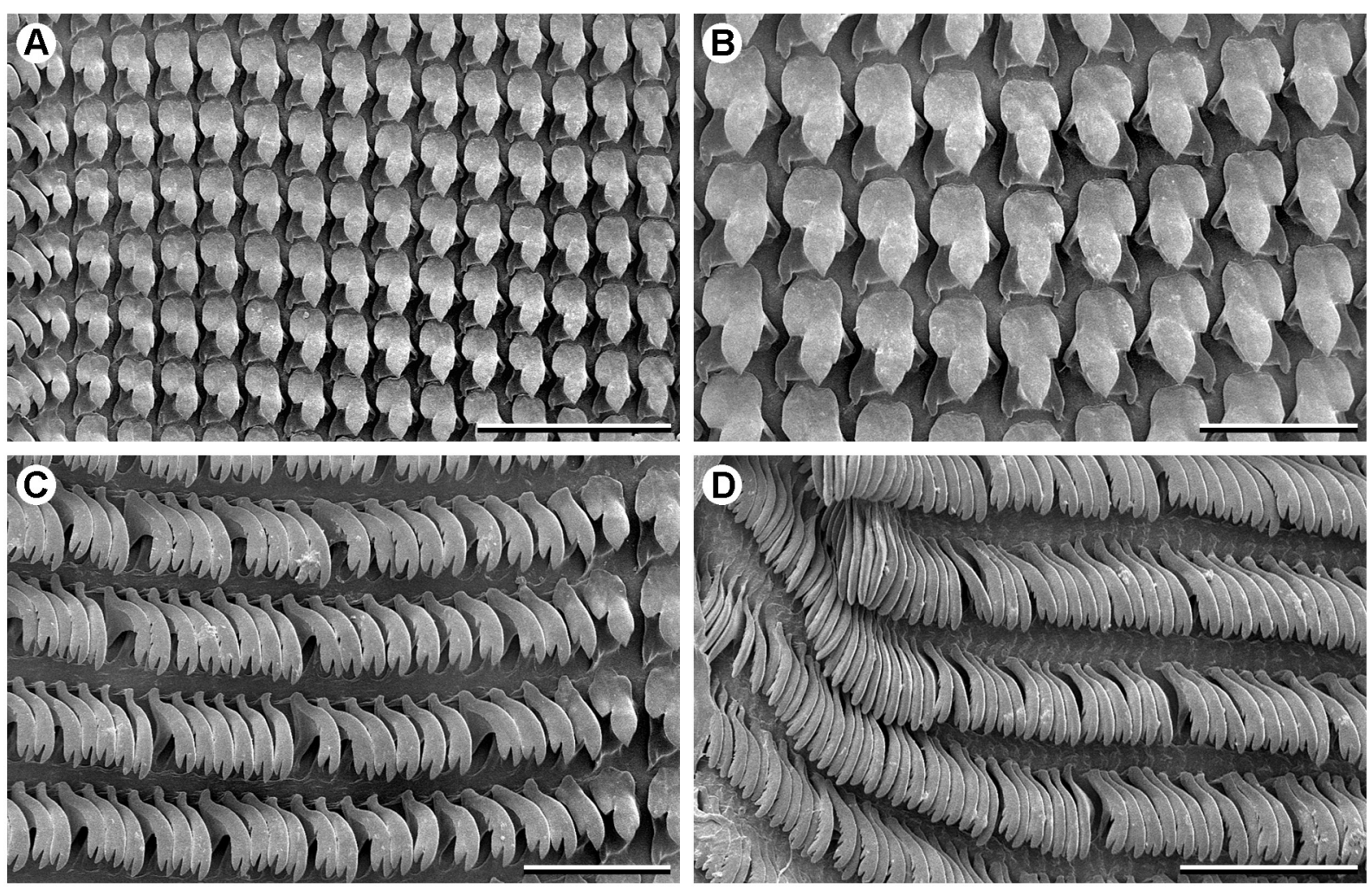

Fig. 13. Kerkophorus scrobicolus sp. nov., holotype, radula (NMSA W4109/T4164). A. Rachidian and left lateral teeth. B. Rachidian and innermost lateral teeth. C. Inner left marginal teeth. D. Outer left marginal teeth. Scale bars: A $=100 \mu \mathrm{m} ; \mathrm{B}-\mathrm{D}=50 \mu \mathrm{m}$. 


\section{Habitat}

Northern Coastal Forest and Scarp Forest (Mucina \& Rutherford 2006); on leaves of understorey vegetation during the wet summer months.

\section{Remarks}

Kerkophorus scrobicolus sp. nov. resembles K. puzeyi (Connolly, 1939), but lacks the marked peripheral angulation characteristic of that species. Neither does it possess the peripheral brown spiral line usually present in K. puzeyi and in the latter the umbilicus is also narrower and more extensively obscured by the reflected columella lip. In addition, although relatively few specimens of $K$. scrobicolus sp. nov. are available, it appears that it does not attain as large a size as does K. puzeyi (diameter up to $23 \mathrm{~mm}$ ).
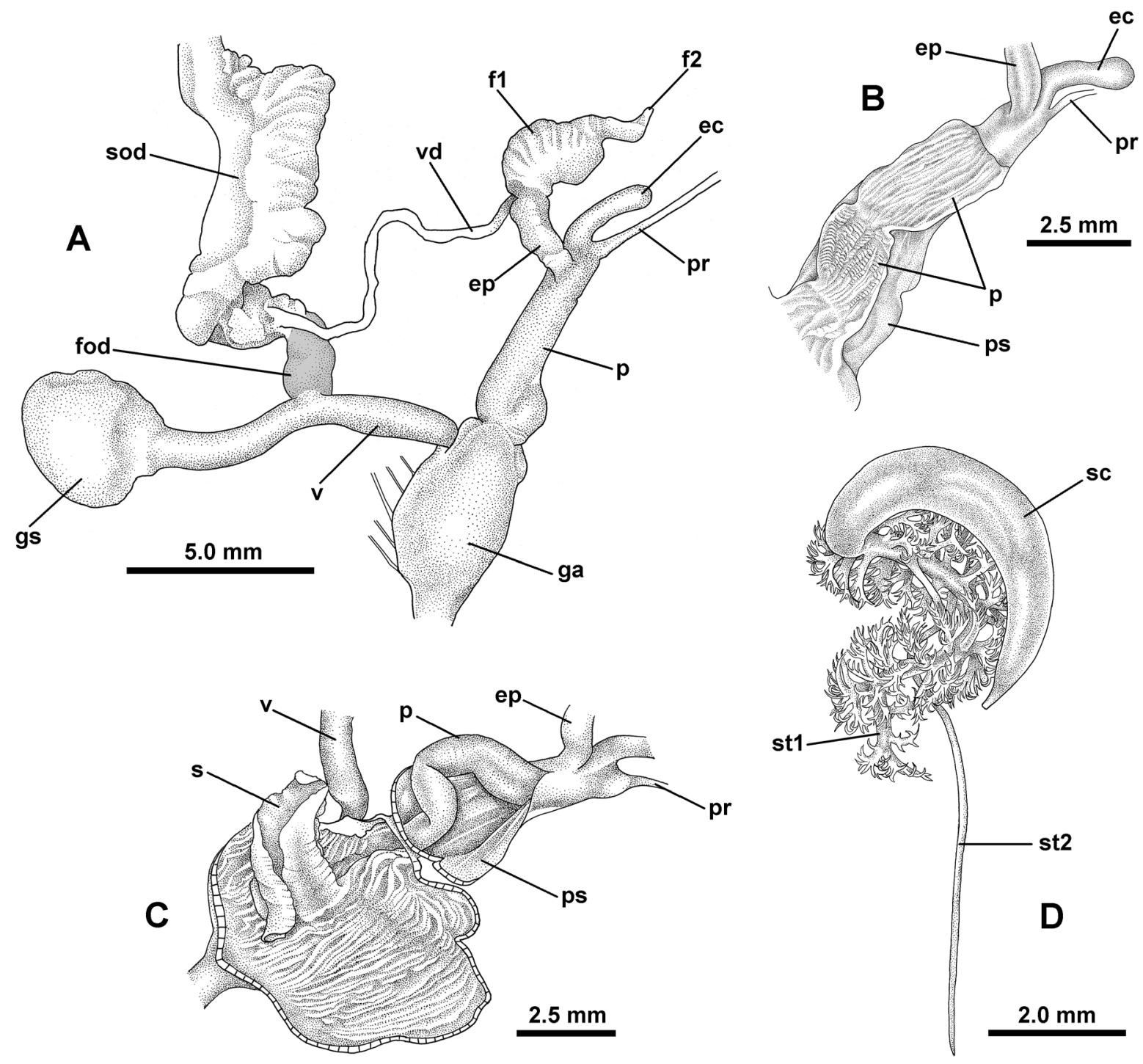

Fig. 14. Kerkophorus scrobicolus sp. nov., genitalia and spermatophore. A-C. Holotype (NMSA W4109/ T4164). A. Distal portion of genital tract. B. Dissection of penis showing difference in structure of lumen wall between apical and basal portions. C. Dissection of genital atrium and penis sheath to show atrial stimulator and kinked penis. D. Spermatophore with bifid tail (paratype, NMSA V8911/T4163). 
The anatomy of the distal genitalia of the two species exhibits no obvious differences and, judging by one damaged example, the spermatophore of K. puzeyi also has a bifid tail and is of similar morphology to that of $K$. scrobicolus sp. nov. This is a feature that I have not observed in other species of Kerkophorus for which spermatophores are available and it may be a synapomorphy indicative of a sister-species relationship. Spermatophores with bifid tails also occur in species of Microkerkus, but in these the spinose limb is much less elaborate, and the morphology of their distal reproductive tract is clearly distinct.

Both K. puzeyi and K. scrobicolus sp. nov. are restricted to forests in close proximity to the coast and, based on existing records, the ranges of the two do not overlap. K. puzeyi occurs to the south of K. scrobicolus sp. nov., ranging from Mbotyi to the Mazeppa Bay area. The interval between the ranges of the two species is only approximately $25 \mathrm{~km}$, but this largely comprises a hinterland of grassland with high coastal cliffs (Waterfall Bluff), which may have limited the potential for genetic exchange, particularly during glacial periods when the extent of coastal forest cover would have been more restricted compared to warmer interglacial periods.

\section{Conservation}

Given that the total known range of Kerkophorus scrobicolus sp. nov. extends for a linear distance of only $\pm 40 \mathrm{~km}$, the species must be considered one of conservation concern. In general, the forests in this region are threatened by a number of activities including on-going coastal development, smallscale agriculture, alien plant invasion, subsistence harvesting of forest products and the incursion of livestock. Those close to the coast are also threatened by dune mining for heavy metals. However, the

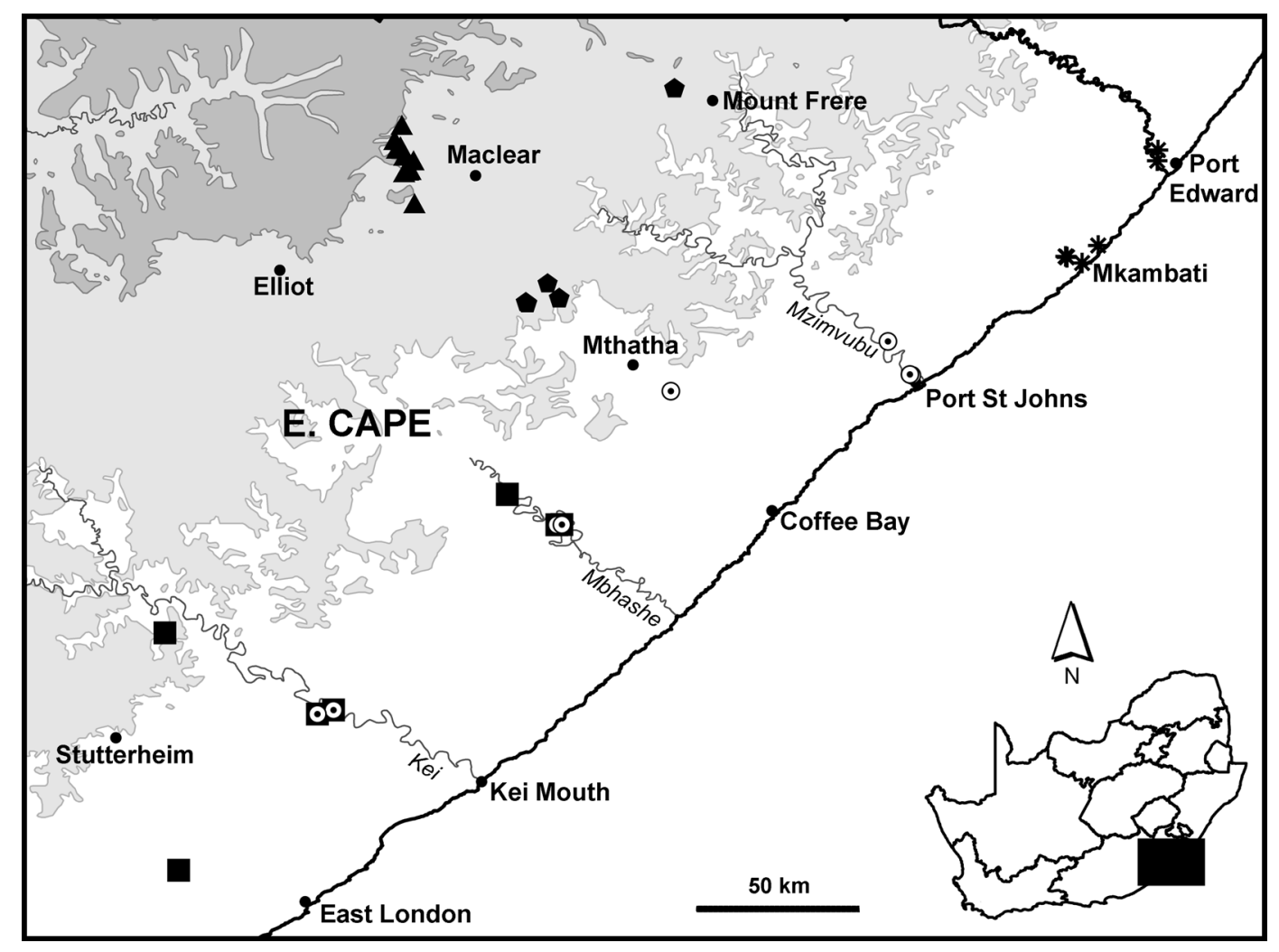

Fig. 15. Distribution of Kerkophorus scrobicolus sp. nov. (asterisks), Kerkophorus terrestris sp. nov. (circumpuncta), Selatodryas luteosoma gen. et sp. nov. (pentagons), S. roseosoma gen. et sp. nov. (triangles) and Sheldonia fingolandensis sp. nov. (squares). Contours at 1000 and $1500 \mathrm{~m}$. 
two localities at which $K$. scrobicolus sp. nov. has been found are formally conserved areas, namely Umtamvuna and Mkambati nature reserves. Thus, provided that conservation protocols are maintained in these reserves, the populations at these localities will be afforded a degree of protection.

\section{Kerkophorus terrestris sp. nov. \\ urn:Isid:zoobank.org:act:CE081A36-1D43-4736-8BE3-15D3677FD0D6}

Figs 15-19

\section{Diagnosis}

Rendered distinctive by the fine but well-defined spiral sculpture on the protoconch, silky texture of the apical surface, lack of a peripheral brown spiral line, and the relatively wide umbilicus.

\section{Etymology}

From the Latin 'terra', earth, and 'terrestris', of the earth; referring to the ground-dwelling habit of the species.

\section{Material examined}

\section{Holotype}

SOUTH AFRICA: E Cape, Mbhashe River valley, Collywobbles, beside thatched picnic site, $32.00442^{\circ} \mathrm{S}, 28.58172^{\circ} \mathrm{E}, 510 \mathrm{~m}$, valley thicket, in leaf-litter under bushes and aloes, D. Herbert and L. Davis leg., st. 06-010, 20 Feb. 2006 (NMSA W3979/T3862, dry shell with body in ethanol).

Paratypes (listed north to south, all E Cape)

SOUTH AFRICA: Port St Johns area, crater-like travertine deposit on S side of Umzimvubu River valley, $31.52053^{\circ} \mathrm{S}, 29.45662^{\circ} \mathrm{E}, 90 \mathrm{~m}$, valley thicket, in leaf-litter, D. Herbert, L. Davis and M. Bursey leg., 22 Apr. 2005 (NMSA W2933/T3863, 18 dry shells with three bodies and two whole juveniles in ethanol; RMNH.5004185, one dry shell); Port St Johns, Mt Thesiger, near airstrip ( Mpembeni), $31.61^{\circ} \mathrm{S}, 29.52^{\circ} \mathrm{E}, 365 \mathrm{~m}, \mathrm{M}$. Hamer leg., 20 Jun. 1998 (NMSA V6515/T3859, three dry shells with bodies and one whole specimen in ethanol); Port St Johns, vicinity of Mpembeni airstrip, $31.60785^{\circ} \mathrm{S}$, $29.51461^{\circ}$ E, $364 \mathrm{~m}$, grassland/rocky outcrop, in rock crevice, A. Moussalli and D. Stuart-Fox leg., 12 Nov. 2005 (NMSA W4134/T3860, two dry shells with bodies in ethanol, plus one whole juvenile in ethanol); Mthatha area, Buntingville, approx. $31.652^{\circ} \mathrm{S}, 28.883^{\circ} \mathrm{E}$, approx. $650 \mathrm{~m}$, Miss J.F. Barrett leg., ex Transvaal Museum 1978 (NMSA W1399/T3861, two dry shells); Mbhashe River valley, Collywobbles, overlooking vulture colony, $32.00396^{\circ} \mathrm{S}, 28.59530^{\circ} \mathrm{E}, 585 \mathrm{~m}$, sparse valley thicket invaded with Lantana, in leaf-litter under aloes and bushes, D. Herbert and L. Davis leg., st. 06-011, 20 Feb. 2006 (NHMUK 20160242, one dry shell; NMSA W4076/T3390, eight dry shells with one body in ethanol); Kei Pass, $32.49364^{\circ} \mathrm{S}, 27.99175^{\circ} \mathrm{E}, 282 \mathrm{~m}$, valley thicket, under rock, A. Moussalli and D. Stuart-Fox leg., 23 Nov. 2005 (NMSA W4172/T3391, one dry shell with body in ethanol); Sihota, W bank of Kei River, approx. $2.5 \mathrm{~km}$ upstream of Kei Bridge, below Moordenaars Kop, $32.50445^{\circ} \mathrm{S}$, 27.94945 E, 200 m, alive in soil under fallen Aloe ferox, M. Cole leg., 9 Jan. 2008 (ELM D15947/T158, one dry shell; ELM D15815/T159, 65 dry shells; NMSA W6387/T3858, 10 dry shells with two bodies and one whole juvenile in ethanol).

\section{Description}

SHELL (Fig. 16). Lenticular, but spire remaining relatively prominent; periphery at mid-whorl, evenly rounded; H:D 0.63-0.73 ( $\mathrm{N}=19)$; suture shallowly indented, inserting above periphery; thin, translucent, pale brownish-yellow to straw-brown when fresh, colour more or less uniform, peripheral brown spiral line absent; apical surface silky, lustreless, base somewhat more glossy. Protoconch diameter 1.47$1.67 \mathrm{~mm}(\mathrm{~N}=5)$; junction with teleoconch usually weakly marked; sculpture comprising numerous fine 
but distinct, close-set microscopic incised spiral striae (Fig. 16E); no evidence of punctation. Teleoconch of up to 3.5 whorls; coiling relatively tight, whorls not expanding rapidly; spiral sculpture of protoconch continues on first whorl, becoming progressively finer with growth, but remaining evident on last adult whorl in form of exceptionally fine and close-set, microscopic spiral lines, giving surface its silky sheen; slightly coarser axial lines also evident in places, but mostly inconspicuous; spiral microsculpture obsolete on base and surface more glossy; teleoconch otherwise only with uneven growth irregularities. Umbilicus open and relatively wide. Aperture roundly and obliquely lunate, upper portion of columella

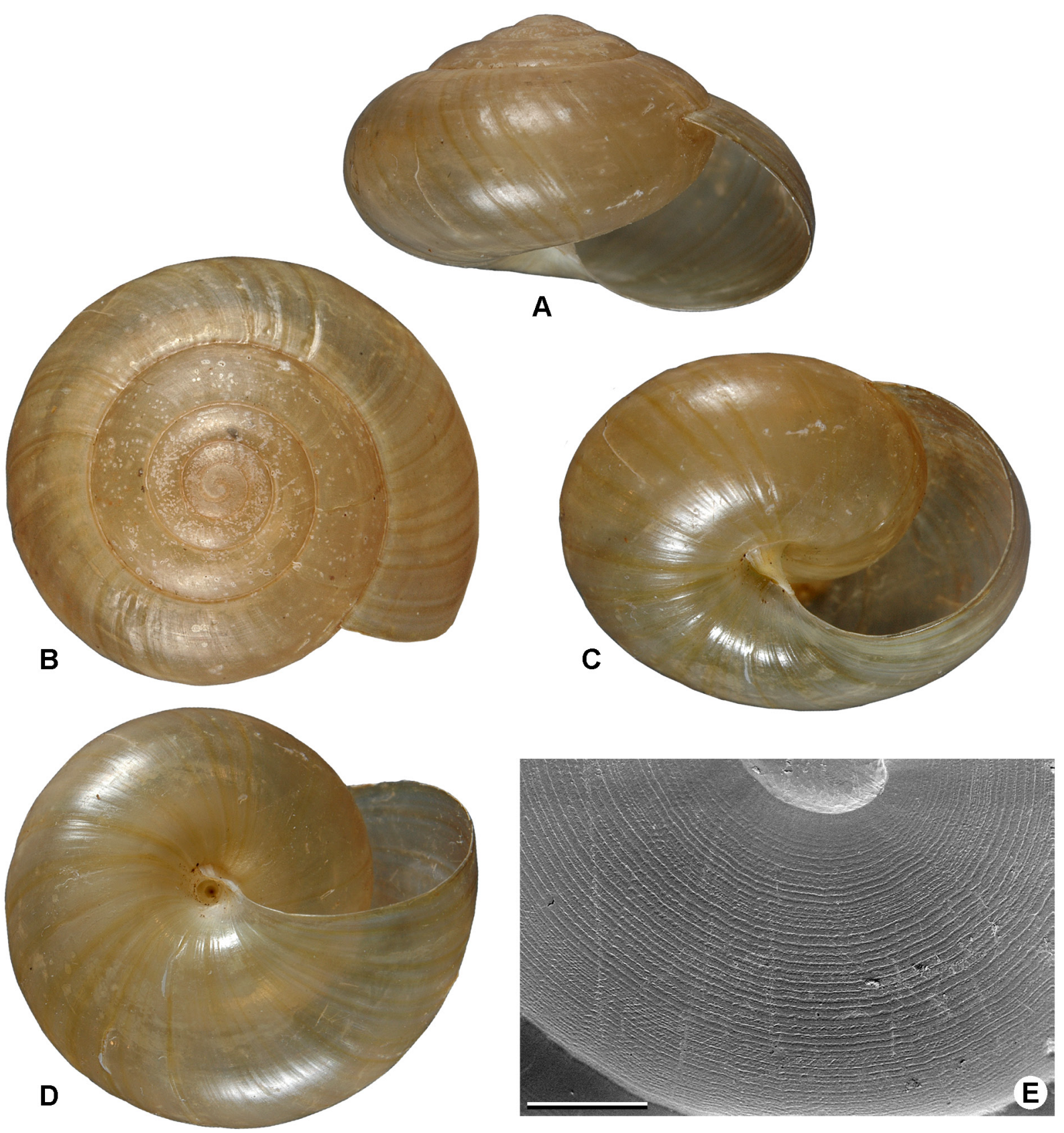

Fig. 16. Kerkophorus terrestris sp. nov. A-D. Holotype, diameter 13.1 mm (NMSA W3979/T3862). E. Close-set microspiral sculpture on protoconch, scale bar $=200 \mu \mathrm{m}$ (paratype, NMSA W2933/T3863). 
lip strongly reflected and partially obscuring umbilicus. Diameter up to $13.7 \mathrm{~mm}$; holotype, diameter $13.1 \mathrm{~mm}$, height $8.3 \mathrm{~mm}$.

Living ANIMAL (Fig. 17). Head-foot colour variable, some specimens pale greyish-brown with yellowishorange pigment granules concentrated in skin tubercles and along pedal margin (Fig. 17A), others with a distinctly reddish hue (Fig. 17B); mantle lobes of similar coloration to body, pigmentation more dense near pneumostome; tentacles and tip of caudal appendage dark grey. Spire viscera and lining of pulmonary cavity with numerous irregular yellowish-white blotches and little dark pigmentation except for a band of dark pigment overlying primary ureter, and a narrow black line on mantle margin beneath outer lip of shell.

Radula (Fig. 18). Formula $\mathrm{R}+(9-10)+(1-2)+(60-70)$; rachidian tricuspid, somewhat asymmetrical; laterals essentially bicuspid with a mesocone and strong basal ectocone, but also with a minute endocone on side of mesocone; laterals followed by 1-2 intermediary teeth and then a long series of marginals; marginals curved, bearing a large terminal cusp with a smaller subterminal cusp on outer (concave) margin, followed by a series of small, indistinct and irregular serrations; marginals progressively decreasing in size toward edge of radula, but otherwise morphologically similar.

Distal genitalia (Fig. 19A-C). Penis with a distinct S-shaped bend or kink in mid-region, dividing it into a relatively slender apical portion and a somewhat broader basal portion, the whole encased in a thin sheath; retractor muscle attached to penis apex. Lumen of basal portion of penis with numerous, fine, close-set papillae and with two thickened pilasters in its lower half that extend from folds in upper part of atrium; lumen of apical portion of penis with slender longitudinal folds; no evidence of a penial verge. Epiphallus very short; caecum well developed, arising close to penis-epiphallus junction, near origin of penial retractor muscle; caecum elongate, longer than epiphallus, its tip somewhat swollen. Flagellum divided into two portions; basal portion (f1) broader and with distinct transverse internal structure; apical portion (f2) longer and more slender, with a tube-like central core. Junction of epiphallus and flagellum, at insertion of vas deferens, with opaque white contents; vas deferens simple and slender. Genital atrium swollen, internal wall with a well-developed stimulator projecting into atrial lumen below opening of vagina; additional folds running from base of stimulator toward penis base; stimulator flaccid rather than muscular, its contracted shape variable between individuals; vagina long; gametolytic sac ovate and thin-walled, its duct relatively short; base of free oviduct swollen, yellowish-brown; spermoviduct divided into distinct prostatic and oviductal portions.
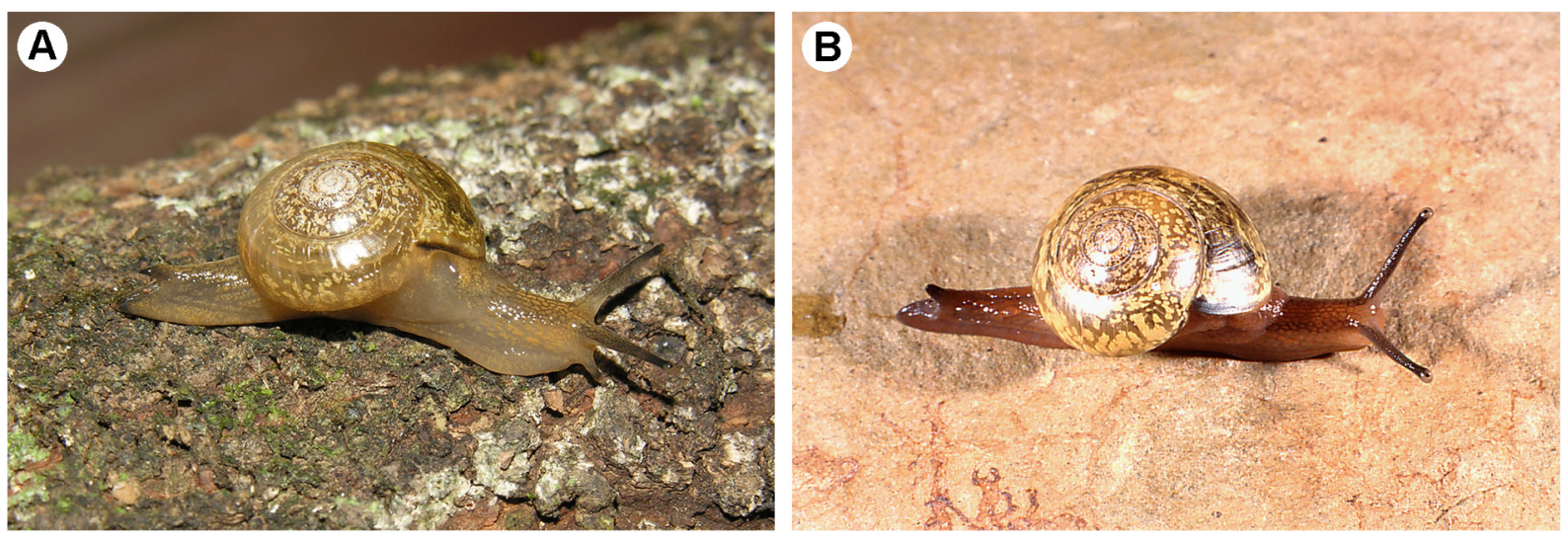

Fig. 17. Kerkophorus terrestris sp. nov., living animals. A. Collywobbles, E Cape, shell diameter $13.1 \mathrm{~mm}$ (holotype, NMSA W3979/T3862). B. Mount Thesiger, Port St Johns, E Cape, shell diameter $10.7 \mathrm{~mm}$ (paratype, NMSA V6515/T3859). 
Spermatophore (Fig. 19D). Elbowed, with a slender elongate capsule (length approx. $4.6 \mathrm{~mm}$ ) and a very long, complexly coiled tail; proximal portion of tail smooth, followed by \pm 1.5 coils bearing a single row of approx. 35 rather short and stout, branched spines; proximal 3-4 spines rapidly increasing in size, those in mid-region of more or less uniform size, then decreasing gradually in size toward spineless region; spines flabellate, terminating in shallowly and broadly V-shaped bifurcations, some almost T-shaped; distal half of tail lacking spines, very slender and somewhat randomly looped and entwined upon itself.

\section{Distribution (Fig. 15)}

A relatively narrow-range endemic, known only from the southern portion of the Transkei region, E Cape, South Africa, specifically the lower catchments of the Umzimvubu, Mbhashe and Kei rivers, and smaller intervening rivers; from $90 \mathrm{~m}$ to $650 \mathrm{~m}$ above sea level.

\section{Habitat}

Found primarily in the Eastern Valley Bushveld (Mucina \& Rutherford 2006); ground-dwelling, living under rocks and fallen aloes, in leaf-litter beneath bushes and in crevices in rock outcrops.

\section{Remarks}

Kerkophorus terrestris sp. nov. is a well characterised species that can be confused with few others. The combination of distinct spiral sculpture on the protoconch, lustreless surface and open umbilicus is exhibited by few other southern African urocyclids. Having said this, the species is very similar to Sheldonia crawfordi (Melvill \& Ponsonby, 1890) from the southern and eastern Karoo. In that species,
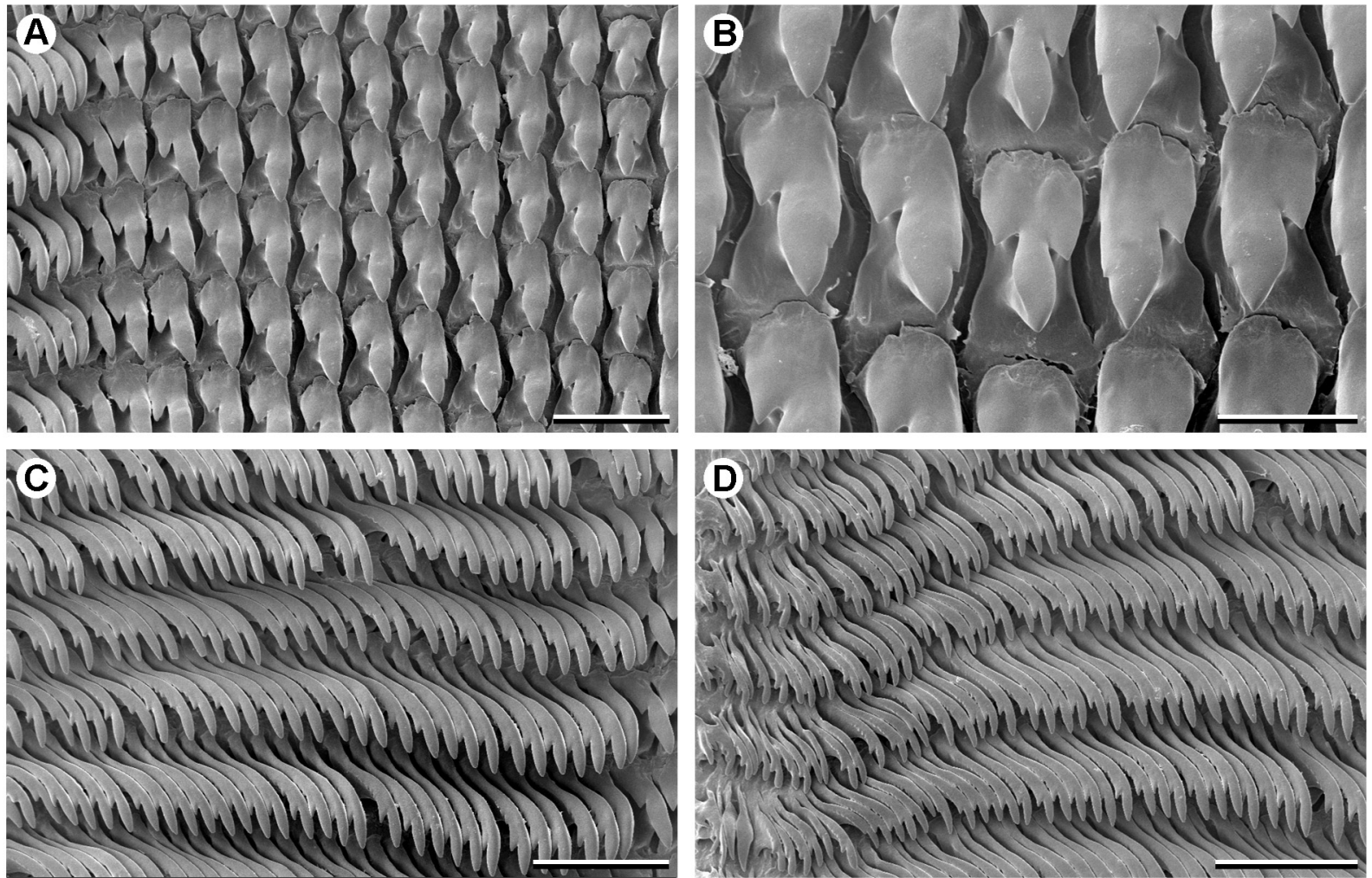

Fig. 18. Kerkophorus terrestris sp. nov., radula (holotype, NMSA W3979/T3862). A. Rachidian and left lateral teeth. B. Rachidian and innermost lateral teeth. C. Inner left marginal teeth. D. Outer left marginal teeth. Scale bars: A, C-D $=50 \mu \mathrm{m} ; \mathrm{B}=25 \mu \mathrm{m}$. 
however, the protoconch has the distinctive punctations with both an axial and spiral alignment seen in many species of Sheldonia s.s. It also attains a considerably larger size (diameter up to $21 \mathrm{~mm}$ ).

The spermatophore of $K$. terrestris sp. nov. is atypical for the genus in having only a single row of spines, and in these being relatively short and stout, with shallowly bifurcating branch tips. Spines of this form are more typical of Sheldonia s.s., but species of that genus also have a double row of nodules on the distal portion of the spermatophore tail (cf. S. fingolandensis sp. nov., below).

The atypical spermatophore, together with the long vagina and distinct spiral microsculpture on the protoconch, set $K$. terrestris sp. nov. apart from other members of Kerkophorus, suggesting perhaps that it belongs to a separate lineage.

\section{Conservation}

The distribution of Kerkophorus terrestris sp. nov. extends for approximately $180 \mathrm{~km}$ along the coastal hinterland of the Transkei region of E Cape. In this region there are few formally protected areas and none of the localities at which this species has been recorded fall within such areas. Conservation of the

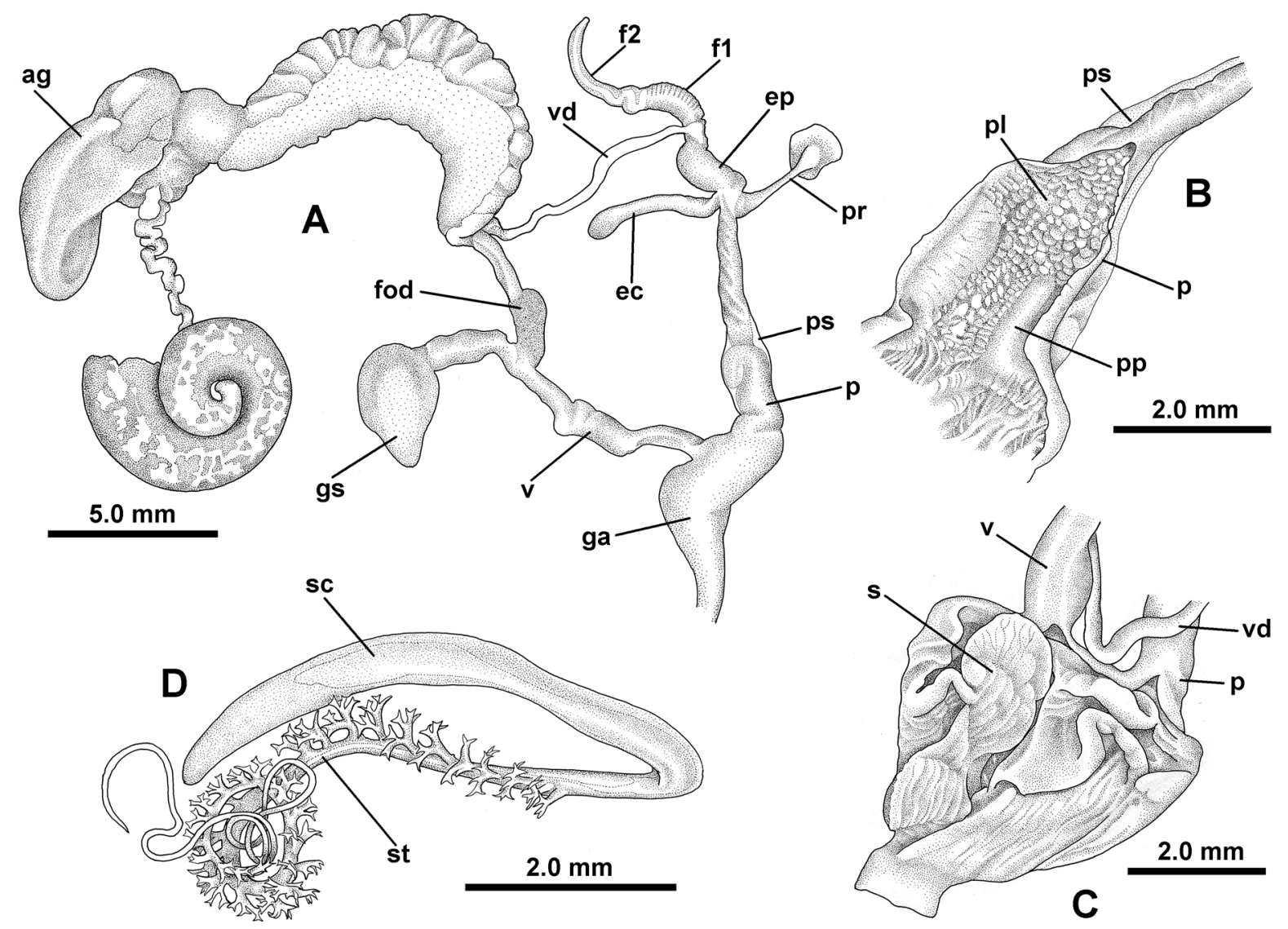

Fig. 19. Kerkophorus terrestris sp. nov., genitalia and spermatophore. A. Entire genital tract (holotype, NMSA W3979/T3862). B. Basal region of penis opened to show papillate lumen and longitudinal pilasters (paratype, NMSA V6515/T3859). C. Genital atrium dissected to show internal folds and atrial stimulator; in this specimen the male system has not been unravelled and the vas deferens is shown in its normal position (paratype, NMSA W4172/T3391). D. Spermatophore (paratype, NMSA W4172/ T3391). 
species will depend upon the preservation of its favoured Eastern Valley Bushveld habitats. Currently such habitats are viewed as 'least threatened' (Mucina \& Rutherford 2006), although alien invasive plants are a concern. Though not wide-ranging, where it occurs, $K$. terrestris sp. nov. is not rare and there is little to suggest that the species is under threat. Nonetheless, its limited range could provide additional motivation for the designation of protected areas in Eastern Valley Bushveld habitats, particularly in the lower reaches of the Umzimvubu, Mbhashe and Kei river valleys. Currently, less than $1 \%$ of this vegetation type is formally protected (Mucina \& Rutherford 2006).

Genus Microkerkus Godwin-Austen, 1912

Microkerkus Godwin-Austen, 1912a: 128. Type species Helix symmetrica Craven, 1880, by subsequent designation (Connolly 1912: 111).

\section{Remarks}

Watson (1934), Connolly (1939) and Zilch (1959-60) treated Microkerkus as a synonym of Kerkophorus, a conclusion justified by the minimal diagnosis provided by Godwin-Austen (1912a). However, there are consistent differences in the morphology of the male distal genitalia of Microkerkus that clearly set it apart from Kerkophorus and other members of Sheldonia s.l. Specifically, the epiphallus is generally longer, the caecum is small, globose rather than elongate, and it is situated more or less in the middle of the epiphallus, rather than adjacent to the penial retractor muscle. Furthermore, the tail of the spermatophore is bifid, comprising a spinose element and a secondary smooth element that branches from it. In terms of the relative length of the two elements of the spermatophore tail, Microkerkus appears divisible into two groups. Typically, after the bifurcation the smooth element is much longer than the spinose element (M. symmetricus, M. maseruensis (Connolly, 1929) and M. arnotti (Benson, 1864)), but in others the two elements, after splitting, are more or less equal in length (M. burnupi (Godwin-Austen, 1914), M. leucospira (Pfeiffer, 1857) and M. pondoensis Godwin-Austen, 1912). This difference is also evident in the morphology of the flagellum, the latter group having a clearly bifid flagellum. (The figure of the genitalia of M. symmetricus given by Godwin-Austen (1914: pl. 19, fig. 2) is almost certainly misidentified and in fact represent a species of Kerkophorus.)

Shell morphology is variable; the shell surface may be lustreless or glossy, the protoconch smooth or spirally lirate, but always lacks punctations; the umbilicus may be relatively broad, narrowly rimate or absent; the coloration is usually uniform, though the apical whorls may be paler, and there is never a brown peripheral spiral band.

\section{Microkerkus sibaya sp. nov. urn:1sid:zoobank.org:act:F4AD8FEE-EF1A-498A-B16A-CD7B60073056}

Figs 6, 20-22

\section{Diagnosis}

Shell globose-lenticular, lustreless, pale corneous brown, with irregular axial bands of short oblique white lines; protoconch non-punctate, but with distinct microspiral sculpture; columella straight, umbilicus present. Epiphallus long with a small, globular caecum just distal to mid-point; flagellum not bifid, with a long, loosely coiled $f 2$.

\section{Etymology}

Name derived from the type locality, Lake Sibaya, in Maputaland, northern KwaZulu-Natal. 


\section{Material examined}

\section{Holotype}

SOUTH AFRICA: KwaZulu-Natal, Lake Sibaya area, E of lake, approx. $27.35^{\circ} \mathrm{S}, 32.68^{\circ} \mathrm{E}$, dune forest, B.H. Lamoral leg., Jul. 1967 (NMSA V6958/T4169, dry shell with body in ethanol).

\section{Paratypes}

SOUTH AFRICA: same data as holotype (NMSA P0658/T4170, three dry shells with bodies in ethanol).
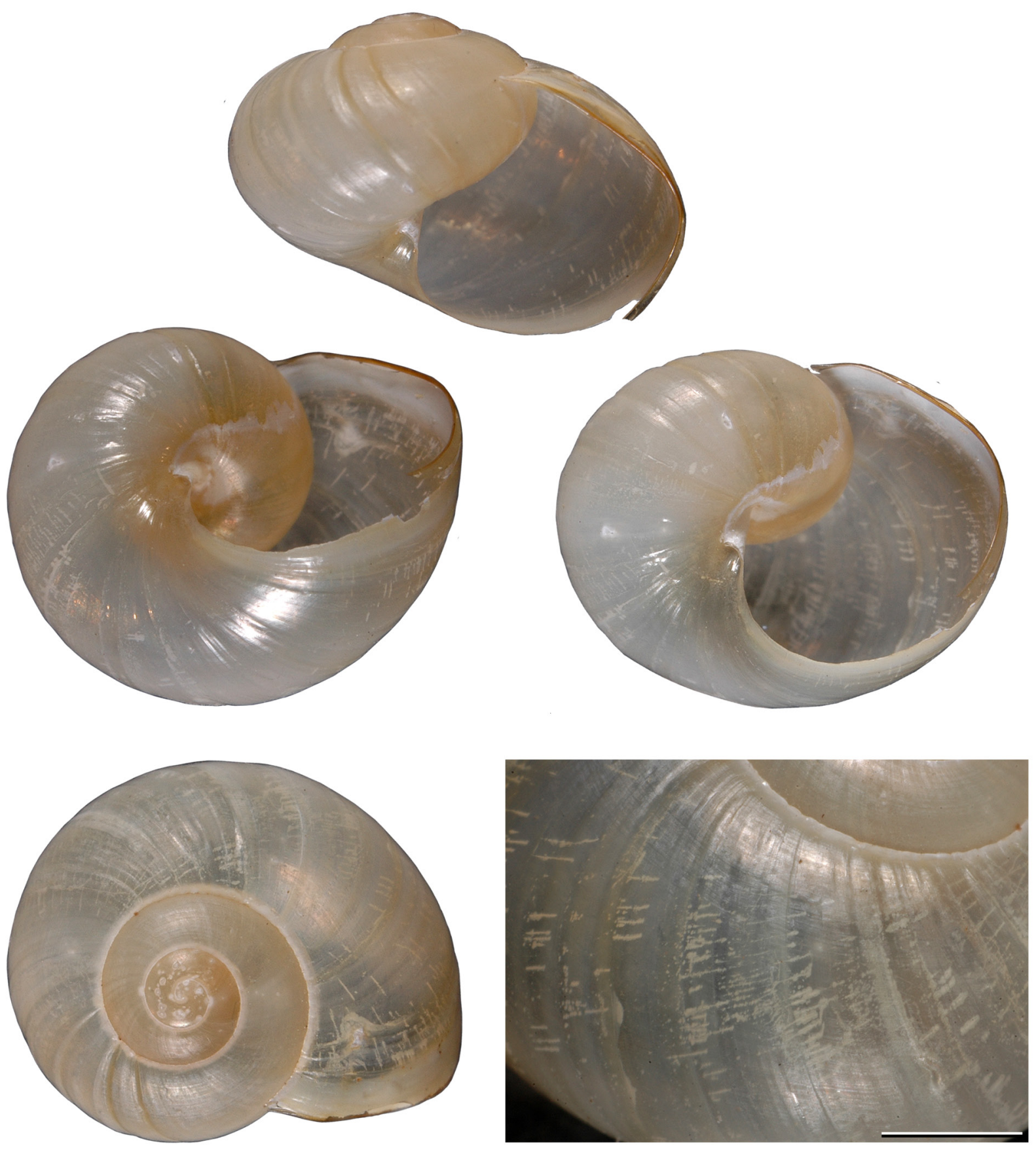

Fig. 20. Microkerkus sibaya sp. nov., holotype, diameter $10.0 \mathrm{~mm}$ (NMSA V6958/T4169), four views of shell and detail of pattern of white lines on body whorl, scale bar $=2.0 \mathrm{~mm}$. 


\section{Description}

SHELL (Fig. 20). Globose-lenticular, spire relatively low; periphery at or close to mid-whorl, evenly rounded; H:D 0.77-0.78 ( $\mathrm{N}=3)$; suture rather distinctly indented, inserting above periphery; thin, translucent pale corneous brown, with short oblique white lines, often arranged in irregular axial bands; surface satin-like, peri-umbilical region somewhat more glossy. Protoconch diameter 1.8-1.9 mm ( N=2); junction with teleoconch poorly defined; sculptured with very fine, close-set, microscopic spiral lirae. Teleoconch of up to 2.25 whorls; sculpture similar to that on protoconch, but finer, producing satin-like shell surface; no axial component evident in microsculpture; growth-lines few on spire whorls, but more frequent on body whorl. Columella relatively straight, upper portion reflected, creating a distinct umbilical channel. Aperture somewhat D-shaped, indented by penultimate whorl in parietal region. Diameter up to $10.9 \mathrm{~mm}$; holotype, diameter $10.0 \mathrm{~mm}$, height $7.7 \mathrm{~mm}$.

LIVING ANIMAL. Only the original specimens in $75 \%$ ethanol are available. Most of the colour in these has been lost and the head-foot and pulmonary cavity are now largely milky-white; the spire viscera apical to the pulmonary cavity are mid-brown with frequent sub-circular cream blotches in the superficial tissue.

RAdULA (Fig. 21). Formula R+9+(2-3)+(30-40); rachidian tricuspid, mesocone slender; anterior margin of shaft base not indented in mid-line; laterals essentially bicuspid with a mesocone and strong basal ectocone, but also with a minute endocone on side of mesocone; laterals followed by 2-3 teeth of intermediate shape; marginals relatively few in number, curved with a large terminal cusp and a weak subterminal one on outer (concave) margin; shaft lacking serrations; marginals progressively decreasing in size toward edge of radula, but otherwise morphologically similar.
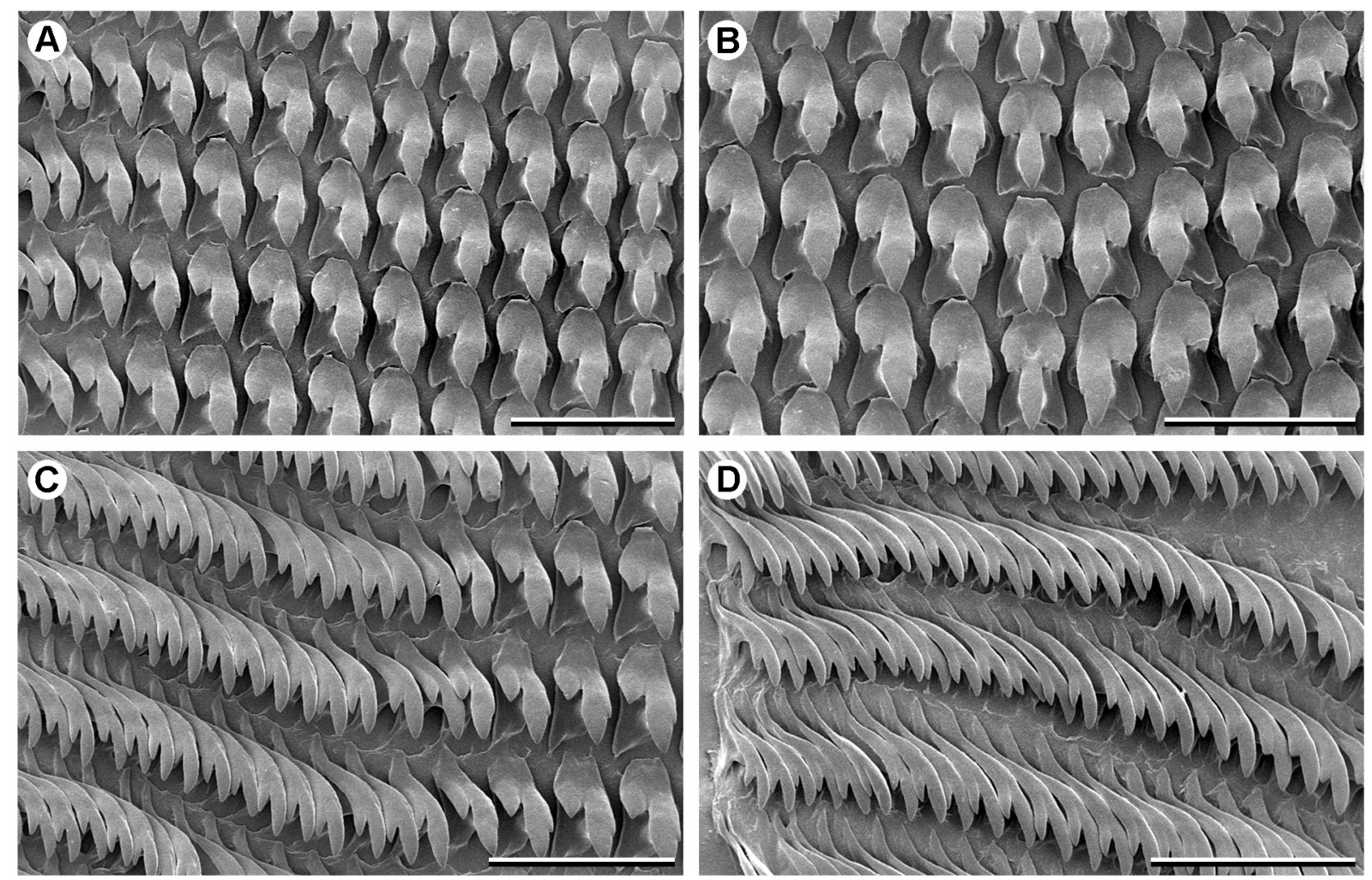

Fig. 21. Microkerkus sibaya sp. nov., radula (holotype, NMSA V6958/T4169). A. Rachidian and left lateral teeth. B. Rachidian and innermost lateral teeth. C. Inner left marginal teeth. D. Outer left marginal teeth. Scale bars $=50 \mu \mathrm{m}$. 
Distal Genitalia (Fig. 22). Penis elongate and cylindrical, looped upon itself in mid-region and surrounded by a thin sheath; retractor muscle attached to penis apex; penis thin-walled, basal half slightly broader; lumen lining not well preserved, but with evidence of longitudinal folds; no evidence of a penial verge. Epiphallus relatively long, with a small globose caecum just distal to mid-point. Flagellum well developed, basal portion (f1) broader and with distinct transverse internal structure; distal portion (f2) more slender, with 1-2 loose coils; proximal part of epiphallus, close to insertion of vas deferens, with opaque white contents; vas deferens simple and slender, running beside vagina and free oviduct to join spermoviduct. Genital atrium small, lacking stimulator. Vagina of moderate length; gametolytic sac elongate-ovate, thin-walled, its duct relatively short; free oviduct not conspicuously enlarged; spermoviduct divided into distinct prostatic and oviductal portions.

SPERMATOPHORE. Unknown.

Distribution (Fig. 6)

Known only from the type locality.

\section{Habitat}

Northern Coastal Forest (Mucina \& Rutherford 2006).

\section{Remarks}

The genital morphology of this species is typical of Microkerkus and I have little hesitation in referring it therein. The form of the flagellum with a long $\mathrm{f} 2$ resembles that of $M$. maseruensis and $M$. symmetricus, and is quite distinct from the bifid flagellum found in M. burnupi, M. leucospira and M. pondoensis. In terms of shell morphology, perhaps the most similar species is M. chrysoprasinus (Melvill \& Ponsonby, 1892), but in that species the shell is more globose and the f2 portion of the flagellum is much shorter.

The occurrence of a species of Microkerkus close to the coast of northern Maputaland is somewhat surprising. The majority of Microkerkus species occur at high altitude ( $800 \mathrm{~m}$ to over $3000 \mathrm{~m}$ ). The only other species occurring below this are M. leucospira and M. pondoensis, which favour open grassland

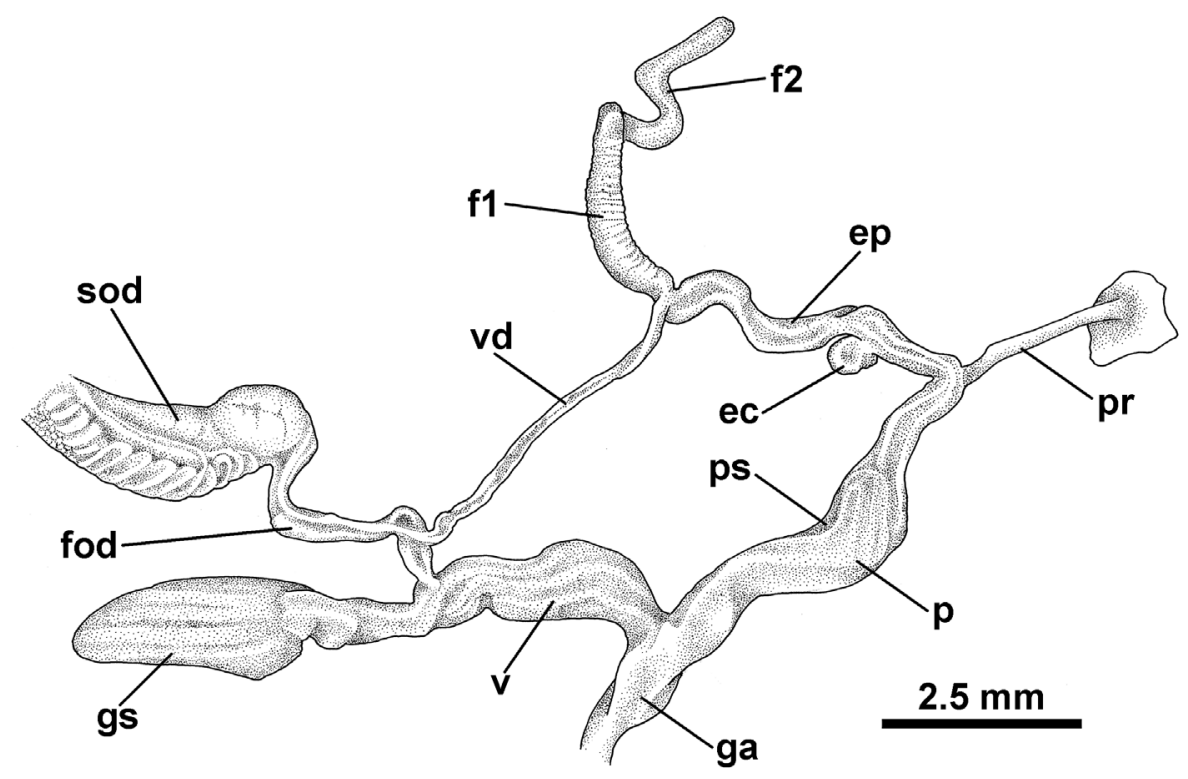

Fig. 22. Microkerkus sibaya sp. nov., distal genitalia (paratype, NMSA P0658/T4170). 
and marsh habitats along the coast and coastal scarp of central and southern KwaZulu-Natal and northeastern E Cape.

The irregular axial bands of short oblique white lines on the shell of this species are an unusual feature. I have not observed similar markings on the shells of any other southern African urocyclids. Although these are present in the shells of all four specimens available and may perhaps be distinctive of $M$. sibaya sp. nov., there is a possibility that they are in fact a preservation artefact. The intact specimens were preserved in ethanol for more than 40 years prior to the bodies being removed from the shells and the latter were then stored dry. There has undoubtedly been some deterioration in the substance of the shell, including partial decalcification close to the growing margin. These unusual lines may be a further manifestation of preservation-related damage rather than a species-specific character.

\section{Conservation}

Little can be said regarding the conservation of Microkerkus sibaya sp. nov. It is clearly a data deficient species for which targeted field work is needed. The type locality falls within the iSimangaliso Wetland Park World Heritage Site and is thus afforded a high level of protection.

Genus Selatodryas gen. nov.

urn:1sid:zoobank.org:act:72AF5C89-20EB-44EE-B2F5-6390BD6E0183

\section{Type species}

Selatodryas roseosoma gen. et sp. nov.

\section{Diagnosis}

Shell small, delicate and glossy, periphery at or just below mid-whorl; umbilicus absent, edge of columella lip reflected and slightly thickened with a thin, whitish callus; columella running into axis of coiling rather than fusing with the parietal region; protoconch essentially smooth. Optic tentacles conspicuously dark. Penis long, coiled inside sheath; epiphallus long; caecum elongate, situated just proximal to mid-point of epiphallus, well separated from insertion of penial retractor muscle; penial verge absent; vagina long. Terminal branches of spermatophore spines bluntly bifid; distal portion of spermatophore tail smooth and relatively short.

\section{Etymology}

From the Greek ' $\sigma \varepsilon \lambda \dot{\alpha} \tau \eta \varsigma^{\prime}, \mathrm{m}$., a snail, and ' $\Delta \rho v \alpha \dot{c} \varsigma^{\prime}$, f., a Dryad or forest nymph; in reference to the delicate shell and preferred habitat of these snails. Gender feminine.

\section{Remarks}

The morphology of the penis and epiphallus, and the bluntly bifid branch tips of the spermatophore spines of Selatodryas gen. nov. suggest a close relationship with Sheldonia s.s. Similarly, the form of the columella region (complete absence of an umbilicus) is a character shared with some species of Sheldonia s.s. (such as S. trotteriana (Benson, 1848), S. natalensis (Pfeiffer, 1846) and S. cotyledonis (Benson, 1850)). However, two characters of Selatodryas gen. nov. set the genus apart from Sheldonia s.s., namely the smooth protoconch and the short distal portion of the spermatophore tail that lacks a double row of blunt projections.

Preliminary mtDNA data confirm this close relationship, placing the two species of Selatodryas gen. nov. in a well-supported clade sister to, but distinct from Sheldonia s.s. (Herbert \& Moussalli 2009). Selatodryas gen. nov. is known only from high altitude forest (Southern Mistbelt). From a biogeographical perspective the ranges of the two genera do not overlap. Sheldonia s.s. occurs over 
a large part of the Eastern and Western Cape, from the Mbhashe River valley west to St Helena Bay, whereas Selatodryas gen. nov. occurs as an almost parapatric isolate to the north-east of Sheldonia s.s., suggesting that Selatodryas gen. nov. diverged from the ancestral Sheldonia stock before Sheldonia s.s. radiated into the drier regions of the southern Cape and Karoo.

The two species of Selatodryas gen. nov. described below differ conspicuously in body coloration and this is reflected in their respective species names. However, the taxonomic value of body colour as a diagnostic character in southern African urocyclid snails must be viewed with caution. A number of species show considerable intra-specific variation in this regard, including Kerkophorus terrestris sp. nov. described above (Fig. 17), as well as Sheldonia monsmaripi Herbert, 2016 and S. natalensis (Pfeiffer, 1846). Such colour differences may relate to ecological rather than genetic factors. The above notwithstanding, in the two species of Selatodryas gen. nov. the colour difference is pronounced and geographically consistent, and there are further correlated differences in genital anatomy and spermatophore morphology, providing confirmatory evidence that the two are distinct species.

Selatodryas roseosoma gen. et sp. nov. urn:1sid:zoobank.org:act:02EF7ACF-2BE4-4435-A973-2FEEDC3BACA3

Figs 15, 23-26

\section{Diagnosis}

Characterised by the low-spired, glossy yellowish-brown shell, non-punctate protoconch and columella that runs into the axis of coiling rather than fusing with the parietal region. Distal genitalia with relatively long flagellum of which f1 comprises approx. three whorls.

\section{Etymology}

From the Latin 'roseus', rose-coloured, and the Greek 'soma', body; referring to the reddish-pink coloration of the living animal.

\section{Material examined}

\section{Holotype}

SOUTH AFRICA: E Cape, Maclear district, Redcliffe valley, $31.00750^{\circ} \mathrm{S}, 28.16429^{\circ} \mathrm{E}, 1538 \mathrm{~m}$, patches of montane forest in gullies, M. Bursey leg., 23 Jan. 2007 (NMSA W5379/T3865, dry shell with body in ethanol).

Paratypes (listed north to south, all E Cape)

SOUTH AFRICA: same data as holotype, adults under logs, immatures under leaves (ELM W3162/ T162, two dry shells with bodies in ethanol; NMSA W5257/T3867, one dry shell with one body and one whole specimen in ethanol; NMSA W5380/T3866, eight dry shells); Maclear district, Redcliffe valley, $31.00962^{\circ} \mathrm{S}, 28.16209^{\circ} \mathrm{E}, 1500 \mathrm{~m}$, southern mistbelt forest, in leaf-litter amongst Dietes clumps, D. Herbert, S. Bell-Cross and L. Davis leg., 11 Apr. 2014 (NHMUK 20160244, two dry shells; RMNH.5004186, two dry shells); Maclear district, Redcliffe valley, $31.01103^{\circ} \mathrm{S}, 28.15975^{\circ} \mathrm{E}, 1500$ $\mathrm{m}$, patches of montane forest in gullies, adults under dead logs, immatures under leaves, M. Bursey and S. Bell-Cross leg., 18 Feb. 2003 (NMSA W5005/T3870, two dry shells with bodies in ethanol; W5381/ T3864, three dry shells; ELM D15747/T163, ten dry shells); Maclear district, Minniehaha, $31.02972^{\circ} \mathrm{S}$, $28.17888^{\circ} \mathrm{E}, 1660 \mathrm{~m}$, patches of montane forest in gullies, adults under dead logs, immatures under leaves, M. Bursey, 24 Jan. 2007 (NMSA W5382/T3869, one dry shell with body in ethanol); Prentjiesberg, $31.04192^{\circ} \mathrm{S}, 28.20285^{\circ} \mathrm{E}, 1386 \mathrm{~m}$, indigenous forest, general searching, M. Hamer et al. leg., MTDP 5389, 9 Feb. 2006 (NMSA W4462/T3868, two dry shells with body of one in ethanol); Prentjiesberg, $31.06729^{\circ} \mathrm{S}, 28.19450^{\circ} \mathrm{E}, 1416 \mathrm{~m}$, indigenous forest, ground searching, M. Hamer et al. leg., site F61, 8 Feb. 2006 (NMSA W5063/T3871, two dry shells, with two bodies and one whole specimen in 
ethanol); Prentjiesberg, $31.15505^{\circ} \mathrm{S}, 28.20529^{\circ} \mathrm{E}, 1534 \mathrm{~m}$, indigenous forest, ground searching, $\mathrm{M}$. Hamer et al. leg., site F65, 7 Feb. 2006 (NMSA W5073/T3872, three dry shells with three bodies and one whole specimen in ethanol).

Other material (listed north to south, all E Cape, NMSA)

SOUTH AFRICA: Maclear district, Woodcliffe valley, $30.94833^{\circ} \mathrm{S}, 28.17194^{\circ} \mathrm{E}$, indigenous forest, under leaves, esp. Rapanea melanophoeos, M. Bursey leg., 17 Feb. 2003 (W9627, W9628, ethanol material only); Maclear district, Woodcliffe valley, $30.98818^{\circ} \mathrm{S}, 28.15246^{\circ} \mathrm{E}, 1415 \mathrm{~m}$, southern mistbelt forest, dead in leaf-litter, D. Herbert and L. Davis leg., st. 14-04, 12 Apr. 2014 (W9724); Maclear district, Redcliffe valley, $31.00962^{\circ} \mathrm{S}, 28.16209^{\circ} \mathrm{E}, 1500 \mathrm{~m}$, southern mistbelt forest, in leaf-litter amongst Dietes clumps, D. Herbert, S. Bell-Cross and L. Davis leg., 11 Apr. 2014 (W9722); Prentjiesberg, $31.06729^{\circ} \mathrm{S}, 28.19450^{\circ} \mathrm{E}, 1416 \mathrm{~m}$, indigenous forest, ground searching, M. Hamer et al. leg., site F61, 8 Feb. 2006 (W9690); Prentjiesberg, 31.06895 ${ }^{\circ} \mathrm{S}, 28.18844^{\circ} \mathrm{E}, 1447 \mathrm{~m}$, indigenous forest, M. Hamer et al. leg., site F63, 4 Feb. 2006 (W5065); Prentjiesberg, 31.07319 ${ }^{\circ}$ S, $28.17802^{\circ} \mathrm{E}, 1640 \mathrm{~m}$, indigenous forest, ground searching, M. Hamer et al. leg., site F64, 5 Feb. 2006 (W5071).
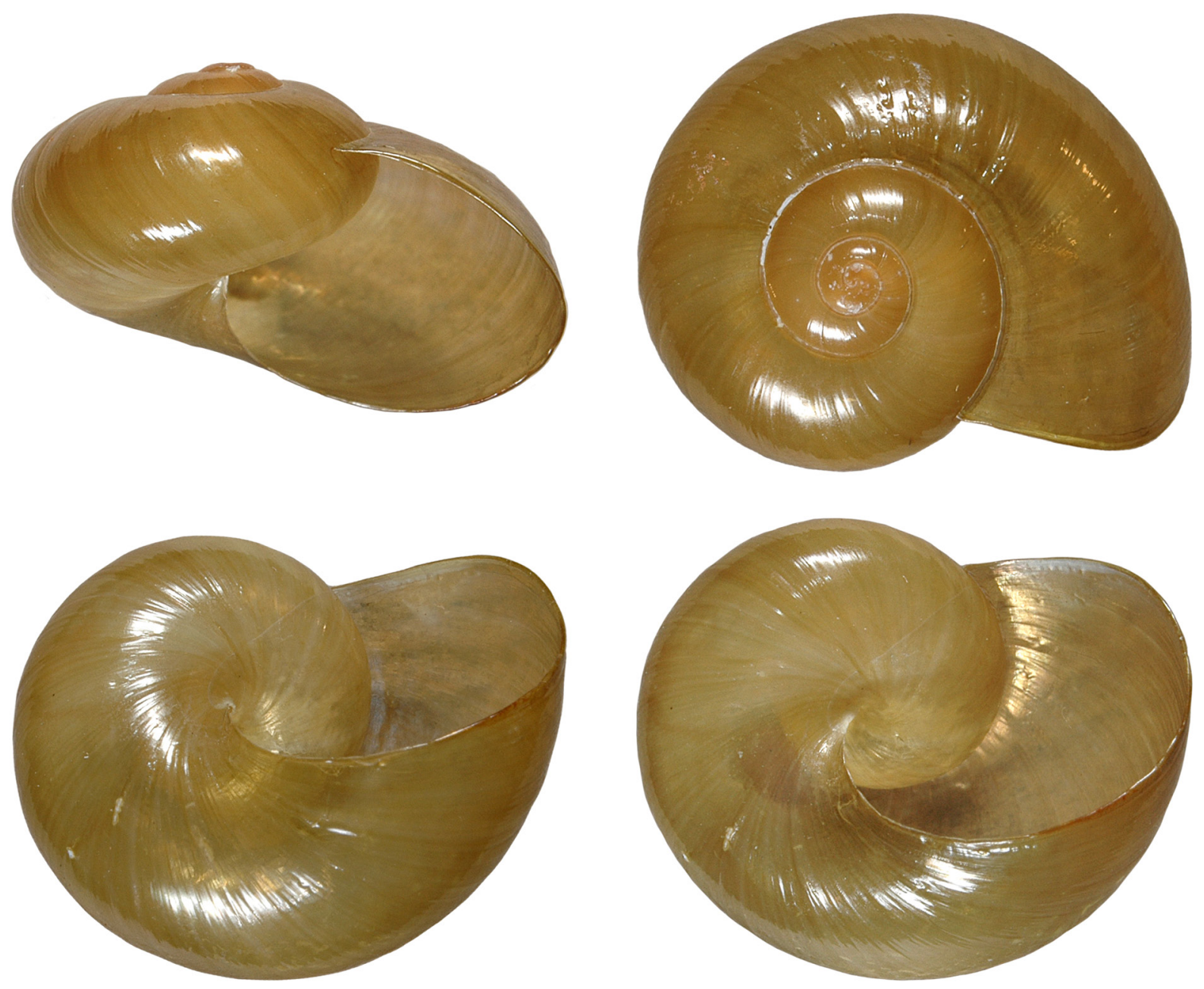

Fig. 23. Selatodryas roseosoma gen. et sp. nov., holotype, diameter 14.9 mm (NMSA W5379/T3865). 


\section{Description}

SHELL (Fig. 23). Lenticular; periphery at mid-whorl, evenly rounded; H:D 0.61-0.69 (N=11); suture rather distinctly indented, inserting just above periphery; very thin and delicate; translucent, more or less uniformly yellowish-brown, some specimens with a greenish tint; apical and basal surfaces both glossy. Protoconch diameter $1.68-1.87 \mathrm{~mm}(\mathrm{~N}=10)$; essentially smooth, but with extremely fine, closeset, microscopic scratch-like spiral lines; no evidence of punctation; junction with teleoconch usually weakly marked. Teleoconch of up to 2.25 whorls; whorls expanding moderately rapidly; spiral sculpture virtually obsolete, later whorls with only the finest traces of microscopic, close-set, wavy, spiral ripples, even weaker on base; teleoconch otherwise only with weak, uneven growth irregularities. Umbilicus absent, edge of columella lip reflected and slightly thickened with a thin, whitish, somewhat pleated callus; columella running into axis of coiling rather than fusing with parietal region; aperture roundly lunate. Diameter up to $15.0 \mathrm{~mm}$; holotype, diameter $14.9 \mathrm{~mm}$, height $9.6 \mathrm{~mm}$.

Living ANIMAL (Fig. 24). Head-foot predominantly reddish-pink, coloration due to presence of numerous microscopic pigment granules; tentacles dark grey-black; caudal appendage well developed, dark grey; peripodial groove distinct and skin grooves on tail region well defined. Body lobes of mantle extensive, coloration similar to that of head-foot; shell lobes well developed; mantle edge bordered internally by a thin cream line behind which is a diffuse grey band; a small dark grey spot on mantle edge posterior to pneumostome; lining of pulmonary cavity with little pigmentation save for sparse irregular cream specks, particularly below suture; spire viscera brown with somewhat more conspicuous cream specks; primary ureter delimited by a diffuse grey band, kidney region pale orange-yellow.

Radula (Fig. 25). Formula R+11+(1-2)+(80-90); rachidian tricuspid, anterior edge of shaft base with V-shaped mid-line notch; laterals essentially bicuspid with a mesocone and strong basal ectocone, but also with a minute endocone on side of mesocone; shaft of laterals rectangular (longer than wide) with mesocone set at a distinct angle to long axis of shaft; laterals followed by 1-2 intermediary teeth and then a long series of marginals; marginals curved, bearing a large terminal cusp with a smaller subterminal cusp on outer (concave) margin, followed by a series of small serrations; marginals progressively decreasing in size toward edge of radula, but otherwise morphologically similar.

Distal genitalia (Fig. 26A-B). Penis long, enveloped in a thin sheath, apical part variously looped within sheath; basal half somewhat broader and with thin, spongy wall, lumen with fine close-set transverse folds throughout; apical half narrower, its wall muscular, lumen with longitudinal folds; retractor muscle attached to penis apex. Epiphallus long, distal portion little differentiated from penis; an elongate caecum arises at approx. one-third length of epiphallus from insertion of vas deferens; caecum
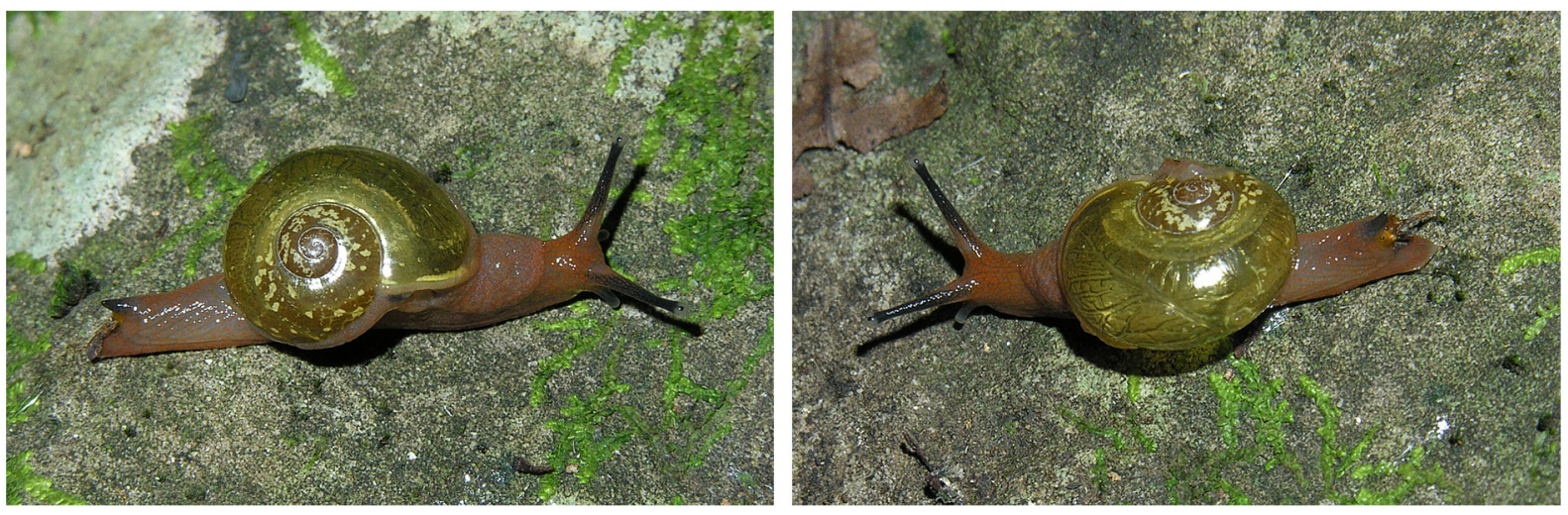

Fig. 24. Selatodryas roseosoma gen. et sp. nov., living animal, Redcliffe, Maclear, E Cape, shell diameter $10.5 \mathrm{~mm}$ (NMSA W9722). 
curved or sinuous; proximal third of epiphallus wider, its wall less muscular. Flagellum of moderate length, tightly coiled; f1 comprising approx. 3.0 whorls, with distinct transverse internal structure; f2 very short, with tubular core. Base of flagellum and proximal region of epiphallus, close to insertion of vas deferens, with opaque white contents; vas deferens slender. Genital atrium small and simple, lacking any accessory modifications; penis base with a weak flange prior to its junction with atrium; vagina long. Gametolytic sac large, its duct relatively short; sac variable in shape and with thin wall. Base of free oviduct swollen, pale apricot in colour; spermoviduct divided into distinct prostatic and oviductal portions.

Spermatophore (Fig. 26C). Elbowed, with a large capsule and well-developed tail (tail length approx. $5.5 \mathrm{~mm}$ ); tail coiled into approximately three revolutions with branched spines; spines possessing up to eight T-shaped tips on initial 1.5 whorls, but those on distal whorl un-branched, the tip remaining T-shaped rather than pointed; spineless tip of tail short and slender.

Distribution (Fig. 15)

A narrow-range endemic, known only from the edge of the Great Escarpment in the Maclear-Ugie area (Prentjiesberg), E Cape, South Africa; at altitudes between $1385 \mathrm{~m}$ and $1660 \mathrm{~m}$ above sea level.

\section{Habitat}

Patches of Southern Mistbelt Forest (Mucina \& Rutherford 2006) on south-facing slopes below sandstone cliffs of the 'Little Berg'; under logs, amongst clumps of forest floor plants, e.g., Dietes spp. (mostly adults) and on the leaves of understorey plants (juveniles).


Fig. 25. Selatodryas roseosoma gen. et sp. nov., holotype, radula (NMSA W5379/T3865). A. Rachidian and left lateral teeth. B. Rachidian and innermost lateral teeth. C. Inner right marginal teeth. D. Outer left marginal teeth. Scale bars: $A=100 \mu \mathrm{m} ; \mathrm{B}-\mathrm{C}=50 \mu \mathrm{m} ; \mathrm{D}=25 \mu \mathrm{m}$. 


\section{Remarks}

Characters separating Selatodryas roseosoma gen. et sp. nov. from S. luteosoma gen. et sp. nov. are given in the remarks for that taxon.

\section{Conservation}

The limited range of Selatodryas roseosoma gen. et sp. nov. renders it a species of conservation concern. The forests in which it occurs are located largely on privately owned farmland. On-going maintenance of the current relatively pristine condition of these forests is thus not secure and is dependent on the environmental oversight exercised by the landowners. Commercial forestry plantations exist in the area, but they are mostly situated at a slightly lower altitude, some distance away from the escarpment-edge forests. Potential threats include livestock disturbance of the forest understorey and runaway fires in the surrounding grasslands.

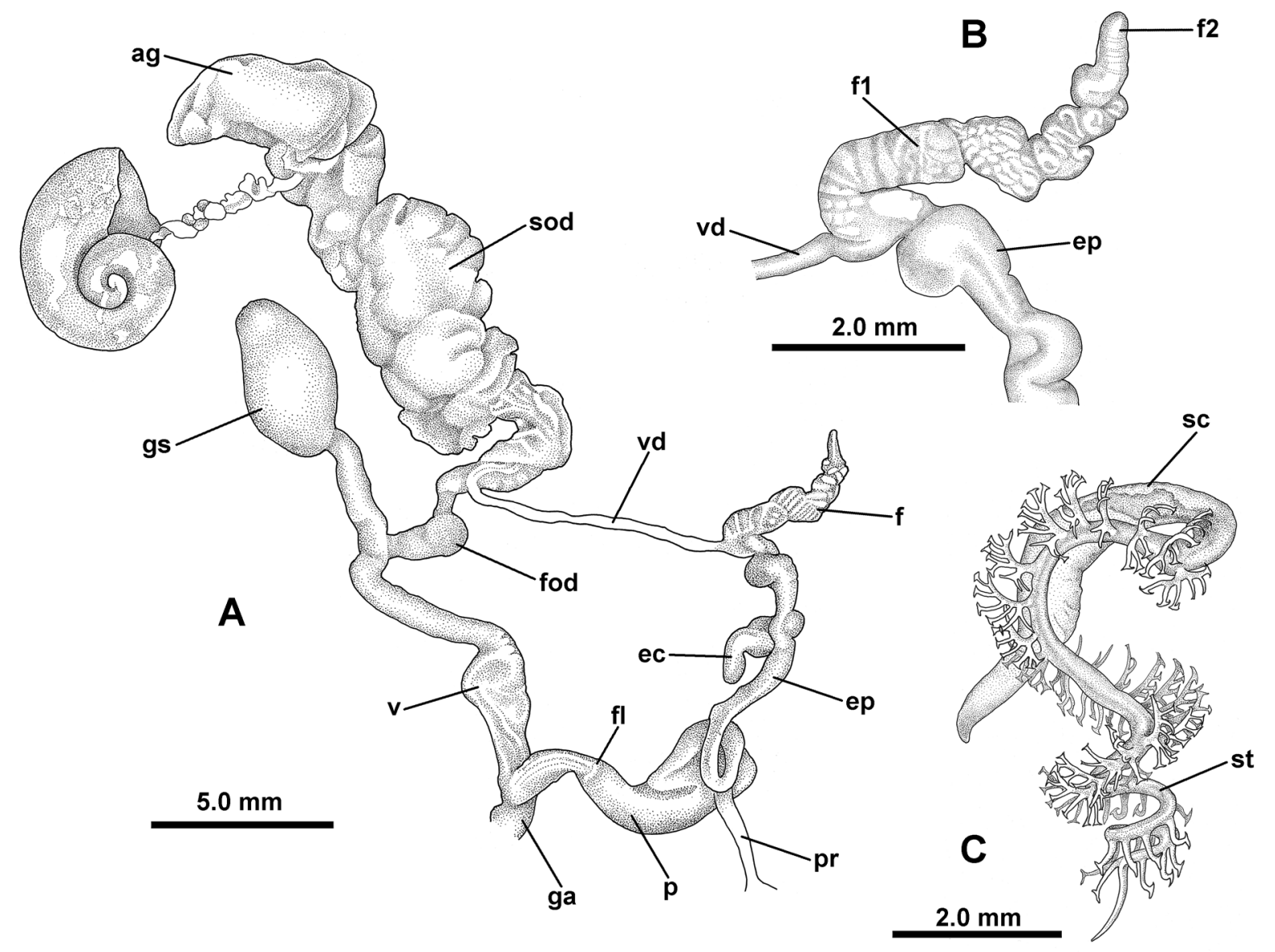

Fig. 26. Selatodryas roseosoma gen. et sp. nov., genitalia and spermatophore. A. Entire genital tract. B. Flagellum. C. Spermatophore. A-B. Paratype (NMSA W4462/T3868). C. Holotype (NMSA W5379/ T3867). 


\section{Selatodryas luteosoma gen. et sp. nov. urn:lsid:zoobank.org:act:3527BF02-E261-4D1A-9978-5460F2BDD562}

Figs 15, 27-30

\section{Diagnosis}

Characterised by the relatively small, low-spired, glossy yellowish-brown shell, non-punctate protoconch and columella that runs into the axis of coiling rather than fusing with the parietal region. Distal genitalia with short flagellum, of which fl comprises only one whorl.

\section{Etymology}

From the Latin 'luteus', yellow, and the Greek 'soma', body; referring to the yellow coloration of the living animal.

\section{Material examined}

\section{Holotype}

SOUTH AFRICA: E Cape, Langeni area, Nocu Forest, $31.41547^{\circ} \mathrm{S}, 28.49998^{\circ} \mathrm{E}$, ca $1190 \mathrm{~m}$, large block of indigenous forest, alive on understorey herbs (Begonia and Plectranthus), D. Herbert and L. Davis leg., st. 06-004, 18 Feb. 2006 (NMSA W3925/T3873, dry shell with body in ethanol).
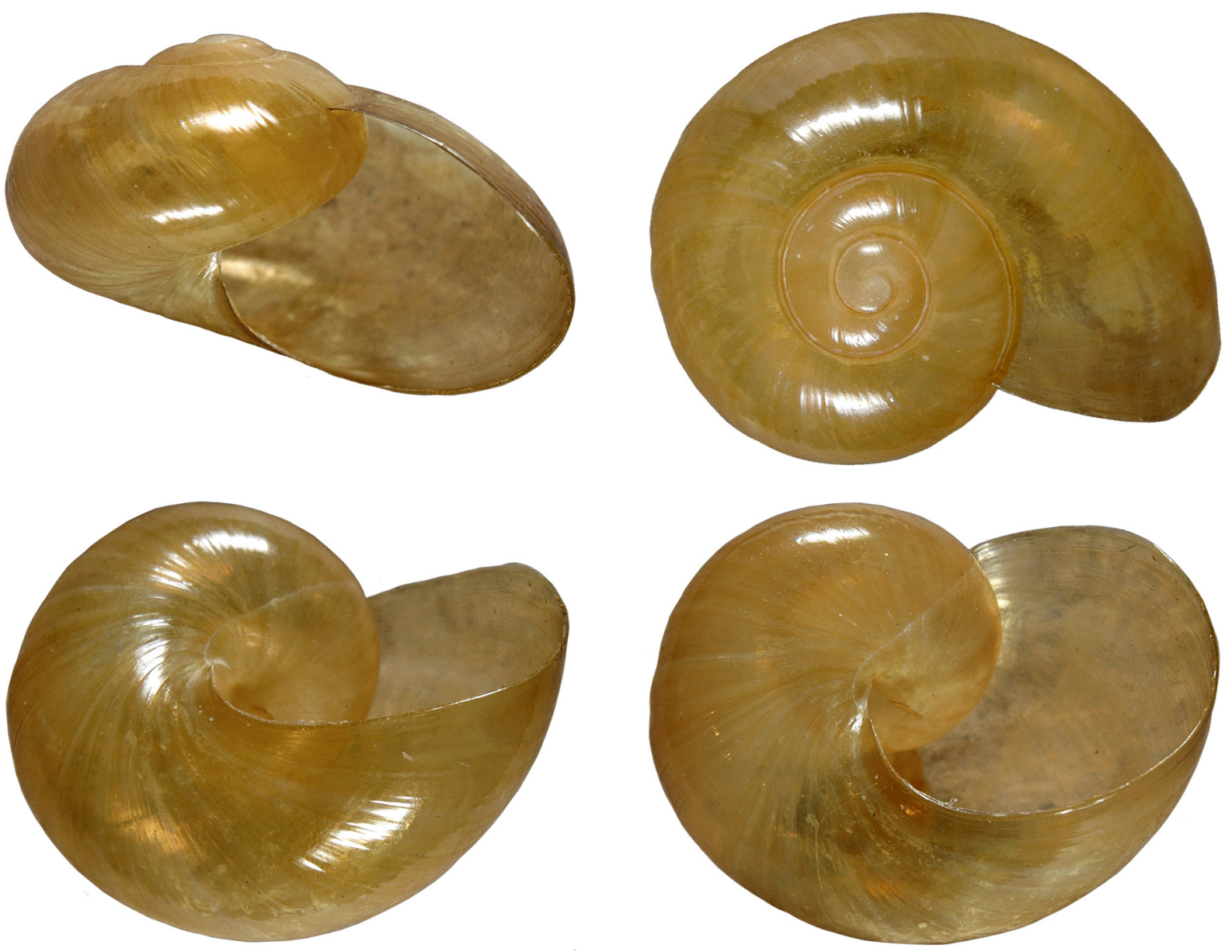

Fig. 27. Selatodryas luteosoma gen. et sp. nov., holotype, diameter 10.5 mm (NMSA W3925/T3873). 
Paratypes (listed north to south, all E Cape)

SOUTH AFRICA: Mount Frere area, just S of Buffalo Nek village, $10 \mathrm{~km} \mathrm{NW}$ of Mount Frere, 30.854799 ${ }^{\circ}$ S, 28.892971 ${ }^{\circ}$ E, 1466 m, M. and K. Cole leg., 7 Apr. 2015 (ELM W3857/T161, whole specimen in ethanol); Langeni area, Cwecwe Forest, $31.388900^{\circ} \mathrm{S}, 28.565878^{\circ} \mathrm{E}, 1149 \mathrm{~m}, \mathrm{M}$. Cole and V. Ndibo leg., 25 Jan. 2013 (ELM W3730/T160, one dry shell with body in ethanol); Langeni area, Jenca Valley, $31.36593^{\circ} \mathrm{S}, 28.55727^{\circ} \mathrm{E}$, ca $1420 \mathrm{~m}$, small piece of indigenous forest in rocky valley above escarpment, D. Herbert and L. Davis leg., 18 Feb. 2006 (NMSA W3937/T3876, 2 dry shells with bodies in ethanol); same data as holotype (NHMUK 20160243, one dry shell; NMSA W9691/T3874, seven dry shells, with seven bodies and one whole specimen in ethanol; W4279/T3875, 6 dry shells).

\section{Other material}

SOUTH AFRICA: E Cape, Langeni area, Nocu Forest, $31.4185^{\circ} \mathrm{S}, 28.5037^{\circ} \mathrm{E}, 1090 \mathrm{~m}$, Afromontane Podocarpus forest, in leaf-litter, D. Herbert leg., 13 May 2001 (NMSA V9083).

\section{Description}

SHELL (Fig. 27). Lenticular; periphery at mid-whorl or slightly below, evenly rounded; H:D 0.61-0.68 $(\mathrm{N}=6)$; suture indented, inserting above periphery; very thin and delicate; translucent, more or less uniformly yellowish-brown; apical and basal surfaces both glossy. Protoconch diameter 1.68-1.75 mm $(\mathrm{N}=5)$; smooth and glossy, sculptured only by extremely fine, close-set, microscopic scratch-like spiral lines; no evidence of punctation; junction with teleoconch poorly defined. Teleoconch of up to 2.25 whorls; whorls expanding moderately rapidly; spiral sculpture virtually obsolete, later whorls with only the finest traces of microscopic, close-set, wavy, spiral ripples, even weaker on base; teleoconch otherwise only with weak, uneven growth irregularities, most evident below suture. Umbilicus absent, edge of columella lip reflected and slightly thickened with a thin, whitish callus; columella running into axis of coiling rather than fusing with parietal region; aperture roundly lunate. Diameter up to $11.7 \mathrm{~mm}$; holotype, diameter $10.5 \mathrm{~mm}$, height $6.7 \mathrm{~mm}$.

Living ANimal (Fig. 28). Head-foot ground colour pale greyish-cream, with pale yellowish pigment granules concentrated in skin tubercles and along pedal margin; optic tentacles and their retractors dark grey to black, tentacle bases speckled with yellowish pigment granules; caudal appendage well developed, dark grey. Body lobes of mantle extensive, pigmentation yellowish-buff and more dense than neck region, shell lobes well developed. Lining of pulmonary cavity with little pigmentation except for an opaque, cream-yellow subsutural band overlying rectal region; this spreading out over viscera posterior to pulmonary cavity, becoming restricted to irregularly shaped blotches on mid-spire viscera;
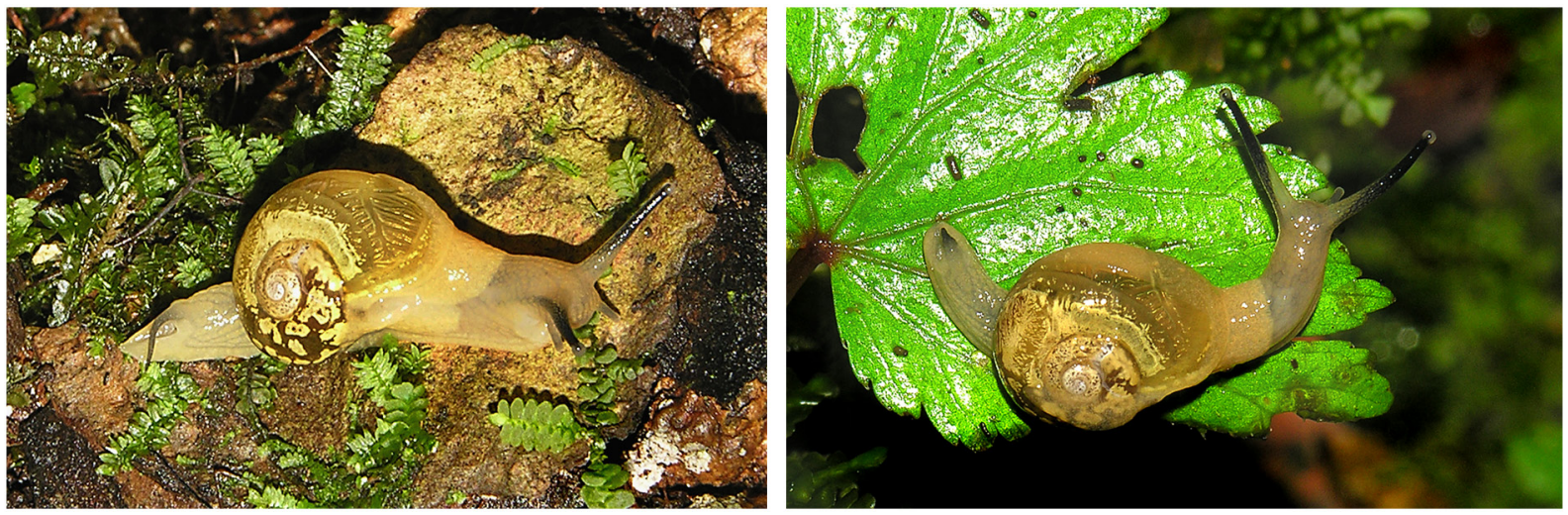

Fig. 28. Selatodryas luteosoma gen. et sp. nov., living animal, shell diameter $10.5 \mathrm{~mm}$ (holotype, NMSA W3925/T3873). 
apical viscera with rather more extensive, finely reticulate, cream pigmentation; no dark pigment band overlying primary ureter, kidney region yellowish-buff.

Radula (Fig. 29). Formula $\mathrm{R}+10+(1-2)+(70-80)$; rachidian tricuspid, anterior edge of shaft base minimally indented in mid-line; laterals essentially bicuspid with a mesocone and strong basal ectocone, but also with a minute endocone on side of mesocone; shaft of laterals roundly quadrate, more or less in line with mesocone (cf. S. roseosoma gen. et sp. nov. above); laterals followed by 1-2 intermediary teeth and then a long series of marginals; marginals curved, with a large terminal cusp and a smaller subterminal one on outer (concave) margin, outer edge of shaft with a series of small serrations; marginals progressively decreasing in size toward edge of radula, but otherwise morphologically similar.

Distal genitalia (Fig. 30A-C). As in Selatodryas roseosoma gen. et sp. nov., but with characteristic differences relating primarily to flagellum and spermatophore. In S. luteosoma gen. et sp. nov., fl component of flagellum shorter, comprising only one whorl; f2 similarly short in both species; additionally, flange at base of penis slightly closer to genital atrium. Gametolytic sac frequently containing allospermatophores (up to three; specimens collected in February).

SPERMATOPHORE (Fig. 30D). Similar to that of Selatodryas roseosoma gen. et sp. nov., but tail shorter (tail length approx. $4.5 \mathrm{~mm}$ ) and coiled into only one revolution; early part of tail with short, branched spines with 3-4 T-shaped tips; spines progressively smaller and with fewer branches toward tail tip, but final 4-5 spines significantly larger, curved, un-branched and their tips pointed rather than T-shaped.
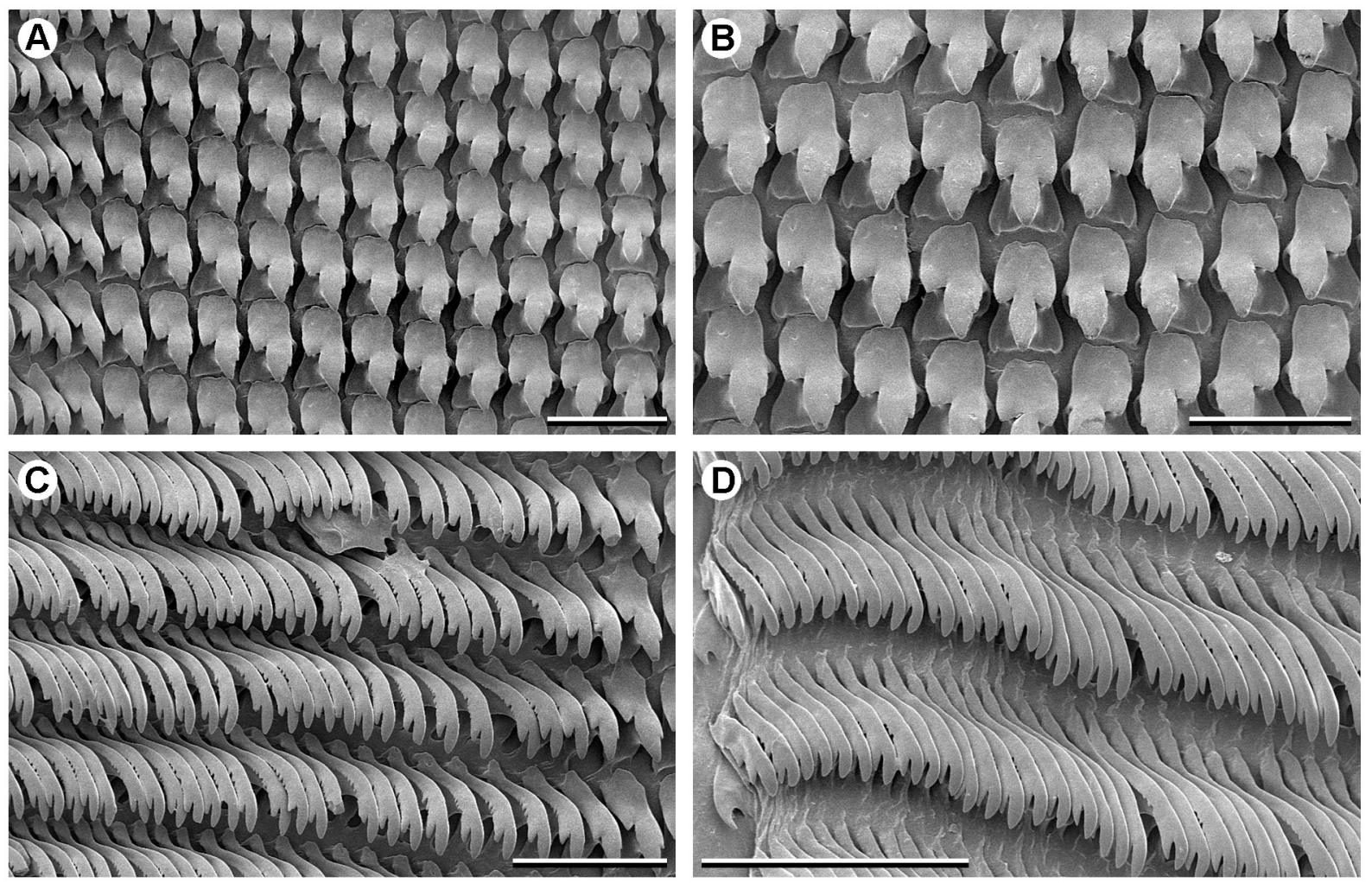

Fig. 29. Selatodryas luteosoma gen. et sp. nov., radula (holotype, NMSA W3925/T3873). A. Rachidian and left lateral teeth. B. Rachidian and innermost lateral teeth. C. Inner left marginal teeth. D. Outer left marginal teeth. Scale bars $=50 \mu \mathrm{m}$. 


\section{Distribution (Fig. 15)}

A narrow-range endemic, known only from the edge of the Great Escarpment in the Mount FrereLangeni area, north and west of Mthatha, E Cape, South Africa; at altitudes between $1090 \mathrm{~m}$ and 1470 $\mathrm{m}$ above sea level.

\section{Habitat}

Southern Mistbelt Forest (Mucina \& Rutherford 2006); living in leaf-litter and on foliage of understorey herbs and forbs.

\section{Remarks}

Selatodryas luteosoma gen. et sp. nov. is clearly close to $S$. roseosoma gen. et sp. nov. from the neighbouring Prentjiesberg. In terms of shape and sculpture, the shells of the two species are virtually indistinguishable. However, that of $S$. roseosoma gen. et sp. nov. attains a larger size (diameter up to
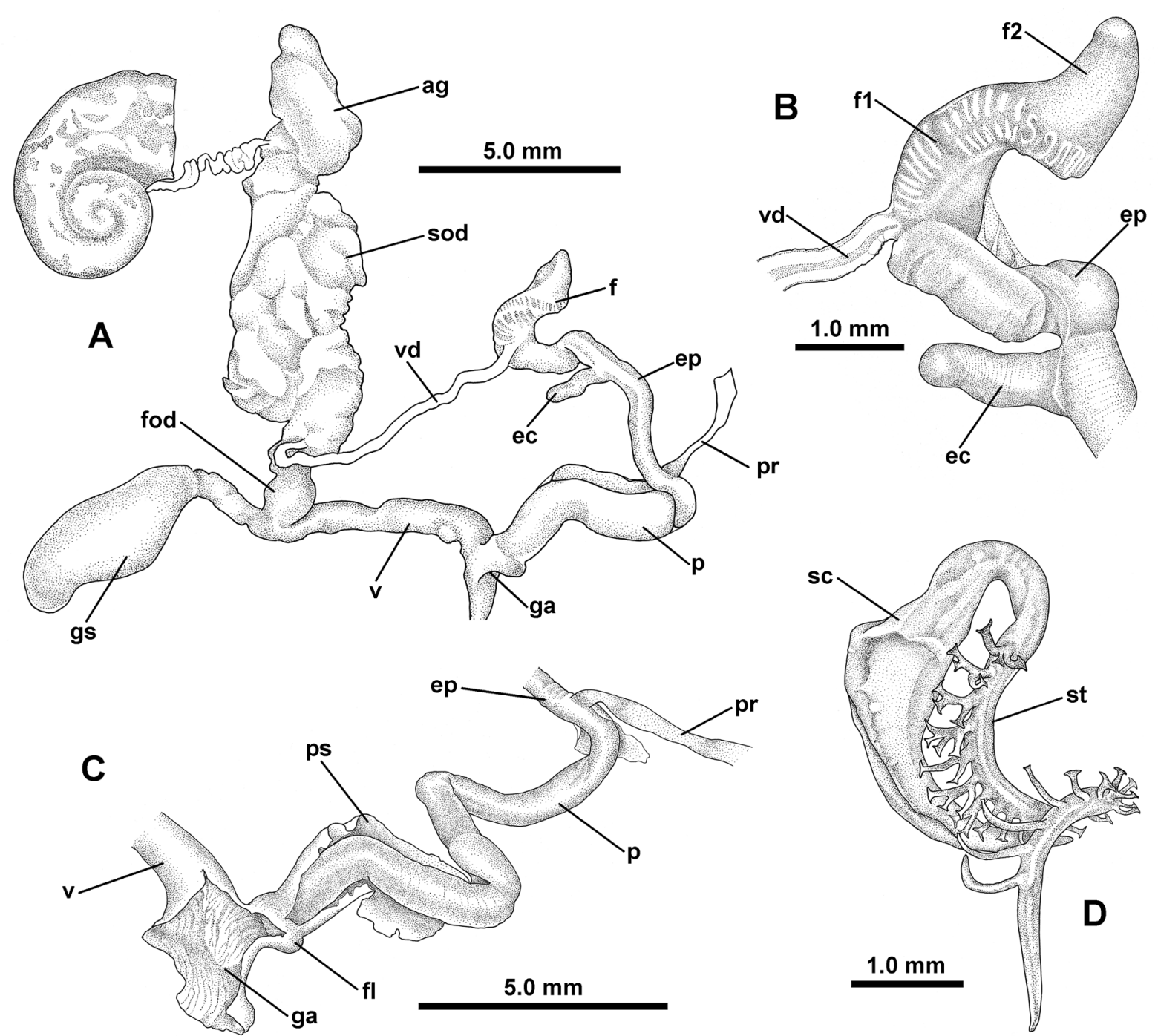

Fig. 30. Selatodryas luteosoma gen. et sp. nov., genitalia and spermatophore. A. Entire genital tract. B. Flagellum. C. Penis extracted from its sheath. D. Spermatophore. A-C. Holotype (NMSA W3925/ T3873). D. Paratype (NMSA W9691/T3874). 
$15 \mathrm{~mm}$ ) and usually has a slightly greenish tint when fresh. There are additional differences in body colour, S. luteosoma gen. et sp. nov. having a predominantly yellowish coloration with extensive pigmentation on the spire viscera, whereas S. roseosoma gen. et sp. nov. has a predominantly reddishpink head-foot with little pigmentation on the spire viscera. There are also significant differences in the distal genitalia and spermatophore structure. In S. roseosoma gen. et sp. nov. the basal component of the flagellum (f1) is twisted through approximately three whorls (only one in S. luteosoma gen. et sp. nov.), a difference reflected also in the coiling of the spermatophore tail. The spermatophore spines are also more extensively branched in S. roseosoma gen. et sp. nov. and the un-branched distal spines have T-shaped tips (pointed in S. luteosoma gen. et sp. nov.). The consistency of these characters has been confirmed in several specimens of each species. A further difference between the species is evident in the radula, where the shaft of the lateral teeth is more or less square and in line with the mesocone in S. luteosoma gen. et sp. nov., but in S. roseosoma gen. et sp. nov. the shaft is rectangular and set at a distinct angle relative to the mesocone.

The ranges of the two species are focused on escarpment-edge forest habitats spanning two altitudinal ranges - S. luteosoma gen. et sp. nov. at ca 1100-1470 $\mathrm{m}$ in the Langeni-Mount Frere area west and north of Mthatha and S. roseosoma gen. et sp. nov. at ca 1380-1700 m in the Prentjiesberg west of Ugie and Maclear. The two escarpments are separated by only ca $50 \mathrm{~km}$, but this has evidently been sufficient to isolate the populations and promote speciation. The overall similarity of the species suggests that they are phylogenetically close, but the consistent differences, particularly in flagellum and spermatophore structure, provide strong evidence that speciation has occurred and that the two populations are distinct species-level entities, most probably sister species.

In terms of body coloration, S. luteosoma gen. et sp. nov. resembles 'Sheldonia' transvaalensis (Craven, 1880 ), particularly with regard to the yellowish-cream pigment blotches on the spire whorls. However, in ' $S$ '. transvaalensis the shell is more globose and has a conventional, rimate umbilicus, albeit narrow. Its penis is also not distally coiled or folded within its sheath, the epiphallic caecum is small and spherical, the flagellum is bifid, and the vagina is comparatively short. As noted by Watson (1934), it is closer to species that I consider referable to Microkerkus (e.g., M. burnupi, M. leucospira and M. pondoensis).

Like $S$. luteosoma gen. et sp. nov., the recently described velvet worm, Opisthopatus amaxhosa Daniels, Dambire, Klaus \& Sharma, 2016, is narrowly endemic to the escarpment forests west of Mthatha (Daniels et al. 2016).

\section{Conservation}

As with Selatodryas roseosoma gen. et sp. nov., the limited range of $S$. luteosoma gen. et sp. nov. renders its conservation a matter of concern. The forests in which it occurs do not fall within formally protected areas, although a degree of oversight may be exercised by the Department of Agriculture, Forestry and Fisheries. Extensive exotic timber plantations surround the remaining pockets of indigenous forest in this area and represent a potential disturbance threat, particularly with regard to invasive alien plants and perhaps also non-native invertebrates dispersed via the sylviculture industry (Herbert 2010). Uncontrolled burning in neighbouring grassland habitats may represent an additional threat.

Genus Sheldonia Ancey, 1887

Sheldonia Ancey, 1887: 53. Type species Helix trotteriana Benson, 1848, by subsequent designation (Connolly 1925: 467).

Peltatus Godwin-Austen, 1908: 131. Type species (original designation) Helix hudsoniae Benson, 1864 (Godwin-Austen (1912a) subsequently re-identified his type material as Vitrina aloicola Melvill \& Ponsonby, 1890, indicating that he considered this to be the type species). 


\section{Remarks}

Sheldonia, like Kerkophorus, includes both arboreal and ground-dwelling species. The shells are lenticular to sub-globose, usually lustreless, and the protoconch is usually punctate. The epiphallus is of moderate length and the caecum is cylindrical, often angled, arising close to the mid-point of the epiphallus. The genital atrium frequently possesses a stimulator and the free oviduct gland is conspicuously enlarged. In addition, the spermatophore has a single tail, the spine branches end in blunt, T-shaped bifurcations, and the spineless distal portion of the tail is relatively long, with stout lateral projections on each side in its mid-region.

Sheldonia fingolandensis sp. nov.

urn:1sid:zoobank.org:act:8620960E-0BBC-49D2-9CF6-69D028EDB052

Figs 15, 31-34

\section{Diagnosis}

Characterised by the axially striped colour pattern, large tumescent shell, finely punctate protoconch sculpture and arboreal habit.

\section{Etymology}

From Fingoland, the territory between the Kei and Mbhashe rivers, E Cape, inhabited by the Fingo people (amaFengu) after their flight south to escape the brutality of King Shaka in the early 1800s.

\section{Material examined}

\section{Holotype}

SOUTH AFRICA: E Cape, Mbhashe River valley, Collywobbles, overlooking vulture colony, $32.00396^{\circ} \mathrm{S}, 28.59530^{\circ} \mathrm{E}, 585 \mathrm{~m}$, sparse valley thicket invaded with Lantana, living on aloes, D. Herbert and L. Davis leg., 20 Feb. 2006 (NMSA W9688/T3383, dry shell).

Paratypes (listed north to south, all E Cape)

SOUTH AFRICA: Mbhashe River valley, near N2 bridge, $31.92461^{\circ} \mathrm{S}, 28.45113^{\circ} \mathrm{E}, 470 \mathrm{~m}$, riverine thicket, living on aloe leaves, A. Moussalli and D. Stuart-Fox leg., 23 Nov. 2005 (NMSA W4169/T3385, six dry shells with six bodies and eight whole specimens in ethanol); Mbhashe River valley, near N2 bridge, $31.92461^{\circ} \mathrm{S}, 28.45113^{\circ} \mathrm{E}, 470 \mathrm{~m}$, riverine thicket, dead in leaf-litter and under fallen aloes, A. Moussalli and D. Stuart-Fox leg., 23 Nov. 2005 (NMSA W5373/T3386, two dry shells); same data as holotype (NHMUK 20160245, one dry shell; NMSA W4075/T3384, seven dry shells with bodies in ethanol; RMNH.5004187, one dry shell); Mbhashe River valley, Collywobbles, slope below carpark on neck, north-facing, valley thicket, under leaves of Aloe ferox, $23.00436^{\circ} \mathrm{S}, 28.58169^{\circ} \mathrm{E}, 510 \mathrm{~m}$, M. Bursey leg., 20 Feb. 2006 (ELM W2927/T164, five dry shells with bodies in ethanol); Mbhashe River valley, Collywobbles, beside thatched picnic site, $32.004417^{\circ} \mathrm{S}, 28.58172^{\circ} \mathrm{E}, 510 \mathrm{~m}$, valley thicket, living under green leaves of aloes, D. Herbert and L. Davis leg., 20 Feb. 2006 (NMSA W3976/ T3387, 20 dry shells with 14 bodies in ethanol); Kei River valley, NNE of Stutterheim, Wedgeley Farm, Shed Camp, 32.28986 ${ }^{\circ}$ S, $27.54674^{\circ}$ E, 835 m, valley thicket, D. Herbert and L. Davis leg., 4 Mar. 2007 (NMSA W5345/T3388, one dry shell); Sihota, west bank of Kei River, approx. $2.5 \mathrm{~km}$ upstream of Kei Bridge, below Moordenaars Kop, 32.50445 ${ }^{\circ}$ S, $27.94945^{\circ}$ E, 200 m, under Aloe ferox leaves, M. Cole leg., 9 Jan. 2008 (ELM W3263/T165, one dry shell with body in ethanol; NMSA W6386/T3389, six dry shells with two bodies in ethanol).

Other material (listed north to south, all E Cape)

SOUTH AFRICA: Kei Pass, $32.49364^{\circ} \mathrm{S}, 27.99175^{\circ} \mathrm{E}, 282 \mathrm{~m}$, valley thicket, dead under rocks, A. Moussalli and D. Stuart-Fox leg., 23 Nov. 2005 (NMSA W5486); Mncotsho, Buffalo River valley, 
$32.917^{\circ} \mathrm{S}, 27.583^{\circ} \mathrm{E}, 360 \mathrm{~m}$, under scattered bushes (esp. Coddia rudis) in grassland near beacon, M. Cole and C. Vernon leg., 6 Nov. 2007 (NMSA P0630).

\section{Description}

SHELl (Fig. 31). Subglobose to globose, spire prominent; periphery at or close to mid-whorl, evenly rounded; H:D 0.72-0.83 (N=9); suture rather distinctly indented, inserting just above periphery; thin,

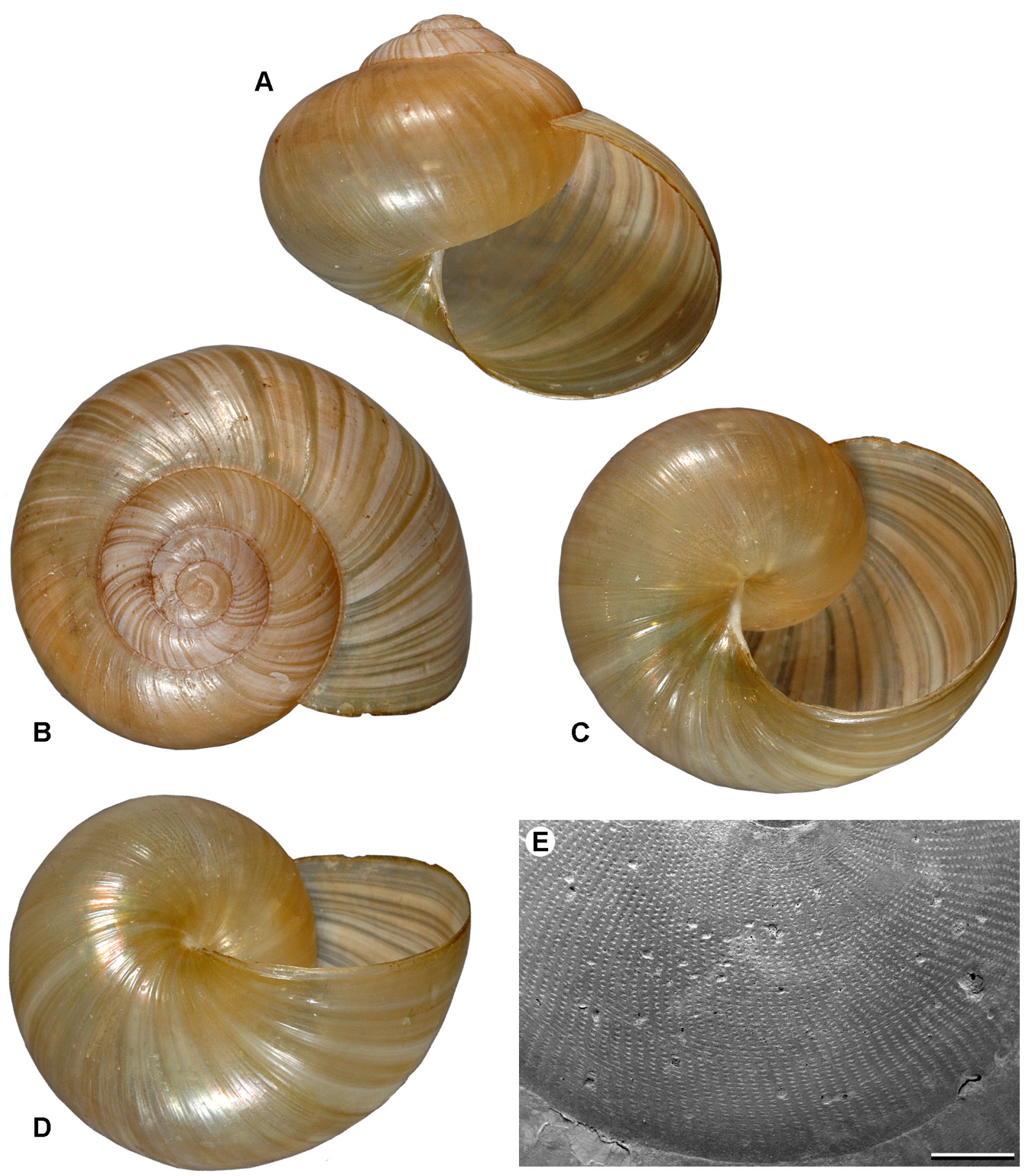

Fig. 31. Sheldonia fingolandensis sp. nov. A-D. Holotype, diameter 18.7 mm (NMSA W9688/T3383). E. Paratype, protoconch, punctate microsculpture with both spiral and radial alignment, scale bar = $200 \mu \mathrm{m}$ (NMSA W3976/T3387). 
translucent straw-brown when fresh, sometimes with a greenish tint and with conspicuous pattern of unevenly spaced, opaque, pale buff-white axial lines and stripes; apical surface satin-like, base more glossy. Protoconch diameter 2.3-2.7 mm ( $\mathrm{N}=6)$; junction with teleoconch sometimes clear, sometimes weakly marked; sculpture very fine, comprising numerous close-set, microscopic spiral lirae, these initially composed of microscopic punctae (Fig. 31E); punctae also with an axial alignment, producing a secondary collabral pattern; latter half whorl of protoconch with spiral lirae only (no longer punctate). Teleoconch of up to almost 3.0 whorls; early part of first whorl with fine spiral sculpture similar to that on protoconch, but finer; remainder of shell with only finest traces of close-set, microscopic lirae, producing satin-like shell surface; an axial component not evident in microsculpture, but uneven growth-lines frequent and appearing to coincide with axial variation in colour pattern; occasional sparse malleation also evident, but insignificant; base more glossy, microsculpture becoming obsolete below periphery. Umbilicus completely absent in adult specimens, edge of columella lip reflected and slightly thickened with whitish callus, running into axis of coiling rather than fusing with parietal region; juvenile and subadult specimens often minutely rimate, columella lip lacking callus thickening and umbilicus remaining as a narrow open channel inside reflected lip. Aperture subcircular, but indented by penultimate whorl in parietal region. Diameter up to $20.9 \mathrm{~mm}$; holotype, diameter $18.7 \mathrm{~mm}$, height $15.0 \mathrm{~mm}$.

Living ANimal (Fig. 32). Head-foot mostly pale yellowish-buff, neck and mantle edge somewhat darker orange-buff, tentacles similarly pale, but caudal appendage slightly darker; coloration of spire viscera generally not visible through shell, but cream blotches sometimes evident overlying darker digestive gland.

RAdULA (Fig. 33). Formula R+17+1+(60-70); rachidian tricuspid; laterals essentially bicuspid with a mesocone and strong basal ectocone, but also with a minute endocone on side of mesocone (scarcely more than a low bump); laterals followed by one intermediary tooth and then a long series of marginals; marginals curved, bearing a large terminal cusp with a smaller subterminal cusp on outer (concave) margin, additional irregular cusps may be present on shaft, but these normally obscured by overlapping outer neighbouring tooth; marginals progressively decreasing in size toward edge of radula, but otherwise morphologically similar.

Distal Genitalia (Fig. 34A-D). Penis elongate and cylindrical, but conspicuously looped upon itself and surrounded by a thin sheath, 2-3 times longer when removed from sheath; retractor muscle attached to
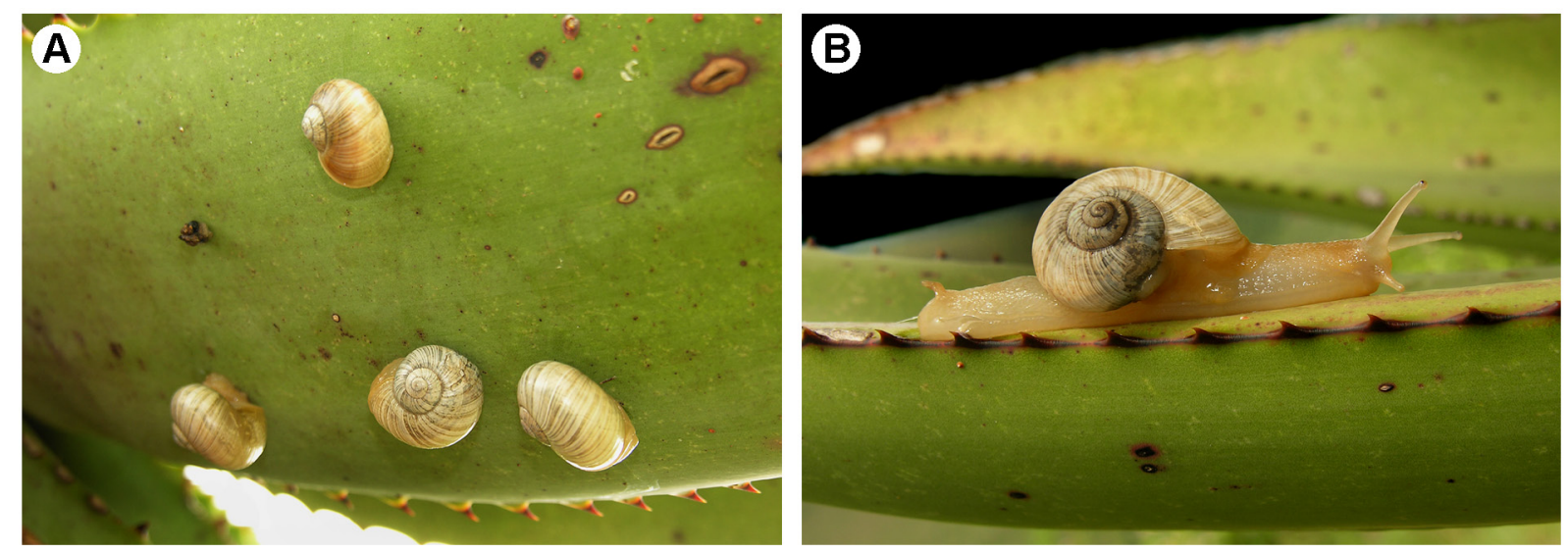

Fig. 32. Sheldonia fingolandensis sp. nov., living specimens, Collywobbles, Mbhashe River valley, E Cape. A. Living specimens resting in situ on underside of Aloe ferox leaf. B. Crawling animal, shell diameter approx. $18 \mathrm{~mm}$. 
penis apex; basal half of penis relatively thin-walled, its lumen lined with close-set, irregularly sinuous transverse folds (Fig. 34D); apical half of penis with thicker wall, lumen lined by longitudinal ridges, these largely smooth near junction with epiphallus, but progressively stronger and more zig-zag toward mid-region of penis (Fig. 34C). Epiphallus short, with a stout, recurved caecum; caecum arising close to middle of epiphallus; lumen of caecum coarsely and irregularly papillate. Flagellum well developed, basal portion (f1) broader and with distinct transverse internal structure; distal portion (f2) longer and more slender, twisted into a spiral of several revolutions with little internal structure evident; junction of epiphallus and flagellum at insertion of vas deferens, with white contents; vas deferens simple and slender, in life running beside vagina and free oviduct to join spermoviduct. Genital atrium globose, lumen almost filled with a well-developed stimulator appearing as an irregularly folded and ridged mass, flaccid rather than muscular, its contracted shape variable between individuals, but occupying most of lumen wall (Fig. 34B). Vagina short; gametolytic sac ovate, thin-walled, its duct short and thickerwalled; free oviduct greatly hypertrophied and convoluted, pale apricot in fresh material, occupying much of body cavity posterior to buccal mass, both dorsal and ventral to gut; spermoviduct divided into distinct prostatic and oviductal portions.

Spermatophore (Fig. 34E). Elbowed, with an elongate capsule and a long, spirally coiled tail of ca 6 revolutions (coiled length of tail approx. $4.1 \mathrm{~mm}$ ); proximal portion of tail (first whorl) with paired branching spines; spines asymmetric, larger on one side; spines in middle part of this whorl largest, progressively smaller distally; spines arching outward and with branches on one side only; branch tips bluntly bifid, ending in short recurved hooks; mid-region of tail ( \pm 1.5 whorls) lacking spines; subsequent whorls $( \pm 2.5)$ of tail somewhat flattened and with short stout projections on both sides, these
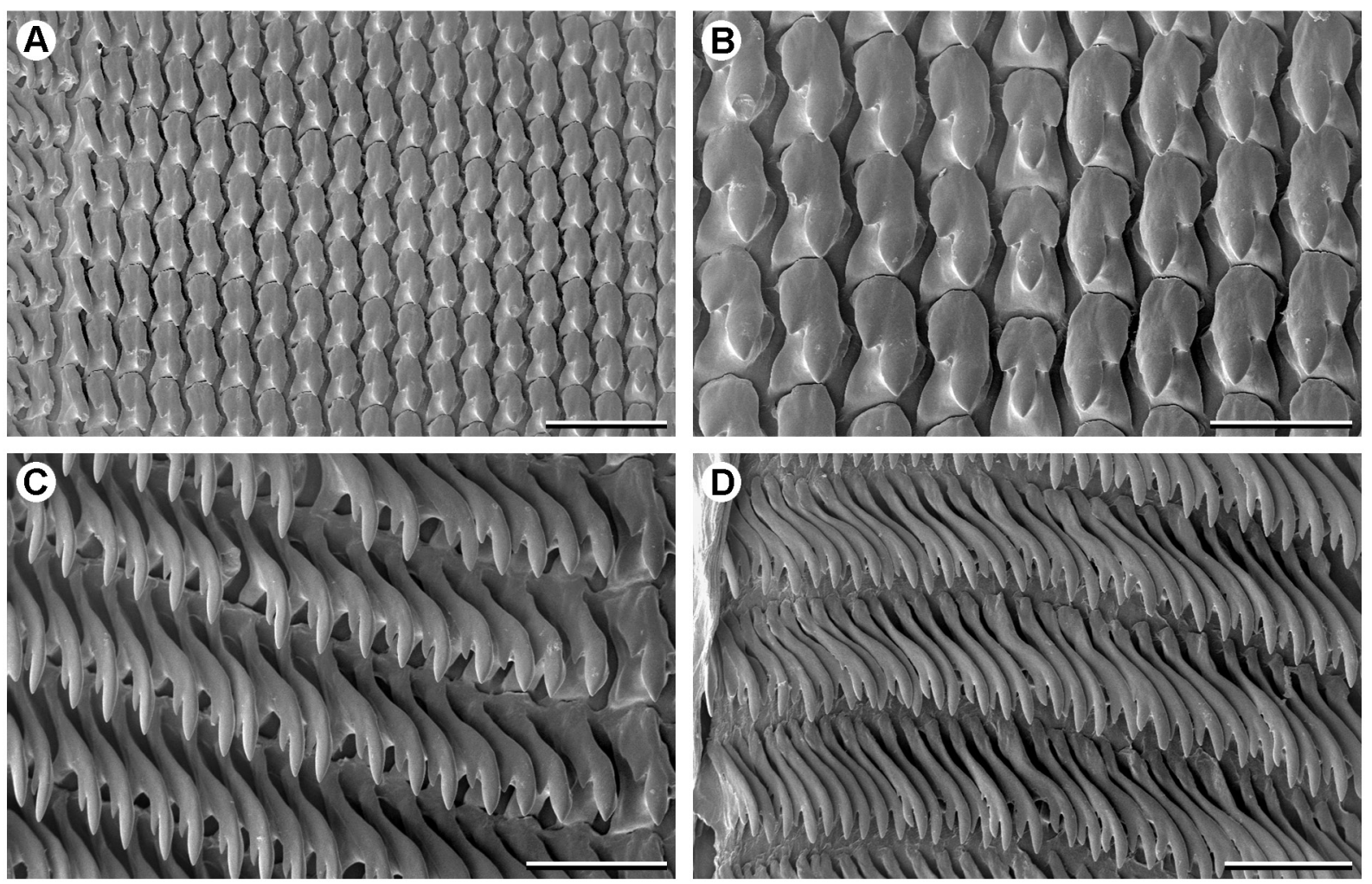

Fig. 33. Sheldonia fingolandensis sp. nov., paratype, radula (NMSA W4075/T3384). A. Rachidian and left lateral teeth. B. Rachidian and innermost lateral teeth. C. Inner left marginal teeth. D. Outer left marginal teeth. Scale bars: $A=100 \mu \mathrm{m} ; \mathrm{B}-\mathrm{D}=50 \mu \mathrm{m}$. 
curve over flattened area delimiting a U-shaped channel that spirals along tail; tip of tail ( \pm one whorl) without spines.

\section{Distribution (Fig. 15)}

A relatively narrow-range endemic, known only from the lower catchments of the Mbhashe and Kei Rivers (formerly known as Fingoland) and southward to the Buffalo River valley near East London; from $200 \mathrm{~m}$ to $835 \mathrm{~m}$ above sea level.

\section{Habitat}

Mostly known from Eastern Valley Bushveld (Mucina \& Rutherford 2006); living amongst the green leaf-bases of candelabra aloes.

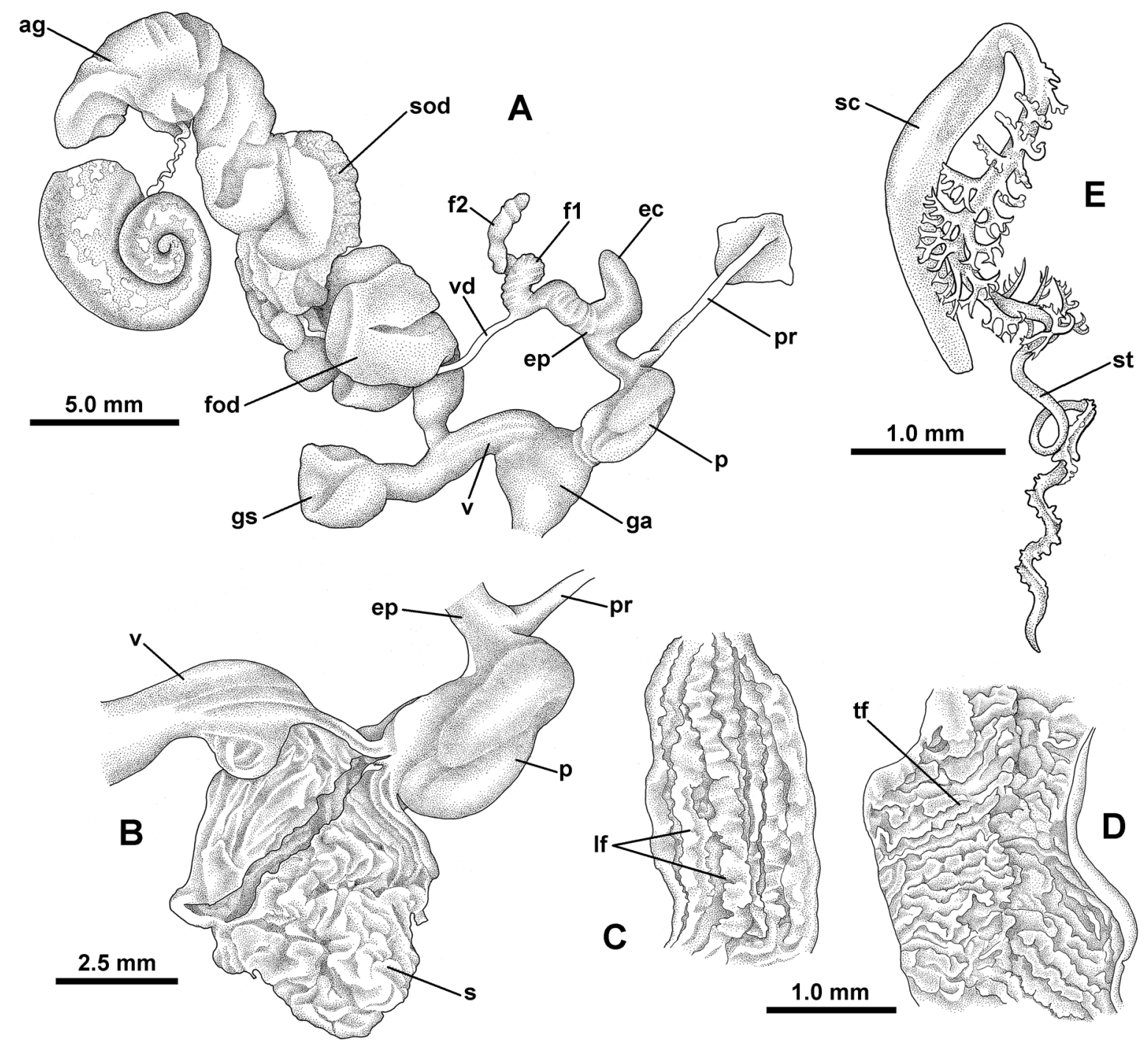

Fig. 34. Sheldonia fingolandensis sp. nov., genitalia and spermatophore. A. Entire genital tract. B. Genital atrium dissected to show irregularly folded stimulator. C-D. Apical and basal portions of penis lumen showing longitudinal and transverse folds respectively. E. Spermatophore. A-D. Paratype (NMSA W4169/T3385). E. Paratype (NMSA W6386/T3389). 


\section{Remarks}

With its rather globose profile, the shell of Sheldonia fingolandensis sp. nov. resembles that of S. trotteriana (Benson, 1848), but it is less elevated, has a more strongly patterned shell and more rapidly expanding whorls. Furthermore, whereas S. fingolandensis sp. nov. is arboreal, S. trotteriana is evidently exclusively ground-dwelling. The aloe-dwelling habit of the new species is shared with S. aloicola (Melvill \& Ponsonby, 1890), but that species has a more depressed, more translucent shell of a more uniform colour. It seems likely, however, that the two are closely related, as the morphology of their distal genitalia is similar. S. fingolandensis sp. nov. may well have originated as a north-eastern isolate of the more southerly and more widespread S. aloicola. The shell of S. natalensis (Pfeiffer, 1846) may also have a colour pattern of narrow axial stripes, but it is more globose, has a smaller protoconch (diameter 1.7-1.8 $\mathrm{mm}$ ) and never attains such a large adult size (diameter $<16.5 \mathrm{~mm}$ )

\section{Conservation}

The observations made above for Kerkophorus terrestris sp. nov. are also applicable to Sheldonia fingolandensis sp. nov.

\section{Discussion}

The discovery of the new taxa described above highlights the fact that although South Africa may be considered one of the malacologically more well-known countries in Africa, there is much additional diversity that awaits detection. More rigorous field work in poorly-sampled areas as well as closer scrutiny of the described taxa continues to uncover both narrow-range endemics (Herbert 2016) as well as cryptic species within those already described (Herbert \& Moussalli 2016). Like streptaxid snails, urocyclids seem to be prone to narrow-range endemism in areas such as the eastern part of E Cape, as illustrated by five of the species described above. This area is a well-known focus of endemism for terrestrial molluscs (Bursey \& Herbert 2004; Herbert \& Kilburn 2004; Herbert 2006; Cole \& Herbert 2009; Herbert \& Moussalli 2010) and other forest animals (Tolley \& Burger 2007; Daniels et al. 2016), and it is also a recognised centre of plant endemism (Jacobs 1996; Van Wyk \& Smith 2001). Similarly, streptaxids and urocyclids with limited distributions are also encountered in ecologically insular habitats (Herbert 2016) and field surveying of such habitats needs to be flagged as a biodiversity research priority.

Since the shell of heliciform urocyclids usually offers few useful characters, it is imperative that data on the appearance of the living animal as well as its internal morphology be acquired. In addition, observations on behaviour and microhabitat preferences may provide further insights. Information of this nature is critical to unravelling what appears in many cases to be confusing variability, and ultimately to determining the true extent of species diversity within this group. The examples of Kerkophorus piperatus sp. nov. and $K$. vittarubra sp. nov., both previously subsumed within a broadly interpreted $K$. inunctus, are illustrative of the need for closer scrutiny of the existing nominal species from a morphological perspective. The unearthing of such erstwhile hidden species, whether it be through more rigorous morphological observation or the use of molecular methods (or both), has important implications not only for taxonomy and systematics, but also for biogeography and biodiversity conservation (Bickford et al. 2006).

\section{Acknowledgements}

I thank Mary Cole (ELM) and Linda Davis (NMSA) for assistance in the field. Linda Davis also skilfully prepared the anatomical illustrations of genitalia and spermatophores from my camera lucida drawings. For access to SEM facilities I thank the Centre for Electron Microscopy, University of KwaZuluNatal, Pietermaritzburg. Collecting permits were provided by: the Department of Economic Affairs, Environment and Tourism, E Cape (per Mary Cole); Ezemvelo KZN Wildlife (4674) and Mpumalanga 
Tourism and Parks (MPV.5109/5174). Mary Cole and Ben Rowson provided valuable comments on the manuscript during review. This research was supported by Incentive Funding from the South African National Research Foundation (grant no 81078).

\section{References}

Ancey C.F. 1887. Descriptions of new genera or subgenera of Helicidae. Conchologist's Exchange 1 (9-10): 53-54.

Bickford D., Lohman D.J., Sodhi N.S., Ng P.K.L., Meier R., Winker K., Ingram K.K. \& Das I. 2006. Cryptic species as a window on diversity and conservation. Trends in Ecology and Evolution 22: 148155. https://doi.org/10.1016/j.tree.2006.11.004

Bouchet P. \& Rocroi J-P. 2005. Nomenclator of gastropod family-group names. Part 1: 5-239. In: Bouchet P. \& Rocroi J-P. (eds) Classification and Nomenclator of Gastropod Families. Malacologia 47 (1-2): 1-397.

Bursey M.L. \& Herbert D.G. 2004. Four new narrow-range endemic species of Gulella from Eastern Cape, South Africa (Mollusca: Pulmonata: Streptaxidae). African Invertebrates 45: 249-262.

Cole M.L. \& Herbert D.G. 2009. Description of four new species of Gulella Pfeiffer, 1856 from Eastern Cape, South Africa, with additional notes on two poorly known species (Mollusca: Eupulmonata: Streptaxidae). Zoologische Mededelingen 83 (6): 547-564.

Connolly M. 1912. A revised reference list of South African non-marine Mollusca; with descriptions of new species in the South African Museum. Annals of the South African Museum 11: 59-306.

Connolly M. 1925. Notes on African non-marine Mollusca, with descriptions of many new species (continued). Annals and Magazine of Natural History, Series 9, 5: 457-479.

Connolly M. 1939. A monographic survey of South African non-marine Mollusca. Annals of the South African Museum 33: 1-660.

Daniels S.R., Dambire C., Klaus S. \& Sharma P.P. 2016. Unmasking alpha diversity, cladogenesis and biogeographical patterning in an ancient panarthropod lineage (Onychophora: Peripatopsidae: Opisthopatus cinctipes) with the description of five novel species. Cladistics 32 (5): 506-537. https:// doi.org/10.1111/cla.12154

Godwin-Austen H.H. 1908. On Peltatus, gen. nov. Zonitidarum: Type P. hudsoniae (Benson). Annals and Magazine of Natural History, Series 8, 1: 131-133. Available from http://biodiversitylibrary.org/ page/24295840 [accessed 7 Mar. 2017].

Godwin-Austen H.H. 1912a. A review of the South-African land-Mollusca belonging to the family Zonitidae - Part I. Annals and Magazine of Natural History, Series 8, 9: 122-139. Available from http:// biodiversitylibrary.org/page/18638879 [accessesd 7 Mar. 2017].

Godwin-Austen H.H. 1912b. A review of the South-African land-Mollusca belonging to the family Zonitidae - Part II. Annals and Magazine of Natural History, Series 8, 9: 569-585. Available from http://biodiversitylibrary.org/page/18639326 [accessed 9 Mar. 2017].

Godwin-Austen H.H. 1914. A review of the South-African land-Mollusca belonging to the family Zonitidae - Part III. Annals and Magazine of Natural History, Series 8, 13: 449-472. Available from http://biodiversitylibrary.org/page/18641208 [accessed 9 Mar. 2017].

Herbert D.G. 2006. Rediscovery of the type species of Euonyma (Subulinidae) and observations on South African species of Gulella (Streptaxidae), with description of two new species (Gastropoda: Eupulmonata). Journal of Natural History 40 (17-18): 1063-1081. https://doi.org/10.1080/00222930600845218

Herbert D.G. 2010. The Introduced Terrestrial Mollusca of South Africa. SANBI Biodiversity Series 15. South African National Biodiversity Institute, Pretoria. 
Herbert D.G. 2016. New narrow-range endemic land snails from the sky islands of northern South Africa (Gastropoda: Streptaxidae and Urocyclidae). European Journal of Taxonomy 236: 1-29. https:// doi.org/10.5852/ejt.2016.236

Herbert D.G. \& Davis L.S. 2016. Slugs and snails and spermatophore tails - new morphological characters for urocyclid systematics (Mollusca: Pulmonata). Biodiversity: past, present, future. Twelfth conference of the Southern African Society for Systematic Biology, Bloemfontein, 10-13 January, 2016: 101.

Herbert D.G. \& Kilburn R.N. 2004. Field Guide to the Land Snails and Slugs of Eastern South Africa. Natal Museum, Pietermaritzburg.

Herbert D.G. \& Moussalli A. 2009. Tail-wagger snails: molecules and morphology - systematics and biogeography (Pulmonata: Urocyclidae). Tenth Anniversary Conference of the Southern African Society for Systematic Biology, Illovo Beach, KwaZulu-Natal, 25-27 July, 2009: 20-21.

Herbert D.G. \& Moussalli A. 2010. Revision of the larger cannibal snails (Natalina s.l.) of southern Africa - Natalina s.s., Afrorhytida and Capitina (Mollusca: Gastropoda: Rhytididae). African Invertebrates 51 (1): 1-132. https://doi.org/10.5733/afin.051.0101

Herbert D.G. \& Moussalli A. 2016. Revision of the dwarf cannibal snails (Nata s.l.) of southern AfricaNata s.s. and Natella (Mollusca: Gastropoda: Rhytididae), with description of three new species. Zootaxa 4094 (1): 1-67. https://doi.org/10.11646/zootaxa.4094.1.1

Jacobs T.V. 1996. Floristics of Transkei sandstone forests (South Africa). In: van der Maesen L.J.G., van der Burgt X.M. \& van Medenbach de Rooy J.M. (eds) The Biodiversity of African Plants: 805-808. Kluwer Academic Publishers, Dordrecht.

Mucina L. \& Rutherford M.C. (eds) 2006. The Vegetation of South Africa, Lesotho and Swaziland. Strelitzia 19, South African National Biodiversity Institute, Pretoria.

Tolley K. \& Burger M. 2007. Chameleons of Southern Africa. Struik Publishers, Cape Town.

Van Wyk A.E. \& Smith G.F. 2001. Regions of Floristic Endemism in Southern Africa. Umdaus Press, Pretoria.

Watson H. 1934. Natalina and other South African snails. Proceedings of the Malacological Society of London 21: 150-193.

Zilch A. 1959-60. Euthyneura. In: Wenz W. (ed.) Gastropoda. Handbuch der Paläozoologie 6 (2). Gebrüder Borntraeger, Berlin.

Manuscript received: 18 May 2016

Manuscript accepted: 1 August 2016

Published on: 10 April 2017

Topic editor: Rudy Jocqué

Section editor : Kurt Jordaens

Desk editor: Kristiaan Hoedemakers

Printed versions of all papers are also deposited in the libraries of the institutes that are members of the EJT consortium: Muséum national d'Histoire naturelle, Paris, France; Botanic Garden Meise, Belgium; Royal Museum for Central Africa, Tervuren, Belgium; Natural History Museum, London, United Kingdom; Royal Belgian Institute of Natural Sciences, Brussels, Belgium; Natural History Museum of Denmark, Copenhagen, Denmark; Naturalis Biodiversity Center, Leiden, the Netherlands. 